


\section{LIOKARY}

Unlt.rstly of

California

Irvtne 
$1+1+2$

$\because \quad$ :

) 


\section{Digitized by the Internet Archive in 2008 with funding from Microsoft Corporation}


to ny collogue and friend G. W. Bots/mot Homniti moore

ECONOMIC CYCLES: THEIR LAW AND CAUSE 


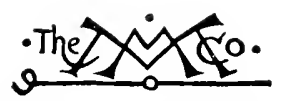

TIIE MACMILLAN COMPAN

NEW YORK - BOSTON - CHICAGO - DALLAS ATLANTA - SAN FRANCISCO

MLACMILLAN \& CO., Limited

LONDON - BOMBAY - CALCUTTI MELBOURNE

THE MACMILLAN CO. OF CANADA, LTD. TORONTO 


\title{
ECONOMIC CYCLES: THEIR LAW AND CAUSE
}

\author{
BY \\ HENRY LUDIVELL MOORE \\ PROFESSOR OF POLITICAL ECONOMY IN COLUMBIA UNIVERSITY \\ AUTHOR OF " LAWS OF WAGES"
}

\begin{abstract}
"Nous croyons en effet, pour notre part, que pour avancer vraiment dans la connaissance économique, il faut s'attaquer directement et d'abord, à des variations, c'est-à-dire à la forme dynamique des phénomènes, par la voie expérimentale."

Frangois Simiand.
\end{abstract}

\author{
Niu Zuırk \\ THE MACMILLAN COMPANY \\ 1914
}

All rights reserved 
Copyright, 1914

BY THE MACMILLAN COMPANY

Published December, 1914. 
To

JANE MOORE

A CRITIC WIO NEVER DISHEARTENS

A CO-WORKEI WHO KEEPS THE F.MTH 



\section{CONTENTS}

\section{CHAPTER I}

Introduction .

CHAPTER II

CYCLES OF RAINFALL

The Use of Fourier's Theorem . . . . . . . . . . . . . . 6

Periodogram of Rainfall . . . . . . . . . . . . . 14

The Equation to the Rainfall Curve . . . . . . . . . 21

Rainfall in the Corn Belt . . . . . . . . . . . . . 26

\section{CHAPTER III}

RAINFALL, AND THE C'ROPS

The Secular Trend in the Yield of the Crops . . . . . . . 35

Critical Periods of Growth . . . . . . . . . . . . 41

Cycles in the Yield of the Representative Crops and the Corresponding Cycles of Rainfall . . . . . . . . 44

Cycles in the Index of Crop Fluctuations and in the Corresponding Index of Mean Effective Rainfall . . . . . 49

CHAPTER IV

THE LAW OF DEMAND

The Theory of Demand . . . . . . . . . . . . . 62 Statistical Laws of Demand . . . . . . . . . . . . 64 The Predietion of Prices . . . . . . . . . . . . . . . . 77 Elasticity of I) mand . . . . . . . . . . . . . . 82 
('HAP'TER V

THE MLHANHS OF CYCLES

The Prices of Agricultural Commodities Correlated with the

Yicld of the Several Crops . . . . . . . . . . 94

Rising and Falling Prices as Related to Yield-Price Curves . 100

The Volume of the Crops and the Activity of Industry . . 103

A New Type of Demand Curves . . . . . . . . . . 110

The Fundamental, Persistent Cause of Economic Cycles . . 116

\section{CHAPTER VI}

SLMMARY AND CONCLUSIONS . . . . . . . . . . . 135 
ECONOMIC C'YCLES: THEIR LAW AND CAUSE 



\section{CHAPTER I}

\section{INTRODUCTION}

There is a considerable unanimity of opinion among experts that, from the purely economic point of view, the most general and characteristic phenomenon of a changing society is the ebb and flow of economic life, the alternation of energetic, buoyant activity with a spiritless, depressed and uncertain drifting. During the creative period of the rhythmic change each factor in production receives an augmenting income, and the mutual adjustment of interests in the productive process is brought about in a natural way, primarily through the operation of competitive law. The period of decline in the cycle presents a sharply contrasted aspect of industry. With the organization of capital and labor at first unchanged, the amount of the product falls; each of the interested factors seeks at least to retain its absolute share of the product; friction and strife ensue with a threatening of the disruption of industry. What is the cause of this alternation of periods of activity and depression? What is its law? These are the fundamental problems of economic dynamics the solution of which is offered in this Essay.

Political Economy began to make progress in a rational way when the Physiocrats put forth their doctrine of the dependence of all forms of economic life 
upon agriculture. Another momentous step was taken in the direction of theoretical development when the English economists formulated the law of diminishing returns in agriculture and traced its all-pervasive influence in the production and distribution of the product of industry. The desideratum of economic dynamies at the present time is the discovery of a law that shall be to a changing society what the law of diminishing returns in agriculture is to a society in a comparatively static condition.

The full truth in the old Physiocratic doctrine has not been exploited. The Department of Agriculture of the United States reaffirms the central idea of the doctrine in its motto: "Agriculture is the Foundation of Manufacture and Commerce," and in the spirit of this motto it publishes invaluable statistical data.

It is proverbial that the farmer is at the mercy of the weather. If it be true that the explanation of economic cycles is to be found in the law of supply of agricultural products, it is surely wise in a study of rhythmic economic changes to inquire whether the law of the changing supply of raw material is not associated with a law of changing weather. Is there a well-defined law of changing weather?

Supposing that it is possible to discover that the weather passes through cycles of definite periods and definite amplitudes, it will then be necessary to show how the crops are affected by the weather and how the cycles of the weather are reproduced in cycles of the yield of the principal crops. 
When the changes in the physical yield of the crops are shown to be dependent upon changes in the weather, the next stage in the investigation is to comect the yiekl with its value, and this brings one face to face with another unsolved problem in theoretical economics. The most recent phase of economic theory opens with a description of the "law of demand," which from the time of Cournot, Dupuit, and Gossen has been assumed in all theoretical discussions, but there has been no method for finding the statistical equation to the law. It will be necessary to overcome the difficulties of this problem before a solution can be offered of the more fundamental inquiry as to the law and cause of cycles in economic phenomena.

When the physical yield of the crops has, on the one hand, been related to the cycles of the weather and, on the other, to the prices of the respective crops, it will then be possible to take the final step and to show how the cycles in the physical yield of the crops produce the cycles in the activity of industry and the cycles of general prices, and how, finally, the law of the cycles of the crops is the law of Economic Cycles. 


\section{CHAPTER II}

\section{CYCLES OF RAINFALL}

"The first thing that in my opinion ought to be done towards making the observations useful for scientific purposes is to perform that kind of more perfect averaging which is afforded by the harmonic analysis. There is a ecrtain amount of averaging done, but that is chiefly daily averages, with monthly averages, and yearly averages; but the more perfeet averaging of the harmonic analysis would give the level of the variation of the phenomenon."

-Lord Kelvin, in his testimony before the Metcorological Committee of the Royal Socicty, 18\%6.

From the point of view of the relation of changing weather to the varying fruitfulness of agriculture, the most important factors that are usually included in the term, weather, are temperature and rainfall. We begin our investigation with this common belief and inquire, in this chapter, whether the varying amount of annual rainfall is subject to any simple law.

In order to carry forward the inquiry as to the existence of a law of annual rainfall an analysis must be made of a long record of precipitation. Our choice of a record is limited by two conditions: First, our object in investigating the periodicity of rainfall is the hope of throwing light upon the periodicity in the yield of the crops, and this expectation obviously makes it desirable that the record of rainfall shall be as representative as possible of the conditions of precipitation 
in our leading crop area; secondly, as the existing meteorological records are of unequal lengths and of varying reliability, it is necessary to take the best long records that can be found within the limits of the crop area.

The principal region of grain production in the United States is in the Mississippi Valley, but the meteorological records of the Middle West do not extend through a long period of time. In order to achieve the two ends of having a long record of precipitation and of having the record typical of the conditions in the grain area, the device has been adopted of investigating rainfall in the Ohio Valley - which affords the longest record obtainable in the neighborhood of the central Mississippi region-and of showing that the rainfall of our leading grain state, Illinois, follows the same law as the rainfall of the Ohio Valley.

The stations in the Ohio Valley with long rainfall records are Marietta, Portsmouth, and Cincinnati. Their mean annual rainfall since 1839 is given in Table $\mathrm{I}^{1}$ of the Appendix to this chapter. The graph of the course of rainfall in the Ohio Valley since 1839 is traced with other graphs on Figures 4, 5, and 6. The problem that must now be faced is the question as to whether the sequence of annual rainfall in the Ohio Valley follows a simple law, and if so, to give a quantitative formulation of the law.

${ }_{1}$ The data were taken from Bulletin $W$ of the Weather Bureau of the United States and from the Annual Reports of the Chief of the Weather Bureau. 


\section{The Use of Fourier's Theorem}

A preliminary examination of the rainfall data of the Ohio Valley leads to the conclusion that there is probably no secular trend to the data, that is to say, there is probably no tendency of the rainfall to increase continuously or to decrease continuously with the flow of time. It is true that when the amount of rainfall is correlated with time, the coefficient of correlation is $r=-.227 \pm .075$, where the coefficient is three times its probable error and is therefore suggestive of a decrease in the amount of rainfall with the flow of time. Moreover, if a straight line is fitted to the data, the indicated annual decrease in the rainfall is seven hundredths of an inch. But these facts are no justification for holding to a secular decrease in the amount of annual rainfall. For, in the first place, if there are cycles in the amount of the rainfall, the low degree of the observed correlation might be due to the data of rainfall including incomplete cycles; in the second place, the record is drawn from only three stations and because of the limited number of stations might give an accidental, low degree of correlation between amount of rainfall and time; and in the third place, improvements in the method of taking the observations might have introduced changes that would account for the observed small annual decrease in the amount of rainfall. In view of these considerations, it is probably best to proceed with our problem on the assumption that there is no secular trend in the amount of annual 
rainfall. If this assumption is true, it follows that, in all probability, the course of rainfall in the Ohio Valley, is cyclical, or a combination of cycles.

In an inductive treatment of any form of rhythmic or cyclical change it is necessary that the method adopted shall satisfy two conditions: (1) It shall be consistent with recognized mathematical processes; (2) It shall afford means of testing the degree of probability that the results are not chance phenomena. Unless the method rests clearly upon an approved mathematical process, it is scarcely possible to say whether the attained results may not be entirely formal; and unless the findings are tested for the degree of their probability, there is no assurance that the adduced cycle may not be a chance occurrence. The literature in which rhythmic phenomena are treated in a statistical way teems with fallacies and uncertainties that illustrate the need of observing the above conditions; for the method frequently adopted of smoothing the data is so arbitrary that one is at a loss to know whether, after all, the alleged periodicity may not, in fact, be due to the process of smoothing; and, in addition, one is left in doubt as to whether an indefinite number of cycles other than the particular one adduced might not, with equal or greater probability, be obtained from the same data.

The method that was employed to reach the results of this chapter rests upon the analysis invented by Joseph Fourier, ${ }^{1}$ which is called, in English treatises,

${ }_{1}^{1}$ The most philosophic exposition of Fourier's theorem is in 
harmonic analysis. The perfection of the method whereby the findings may be subjected to the test of probability is the work of Professor Arthur Schuster ${ }^{1}$ of Manchester.

We may begin the presentation of the method with a definition of a series of terms that constantly recur in

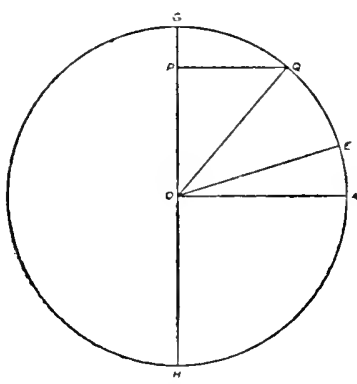

Figure 1. the treatment of periodic phenomena. Figure 1 will facilitate the exposition by affording a graphic description of the terms dealt with.

Suppose that the point $Q$ mores uniformly in the circle of Figure 1, that is to say, suppose that the point $Q$ describes equal ares in equal times and, therefore, proportional arcs in different times. Then, if the measurements of the ares of the circle are made from the point $A$ and the reckoning of time is begun when $Q$ is at $E$, the angle $A O E$ is called the angle at epoch, or simply

Fourier's own work: Théorie ancilytique de la chalew. In Freeman's English translation the treatment is found on pp. 137-212.

1 The fundamental memoirs of Professor Schuster are

"On the Investigation of Hidden Periodicities with Application to a Supposed 26 Day Period of Meteorological Phenomena." Terrestrial Magnetism for March, 1898.

"The Periodogram of Magnetic Declination as obtained from the records of the (ireenwich Observatory during the years 1871-1595." Cambridge Philosophical Society Transactions, Vol. 18, 1899.

"On the Periodicity of Sunspots." Philosophical Transactions of the Royal society of London, A, Vol. 206, 1906.

"The Periodogram and its Optical Analogy:" Proceedings of the Roynd sicciety of Lomblon, 1 , Vol. 77, 1906. 
the epoch of the uniform circular motion. The radius of the circle is the amplitude of the motion; the time of going once around the circle is the period of the motion; the ratio of $A Q$ to the circumference of the circle is the phase of the motion:

If from each position of $Q$ a perpendicular is dropped upon the diameter of the circle, $G H$, the foot of the perpendicular will describe a simple harmonic motion. The amplitude of the simple harmonic motion is onehalf of the range of the motion, that is, one-half of $G H$, or the radius of the circle. The period of the simple harmonic motion is the interval between the passing of the point $P$ twice through the same position in the same direction. The distance of the point $P$ from the middle of its range, $O$, is a simple harmonic function of the time, $O P=y=a \sin (n t+e)$, where $a$ is the radius of the circle-or the amplitude of the simple harmonic motion - $e$ is the angle of epoch, and $n$ is the angle described by the moving point $Q$ in the unit of time. The period of the simple harmonic motion is, in the above case, $\frac{2 \pi}{n}$. Its phase is $\frac{n t+e}{2 \pi}$.

Figure 2 presents a graph of simple harmonic motion. As in Figure 1, the point $Q$ moves uniformly in the circle; the point $P$ performs simple harmonic motion according to the formula $y=a \sin (n t+e)$, where $a$ is the amplitude of the motion, or radius of the circle, $e$ is the angle of the epoch, namely, $A O E$, and $n$ is the arc described by $Q$ in the unit of time. If time is meas- 
ured upon the line $B C$, the sinuous curve of Figure 2 is the graph of the function, $y=a \sin (n t+e)$.

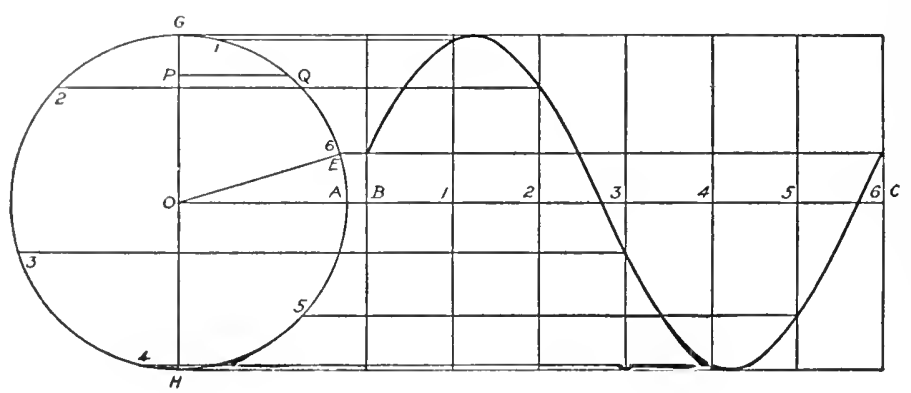

Figure 2.

The importance of simple hamonic functions in the study of periodic phenomena grows out of the fact that any periodic curve however complex ${ }^{1}$ can be expressed mathematically by a series of simple harmonic functions. By the help of Fourier's analysis a periodic function may be put in the form

(1) $y=A_{\circ}+a_{1} \cos k t+a_{2} \cos 2 k t+a_{3} \cos 3 k t+\ldots$ $+b_{1} \sin k t+b_{2} \sin 2 k t+b_{3} \sin 3 k t+\ldots$

If in (1), we put,

$$
\begin{aligned}
& a_{1}=A_{1} \sin e_{1} ; a_{2}=A_{2} \sin e_{2} ; a_{3}=A_{3} \sin e_{3} ; \& c ., \\
& b_{1}=A_{1} \cos e_{1} ; b_{2}=A_{2} \cos e_{2} ; b_{3}=A_{3} \cos e_{3} ; \& c .,
\end{aligned}
$$

We get,

$$
\text { (2) } \begin{aligned}
y= & A_{\circ}+A_{1} \sin \left(k t+e_{1}\right)+A_{2} \sin \left(2 k t+e_{2}\right) \\
& +A_{3} \sin \left(3 k t+e_{3}\right)+\ldots
\end{aligned}
$$

where $y$ is expressed as a series of sines. In a similar manner, equation (1) may be expressed as a series of cosines,

${ }^{1}$ The few exeeptions to the general rule are discussed in the mathematical texts that develop fourier's theorem. 
(3) $y=A_{\circ}+B_{1} \cos \left(k t-\epsilon_{1}\right)+B_{2} \cos \left(2 k t-\epsilon_{2}\right)$ $+B_{3} \cos \left(3 k t-\epsilon_{3}\right)+\ldots$

In the use of Fourier's theorem for the purpose of analyzing periodic phenomena, we follow a process analogous to the use of Taylor's theorem in the simpler demonstrations of mathematical economics. By far the greater part of Cournot's pioneer treatise and of subsequent work of his school is based upon the assumption that, if the economic function under investigation is $y=f(x)$, then $f(x+h)$ may be expanded by Taylor's theorem, and the first terms of the series may be used as an approximation to the form of $f(x)$. Similarly, in our use of Fourier's series, the attention will be focussed upon a few harmonics as a first approximation to the solution of the problem in hand of expressing in mathematical form the periodicity of annual rainfall.

Assuming that any periodic function may be expressed as a Fourier series, the problem is presented of determining the values of the coefficients. The series, as we know, is of the form

$$
\begin{aligned}
y=f(t)=A_{\circ} & +a_{1} \cos k t+a_{2} \cos 2 k t+\ldots \\
& +b_{1} \sin k t+b_{2} \sin 2 k t+\ldots
\end{aligned}
$$

What are the values of the first term and of the coefficients of the sines and cosines? In order to deduce the necessary values, we shall have need of the following lemma:

If $m$ and $n$ are two unequal integers and $k$ is put equal to $\frac{2 \pi}{T}$, then 


$$
\begin{aligned}
& \int_{0}^{\mathrm{T}} \cos m k t \cos n k t d t=0, \\
& \int_{0}^{\mathrm{T}} \sin m k t \sin n k t d t=0, \\
& \int_{0}^{\mathrm{T}} \sin m k t \cos n k t d t=0 .
\end{aligned}
$$

The lemma may be proved to be true by evaluating the three integrals according to the usual methods. The first integral, for example, becomes

$$
\begin{aligned}
\int_{\mathrm{o}}^{\mathrm{T}} \cos m k t \cos n k t d t & =\frac{1}{2} \int_{\mathrm{o}}^{\mathrm{T}}\{\cos (m-n) k t+\cos (m+n) k t\} d t \\
& =\left[\frac{\sin (m-n) k t}{2(m-n) k}+\frac{\sin (m+n) k t}{2(m+n) k}\right]_{0}^{\mathrm{T}}
\end{aligned}
$$

But $k=\frac{2 \pi}{T}$, and, consequently, $\int_{\mathrm{o}}^{\mathrm{r}} \cos m k t \cos n k t d t=0$.

With the aid of this lemma we may proceed to evaluate the coefficients in Fourier's series. If we integrate the series between the limits $o$ and $T$, we get,

$$
\int_{0}^{\mathrm{T}} f(t) d t=A_{0} \int_{0}^{\mathrm{T}} d t+a_{1} \int_{0}^{\mathrm{r}} \cos k t d t+b_{1} \int_{0}^{\mathrm{r}} \sin k t d t+\ldots
$$

But all of the terms except the first on the right-hand side of the equation will vanish, and consequently

$$
\int_{0}^{\mathrm{T}} f(t) d t=A_{\circ} \int_{0}^{\mathrm{T}} d t=A_{\circ} T, \text { or } A_{\circ}=\frac{\int_{\mathrm{o}}^{\mathrm{T}} f(t) d t}{T}
$$

Since $\int_{0}^{{ }^{T}} f(t) d t$ is the area of the original curve for one whole period $T$, the constant term in Fourier's series is equal to the value of the mean ordinate of the original curve. 
To determine the value of $a_{1}$, multiply throughout by $\cos k t$ and integrate between limits $o$ and $T$.

$$
\begin{aligned}
\int_{0}^{\mathrm{T}} f(t) \cos k t d t= & A_{0} \int_{0}^{\mathrm{T}} \cos k t d t+a_{1} \int_{0}^{\mathrm{o}^{\mathrm{T}}} \cos ^{2} k t d t \\
& +b_{1} \int_{0}^{\mathrm{T}} \sin k t \cos k t d t+\ldots
\end{aligned}
$$

Or $\int_{0}^{\mathrm{T}} f(t) \cos k t d t=a_{1} \int_{0}^{\mathrm{T}} \cos ^{2} k t d t$, since $\int_{0}^{\mathrm{T}} \cos k t d t$ and $\int_{0}^{\mathrm{T}} \sin k t \cos k t d t$ are both equal to zero and all the other terms on the right-hand side of the equation, according to our lemma, disappear. But

$$
\int_{0}^{\mathrm{T}} \cos ^{2} k t d t=\int_{0}^{\mathrm{T}} \frac{1+\cos 2 k t}{2} d t=\frac{1}{2}\left[t+\frac{\sin 2 k t}{2 k}\right]_{0}^{\mathrm{T}}=\frac{T}{2}
$$

and as a result, we have

$$
a_{1} \frac{T}{2}=\int_{0}^{\mathrm{T}} f(t) \cos k t d t, \text { or } a_{1}=2 \frac{\int_{0}^{\mathrm{T}} f(t) \cos k t d t}{T} .
$$

Therefore $a_{1}$ is equal to twice the mean value of the product $f(t) \cos k t$.

In a similar manner the value of any other coefficient may be determined. Take, for example, $b_{n}$. Multiply throughout by $\sin n k t$ and integrate between $o$ and $T$,

$$
\begin{gathered}
\int_{0}^{\mathrm{T}} f(t) \sin n k t d t=b_{n} \int_{0}^{\mathrm{T}} \sin ^{2} n k t d t=b_{n} \int_{0}^{\mathrm{T}} \frac{1-\cos 2 n k t}{2} d t= \\
b_{n}\left\{\frac{1}{2}\left[t-\frac{\sin 2 n k t}{2 n k}\right]_{0}^{\mathrm{T}}\right\}=b_{n} \frac{T}{2}
\end{gathered}
$$

and, consequently, $b_{n}=2 \frac{\int_{0}^{\mathrm{T}} f(t) \sin n k t d t}{T}$. Therefore $b_{n}$ 
is equal to twice the mean value of the product $f(t) \sin n k t$.

Having found the algebraic values of the coefficients in Fourier's series, we may now proceed to determine their statistical equivalents in the case of annual rainfall.

\section{The Periodogram of Rainfall}

If the length of a cycle of rainfall were known beforehand, the preceding exposition of Fourier's theorem would suffice to determine, from the data of precipitation, the amplitudes and phases of the harmonic constituents of the Fourier series deseriptive of the rainfall cycle. But in the problem before us of analyzing the rainfall data of the Ohio Valley, we do not know whether there are many cycles or only one eycle or, indeed, whether there are any cycles at all. And there is no short method of solving the problem.

Suppose, for example, it were assumed from a priori considerations that the amount of rainfall is affected by sunspots, and, as sunspots are known to oceur in periods of about eleven years, suppose it should be inferred that the annual rainfall will likewise show a period of eleven years. If the rainfall data of the Ohio Valley are examined for an eleven years period, it will be found that the data yield a definite amplitude and a definite phase for a cycle of eleven years, but this fact is no warrant for holding that there is a true rainfall period of eleven years. Every other grouping of the seventy-two years record will likewise show a definite amplitude 
and a definite phase. The questions that one is interested to have answered are: (1) What is the law of the distribution of Fourier coefficients when the data are analyzed for all possible periods; and (2) how may the true cycles be separated from the accidental, spurious cycles that are obtained when the data are exhaustively analyzed?

In Figure 3 the results of a detailed, laborious examination of the data of annual rainfall in the Ohio Valley are presented in graphic form. On the axis of abscissas are measured, within assigned limits, the possible lengths of cycles in the 72 years of rainfall. By extending the calculations to 36 years, we obtain for the assumed periods a record of possible recurrences varying from 2, in case of the period of 36 years, to 24 , in case of the period of 3 years. On the axis of ordinates are measured the squares of the coefficients of the first harmonic in the Fourier series corresponding to the lengths of periods recorded on the axis of abscissas. The numerical values of these squares are given in the fourth and eighth columns of Table II in the Appendix to this chapter. The method of deriving the values may be illustrated by taking the cycle of 8 years. Suppose, as a first approximation, that the equation to Fourier's series is put in the algebraic form

$$
y=F(t)=A_{\circ}+a_{1} \cos k t+b_{1} \sin k t=A_{0}{ }^{\prime}{ }^{\prime} A_{1} \sin (k t+e) .
$$

Then the corresponding arithmetical values derived from the Ohio rainfall data are 


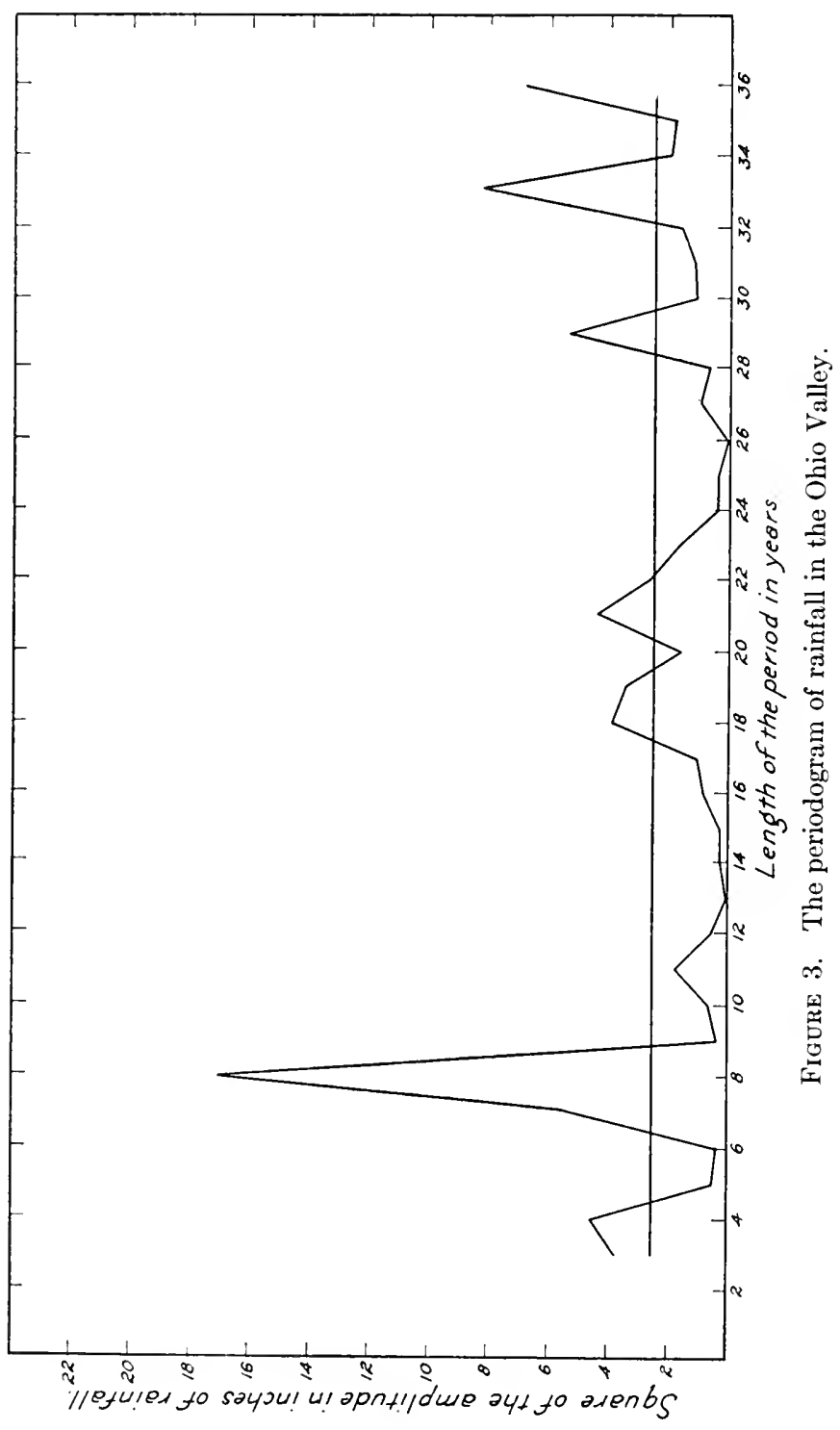




$$
\begin{aligned}
y=F(t) & =41.19-3.13 \cos \frac{2 \pi}{8} t+2.69 \sin \frac{2 \pi}{8} t \\
& =41.19+4.13 \sin \left(\frac{2 \pi}{8} t+310^{\circ} 41^{\prime}\right) .
\end{aligned}
$$

The values of the terms $a_{1}^{2}, b_{1}^{2}, A_{1}^{2}$ are respectively $(3.1339)^{2},(2.6938)^{2},(4.1325)^{2}$, and these values are given in the proper columns of Table II in the Appendix. In Figure 3, the values of $A^{2}$ for the several periods are measured on the axis of ordinates.

An examination of Figure 3 will illustrate the truth of a statement advanced a moment ago. It is clear from the course of the periodograph ${ }^{1}$ that if one were to take any period at random between the limits of 3 years and 36 years, he would in every case obtain a finite value for the amplitude of the selected cycle; and if, by chance, selection should fall upon, say, 1S, or 21 , or 29 , or 36 years, an argument might be made with some degree of plausibility that a real cycle had been discovered. But, in truth, the real significance of no one cycle taken at random can be judged apart from its place in the distribution of all the cycles that can be derived from the data.

This last point is of fundamental importance. The only object of investigating cycles of rainfall or cycles of economic phenomena is that the knowledge of the

1 The terms periodograph and periodogram were coined by Professor Schuster.

The periodograph is the curve tracing the values of $A^{2}$; the periodogram is the surface between the periodograph and the base line giving the lengths of the periods. Schuster: "The Periodogram of Magnetic Declination," p. 108. 
constant recurrence of the cycles may place one in a position to foresee and utilize the dependent phenomena. But the control of phenomena dependent upon a cycle presupposes that the cycle is itself a real phenomenon with a natural cause, and that consequently it persists with an increase in the number of observations. If, however, an apparent cycle of any length taken at random is obtained from the given data, one would surely misspend his time if he were to set about the search for its cause, and were to derive conclusions based upon the hypothesis of the persistence of the cause. The cycles due to formal, accidental causes must be discriminated from the cycles with natural causes.

The separation of true cycles from spurious or accidental cycles is facilitated by the periodogram ${ }^{1}$ of observations. If, following Professor Schuster, we call the square of the amplitude of any given period the "intensity" of the period, then it may be said that the probability of the reality of a period is dependent upon the ratio of its intensity to the mean intensity of the periodogram. Or, again following Professor Schuster, if we call the mean intensity of the periodogram the "expectancy," then the reality of a period is dependent upon the ratio of its intensity to the expectancy of the periodogram. For instance, if in case of a given period the ratio of intensity to expectancy is, say, 3 to 1 , then in about one case in twenty we should expect to obtain by chance a greater amplitude than the amplitude of the particular period in question. If, on the other hand,

${ }^{1}$ See the preceding note. 
the ratio were say, 7 to 1 , a greater ratio would not occur by chance once in a thousand times. ${ }^{1}$

With these facts in mind, let us again examine Figure 3. It is clear that the principal periods needing attention are those respectively of $8,29,33,36$ years. In case of the 8 year cycle there can be very little doubt as to the existence of a true periodicity approximating 8 years in length. The ratio of the square of its amplitude to the mean square amplitude of the periodogram is 6.71 to 1 . We may accordingly accept with considerable confidence the existence of a natural period of rainfall in the Ohio Valley approximating 8 years in length.

The cycle of 33 years, inasmuch as the ratio of the square of its amplitude to the mean square amplitude of the periodogram is 3.27 to 1 is in all probability a true cycle. The doubt that exists is due to the smallness of the ratio and the few recurrences-only two ${ }^{2}-$

1 Schuster: "The Periodogram of Magnetic Declination," pp. 124125 .

${ }^{2}$ Those who deprecate the use of such meager data should consider well the testimony of Lord Kelvin before the Meteorologieal Committee of the Royal Society, 1876 .

Question 1710. "The sum which parliament will give for this purpose being a limited sum, do you think that it would be well to reduce the number of observations in order to have more money to spend upon the reduction of observations? I think at all crents until one eleven years period, the sun spot period, is completed, it would be urong to rectuce the number of observations."

Question 1735. "Supposing that you had one of these analyses ealculated for a period of 11 years, would each year's observations and still more each period of 11 years observations, require to be introduced into this analysis so that you would have an analysis of 22 years, and an analysis of 33 years, and so on from time to time, 
that our data afford. A greater confidence in the existence of a real period of 33 years is given by the fact that Brückner ${ }^{1}$ claims to have found a true period of about 35 years in an examination of a vast mass of rainfall material all over the world. Accordingly, the existence in the Ohio Valley of a real 33 years period of rainfall we shall assume to be very probable.

The other two periods of 29 years and 36 years are not easily disposed of. But in the first place, the ratios of the squares of the respective amplitudes to the mean square amplitude of the periodogram are not such as to justify the acceptance, with any degree of confidence, of the existence of true cycles of 29 years and 36 years. In the second place, they are both so close to the period of 33 years as to cause a doubt as to whether they may not be spurious periods that are likely to appear in the neighborhood of a real period. ${ }^{2}$

Considering the short range of our data it would not be properly cautious to press the point of the existence of any definite real cycle. But this much is certain: If there are true cycles in the data of the 72 years of rainfall in the Ohio Valley, there is far greater probability that two cycles are those of 8 years and 33 years than of any other round numbers between 3 and

or, being done, would it be done once for all? I cannot say whether anything with reference to Terrestrial Meteorology is done once for all. I think probably the work will never be done."

${ }^{1}$ Edward Brückner: Klimaschwankungen seit 1\%00. Brückner's period fluctuates greatly in length and has an average value of 35 years.

2Schuster: "The Periodogram of Magnetic Declination," p. 130. 
36 years. Moreover, the periods of 8 years and 33 years afford the most probable basis derivable from the data upon which to reason both as to the future course of rainfall in the Ohio Valley and as to the course of the phenomena dependent upon rainfall.

Assuming, then, that for the purpose in hand, the 33 years and 8 years periods are the most probable and valuable, we turn to the consideration of the equation to the graph giving the course of rainfall in the Ohio Valley.

\section{The Equation to the Rainfall Curve}

It will be helpful to approach the algebraic description of the cyclical movement of rainfall in the Ohio Valley, by observing how we obtain an increasingly accurate account of the actual rainfall by superposing the constituent cycles. We shall use, as an index of the relative fit of the several curves, the root-mean-square deviation of the observations from each curve.

If, as a preliminary step, the raw data of the course of annual rainfall are examined, it is found that the mean annual rainfall in the Ohio Valley is 41.19 inches, and the root-mean-square deviation about the mean is $S=6.70$ inches.

If the long 33 years cycle is considered by itself, it appears that the root-mean-square deriation about the 33 years curve is $S=6.39$ inches. The graph of the 33 years cycle is given in Figure 4 . Its equation is

$$
y=41.19+2.88 \sin \left(\frac{2 \pi}{33} t+328^{\circ} 7^{\prime}\right),
$$




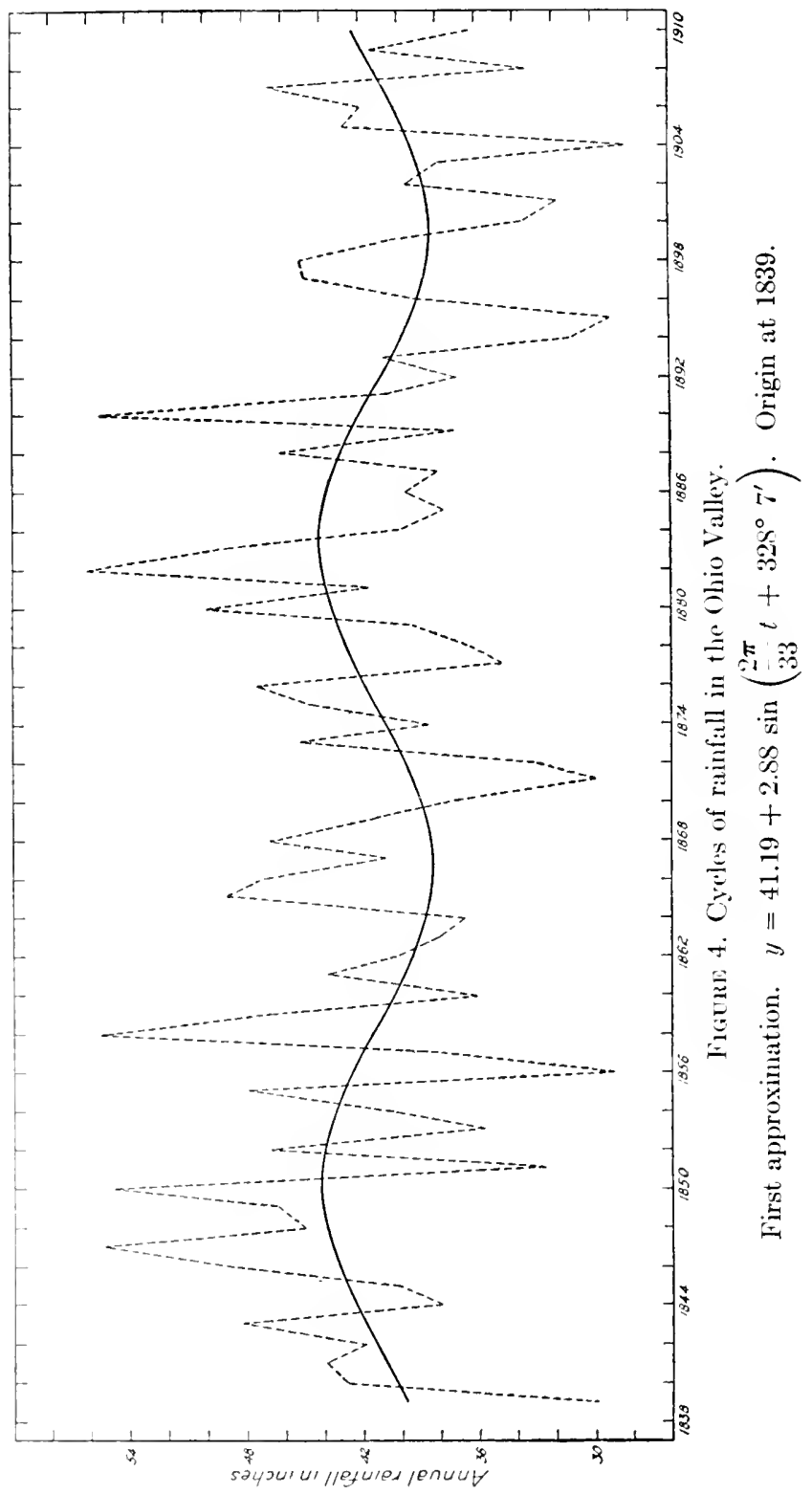


the origin being at 1839. This curve traces in bold outline the general course of rainfall. It gives the ground-swell of the rainfall movement.

If the 8 years cycle is superposed upon the 33 years cycle, the root-mean-square deviation about the curve becomes $S=5.66$ inches. The graph of the combination of these two curves is traced in Figure 5. Its equation is

$y=41.19+2.88 \sin \left(\frac{2 \pi}{33} t+328^{\circ} 7^{\prime}\right)+4.13 \sin \left(\frac{2 \pi}{8} t+310^{\circ} 41^{\prime}\right)$,

the origin being at 1839. A point of interest with regard to the flow of the curve is the rapidity with which it rises from the least minimum to the greatest maximum, and the slowness with which it then descends to the subsequent least minimum.

If the 8 years cycle and its semiharmonic of 4 years are combined with the 33 years cycle and its semiharmonic of 16.5 years, the root-mean-square deviation about the compound curve becomes $S=5.29$ inches. The graph of the curve is given in Figure 6. Its equation is

$$
\begin{aligned}
y=41.19 & +2.88 \sin \left(\frac{2 \pi}{33} t+328^{\circ} 7^{\prime}\right)+2.25 \sin \left(\frac{4 \pi}{33} t+271^{\circ} 42^{\prime}\right) \\
& +4.13 \sin \left(\frac{2 \pi}{8} t+310^{\circ} 41^{\prime}\right)+2.14 \sin \left(\frac{4 \pi}{8} t+180^{\circ} 28^{\prime}\right),
\end{aligned}
$$

the origin being at 1839 . In this closer approximation the characteristic rapid rise to a general maximum and slow fall to a general minimum is reproduced. Another characteristic is the longer interval that the curve 


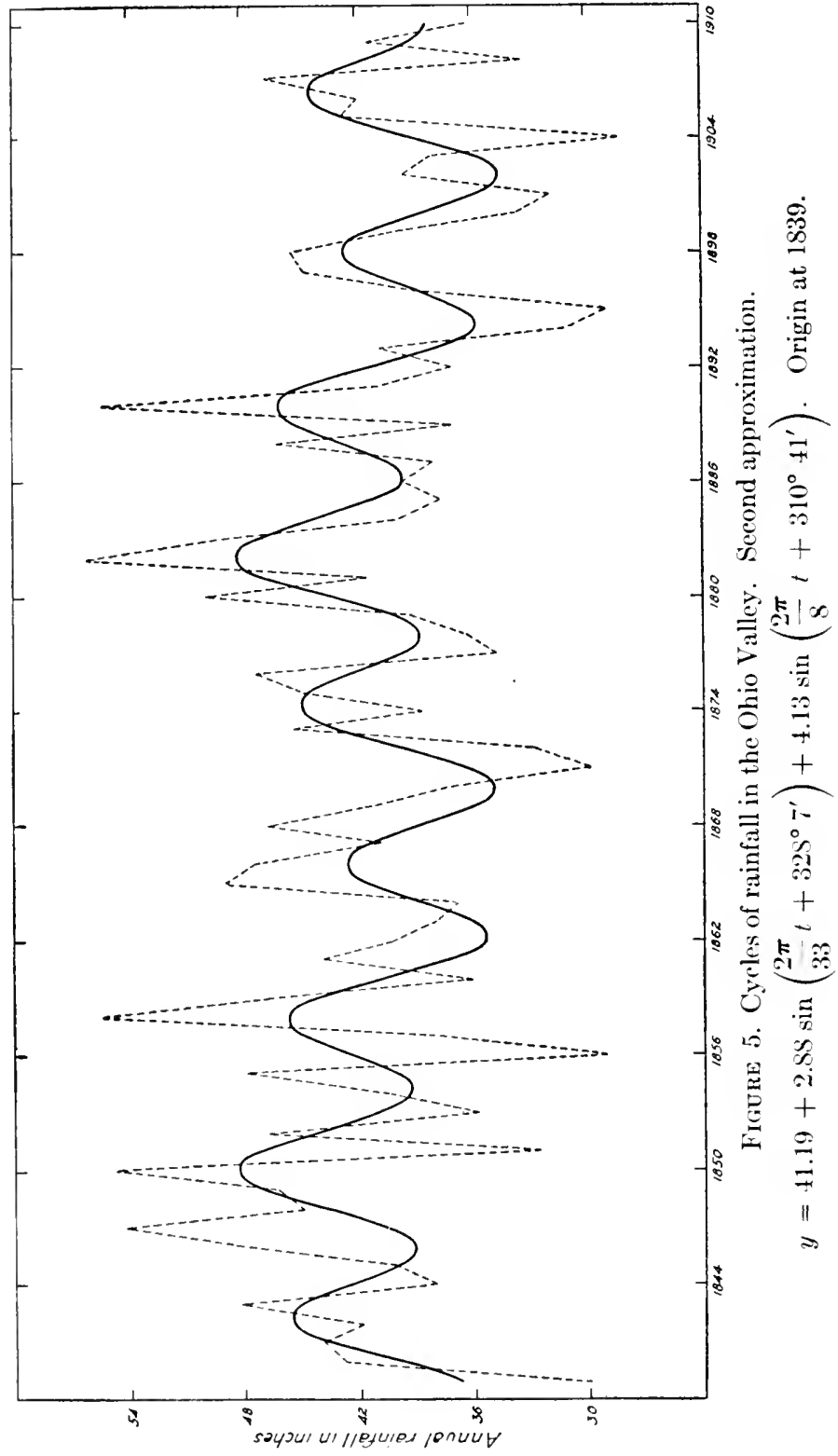




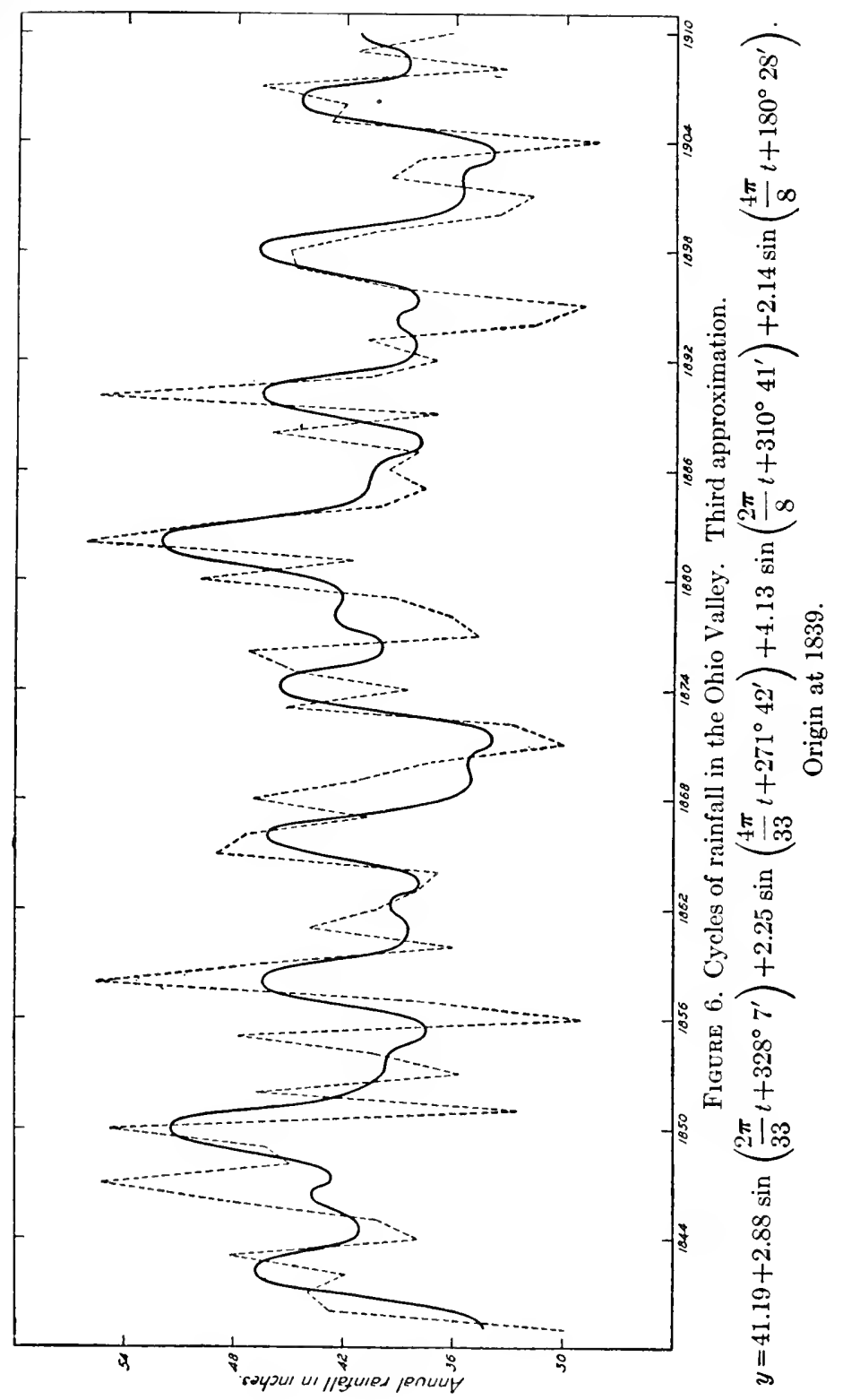


lingers at the minima and the short period during which it flows in the neighborhood of the maxima. ${ }^{1}$

\section{Rainfall in the Corn Belt}

Thus far we have dealt with the law of rainfall only in the Ohio Valley. The object in taking the Ohio data, rather than the data of a state more representative of the leading cereal area, was to make an investigation of a longer meteorological record than is afforded by the data of the central Mississippi Valley. But our purpose in dealing with meteorological records at all is to show the dependence of crops upon the cyclical movement of the elements of the weather. We must, therefore, prove that the cycles of rainfall which we have

${ }^{1}$ I should like to make clear the method I have followed in the derivation of the equations to the curves. My object was to obtain a summary description of the general course of rainfall in order that I might discover, later on, whether the characteristic general features of the movement of rainfall are reproduced in the changing yield per acre of the crops. As a first step I tried to detect the real cycles in rainfall and I believe I have shown that, if the 72 years record is sufficiently long to reveal the true cycles, then the most probable lengths of the eycles are, in round numbers, 33 years and $S$ years respectivety. With so short a range of data I regarded it as useless to attempt to calculate the lengths of the periods to a greater degree of precision. I next had to derive the equations to the curves showing the characteristic general course of rainfall, and it seemed to me that, for this purpose, the method described in the text for evaluating the coefficients in a Fourier series might properly be used. If the 33 years cycle were taken as the fundamental cycle, then the 8 years cycle would be approximately the fourth harmonic in the series, and the 4 years eycle would be the eighth harmonic.

The arithmetical process for computing the coefficients is indieated by Professor Schuster in Hidden Periodieities, pp. 13, 14 and is briefly described by Professor Perry in an articte on "Harmonic Analysis" in The Electrician, for February 5, 1892. 
discovered for the Ohio Valley are likewise the cycles that exist in the heart of the grain producing area.

Among the states of the Middle West, Illinois is probably the most highly representative of American cereal production. It produces the largest crop of corn, ${ }^{1}$ which is the leading American cereal, and it ranks second in the production of oats. Most of the other cereals that are produced in the upper Mississippi Valley are likewise cultivated with success in Illinois. Another fact that makes Illinois a desirable state for our purpose is that its meteorological records are fairly long and are obtainable from so many stations as to be representative of the weather conditions in the entire state. This last fact is all-important if the statistics for crop production of the whole state are to be considered in relation to the weather cycles of the state.

In Table III of the Appendix to this chapter the record of the annual rainfall in Illinois is given for a period of 41 years. $^{2}$ The ideal direct method with

1 This statement was accurate when it was first written. But in 1912 Iowa gained by a narrow margin the first place among the corn produeing states.

2 The raw data were taken from Bulletin $W^{\prime}$ of the Weather Bureau of the United States and from the Anmual Reports of the Chief of the Weather Bureau. The stations used in eomputing the mean annual rainfall were:-In Northern Illinois: Aurora, Cambridge, Chicago, Tiskilwa, Cialva, Kishwaukee, Ottawa, Winnebago, and Henry. In Central Illinois: Charleston, Carlinville, Coatsłurg, Decatur, Griggsville, Knoxville, Havana, LaHarpe, Pana, Peoria, and Springfield. In Southern Illinois: Cairo, Cobden, Carlyle, Golconda, Flora, Greenville, MeLeansboro, Mascoutah, Mt. Carmel, and Palestine.

All of these stations to not present full records for the 41 years, 
reference to these data would be to compute the periodogram in the same manner in which it was computed in the case of the Ohio Valley data, and then compare the periodograms. But this method has not been followed. A less direct, and far less laborious, process has been adopted. We know from the Ohio data that there are two cycles of rainfall, a 33 years cycle and an 8 years cycle, and we know, furthermore, that when the curve for rainfall in the Ohio Valley is computed for the 33 years and 8 years periods and their semiharmonics, a good fit to the data is obtained. The questions that are asked with reference to the Illinois data are these: If we assume the existence of a 33 years period and an 8 years period in the Illinois rainfall data, will the rainfall curve fit the Illinois data as well as the Ohio curve fits the Ohio data? Will the Illinois curve reproduce the characteristic features of the Ohio curve? A presumption in favor of an affirmative answer to these questions is suggested by the fact that the correlation between the annual rainfall in the Ohio Valley and the annual rainfall in the state of Illinois is $r=6.00$.

The graph of the curve of rainfall in Illinois is given in Figure 7. Its equation is

$$
\begin{aligned}
y=38.53 & +3.03 \sin \left(\frac{2 \pi}{33} t+325^{\circ} 35^{\prime}\right)+1.87 \sin \left(\frac{4 \pi}{33} t+194^{\circ} 55^{\prime}\right) \\
& +3.05 \sin \left(\frac{2 \pi}{8} t+241^{\circ} 52^{\prime}\right)+1.12 \sin \left(\frac{4 \pi}{8} t+232^{\circ} 26^{\prime}\right),
\end{aligned}
$$

the origin being at 1870. The root-mean-square deviabut in no year were fewer than seven records obtainable while for a large proportion of the years the thirty reeords were complete. 


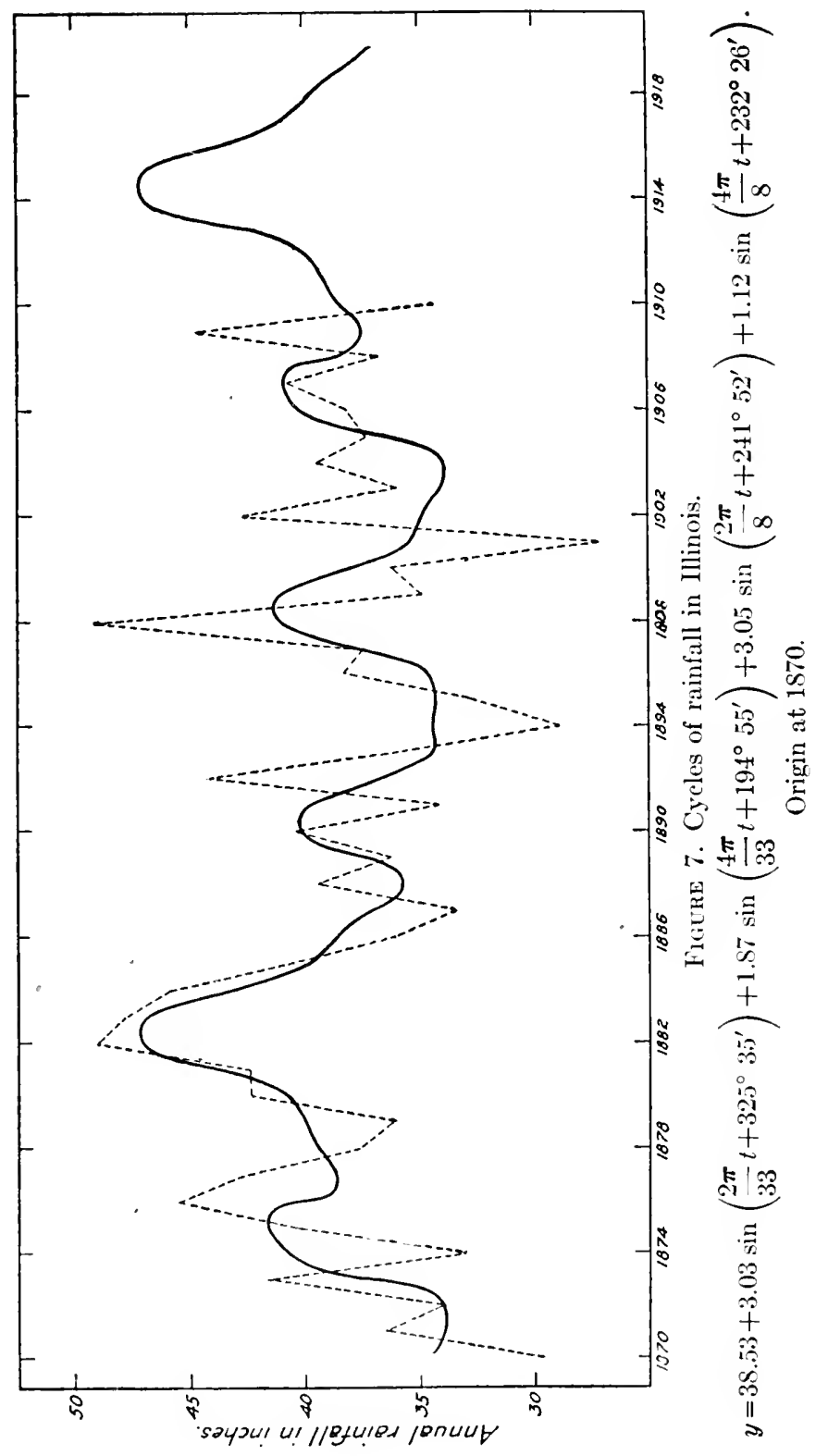


tion of the observations from this curve is $S=4.20$. In case of the Ohio curve the root-mean-square deviation was $S=5.29$. But this is a better relative fit for the Illinois curve than we have a right to claim, because in Ohio the mean annual rainfall is 41.19 , while in Illinois the mean is 38.53 . If we express the relative scatter of the observations about the curve as the ratio of the root-mean-square deriation of the observations to the mean rainfall, we get for Ohio and Illinois, respectively, $S^{1}=.128 ; S^{1}=.109$.

In Figure 8, the Ohio curve for 1870-1910 is placed upon the same chart as the Illinois curve for the same flow of time, and the degree of correspondence of the two curves is seen to be so close that, with due allowance for the difference in their mean annual rainfall, they seem to be almost congruent.

We may say, therefore, that the two curves fit their respective data equally well.

Our problem has now received its solution. Annual rainfall in the chief grain-producing area of the United States has no secular trend, but its mean course is the resultant of causes producing two cycles of 33 years and 8 years respectively. The manner in which these cycles of rainfall produce a rhythmical expansion and contraction in the yield of the crops we shall examine in the next chapter. 
Cycles of Rainfall

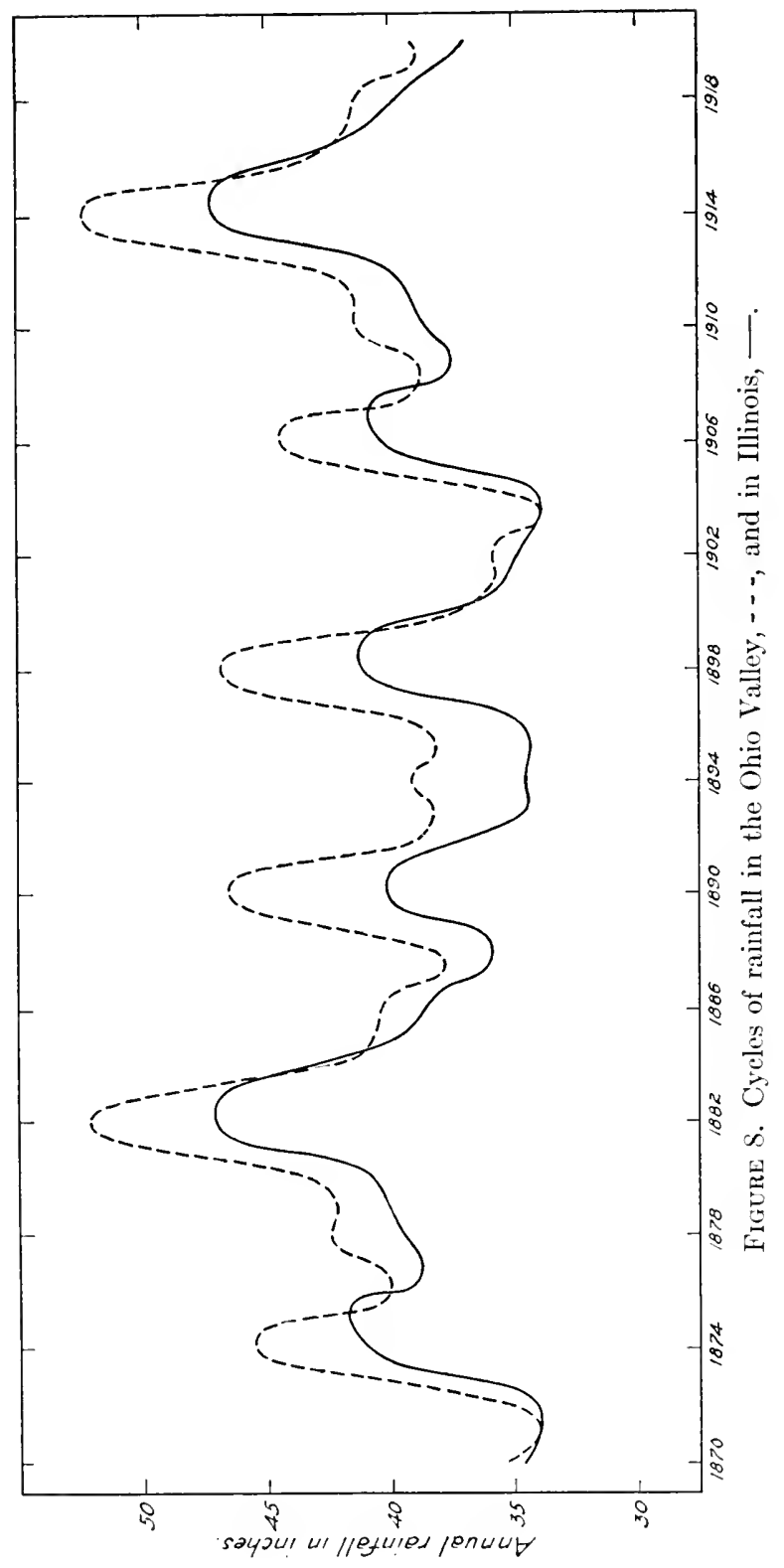




\section{APPENDIX}

TABle I.-Anvual Rainfall in the Ohio Valley

Stations: Cincinnati, Portsmouth, Marietta

\begin{tabular}{|c|c|c|c|c|c|}
\hline YeAR & $\begin{array}{c}\text { RaINFALL IN } \\
\text { INCHES }\end{array}$ & YE.AR & $\begin{array}{c}\text { RAINFALL IN } \\
\text { INCHES }\end{array}$ & year & $\begin{array}{l}\text { RaINFALL IN } \\
\text { INCHES }\end{array}$ \\
\hline 1839 & 29.92 & 1863 & 37.95 & 1857 & 38.00 \\
\hline 1840 & 42.84 & 1864 & 36.68 & 1858 & 46.19 \\
\hline $18+1$ & 43.94 & 1865 & 48.93 & 1889 & 37.06 \\
\hline 1842 & 41.89 & 1866 & 47.37 & 1890 & 55.43 \\
\hline 1843 & 48.20 & 1867 & 40.72 & 1891 & 40.68 \\
\hline 1844 & 37.95 & 1868 & 46.87 & 1892 & 36.96 \\
\hline $1 S 45$ & 40.11 & $1 S 69$ & 41.29 & 1893 & 40.80 \\
\hline 1846 & 48.39 & 1870 & 37.46 & 1894 & 31.07 \\
\hline 1847 & 55.26 & 1871 & 29.91 & 1895 & 29.06 \\
\hline 1848 & 44.97 & 1872 & 32.90 & 1896 & 39.22 \\
\hline 1849 & 46.37 & 1873 & 45.18 & 1897 & 44.80 \\
\hline 18.50 & 54.77 & 1574 & 38.48 & 1898 & 45.04 \\
\hline 1851 & 32.54 & 1875 & $44.7 \mathrm{~s}$ & 1899 & 40.46 \\
\hline 1852 & 46.73 & 1876 & 47.34 & 1900 & 33.60 \\
\hline 18.53 & 35.67 & 1877 & 34.69 & 1901 & 31.78 \\
\hline 18.54 & 40.30 & 1878 & 36.35 & $190^{\circ}$ & 39.53 \\
\hline 1855 & 47.89 & 1879 & 39.22 & 1903 & 37.98 \\
\hline 18.56 & 28.98 & 1880 & 49.94 & 1904 & 28.24 \\
\hline 1857 & 37.95 & 1881 & 41.60 & 1905 & 42.81 \\
\hline $1 \mathrm{S.58}$ & 55.48 & 1882 & 56.10 & 1906 & 41.95 \\
\hline 1859 & 46.68 & 1883 & 49.25 & 1907 & 46.68 \\
\hline 1860 & 36.00 & 1884 & 40.05 & 1908 & 33.29 \\
\hline $1 S t j 1$ & 43.81 & 1885 & 37.63 & 1909 & 41.40 \\
\hline 1862 & 40.26 & 1886 & 39.61 & 1910 & 36.20 \\
\hline
\end{tabular}


Table II.-The Periodogram of Rainfall in the Oho VAlLEY

$$
y=F(t)=A_{\circ}+a_{1} \cos k t+b_{1} \sin k t=A_{\circ}+A_{1} \sin (k t+e)
$$

\begin{tabular}{|c|c|c|c|c|c|c|c|}
\hline $\begin{array}{c}\text { LeNoth } \\
\text { OF } \\
\text { PERIOD } \\
\text { IN YEARS }\end{array}$ & $a^{2}$ & $b^{2}$ & $a^{2}+b^{2}=A^{2}$ & $\mid \begin{array}{c}\text { LENOTH } \\
\text { OF P PE- } \\
\text { HIOD IN } \\
\text { YEARS }\end{array}$ & $a^{2}$ & $b^{2}$ & $a^{2}+b^{2}=A^{2}$ \\
\hline 3 & 1.2628 & 2.4821 & 3.7449 & 21 & .0046 & 4. 4260 & 4. 4306 \\
\hline 4 & .0003 & 4.5689 & 4.5692 & 22 & 2454 & $2 .+237$ & 2.6691 \\
\hline 5 & .0897 & .4520 & .5417 & 23 & .8471 & .8711 & 1.718 .5 \\
\hline 6 & .2220 & .1403 & .3623 & 24 & .3551 & .0678 & .4229 \\
\hline 7 & 2.1838 & 3.7869 & 5.9707 & 25 & .2755 & .1327 & .4082 \\
\hline 8 & 9.8215 & 7. .2563 & 17.0778 & 26 & .0566 & $.000^{\circ}$ & .0568 \\
\hline 9 & .0327 & .3120 & .3447 & 27 & .9692 & .0019 & .9711 \\
\hline 10 & .5978 & .0190 & .6168 & $2 S$ & .6227 & .0300 & .6527 \\
\hline 11 & 1.0756 & .6791 & 1.7547 & 29 & 4.2657 & 1.1153 & $5.3 \$ 10$ \\
\hline 12 & .4371 & .1143 & .5514 & 30 & .6464 & .4767 & 1.12:31 \\
\hline 13 & .0044 & .0007 & .0051 & 31 & .6112 & .5923 & 1.2035 \\
\hline 14 & .1078 & .1670 & $.274 \mathrm{~S}$ & 32 & .5776 & 1. $116 \mathrm{~s}$ & 1.6944 \\
\hline 15 & .1874 & .0863 & .2737 & 33 & 2.3199 & 5.9974 & 8.3173 \\
\hline 16 & .7691 & .0424 &.$\$ 115$ & 34 & .2017 & 1.7652 & 1.9669 \\
\hline 17 & .9795 & .0626 & 1.0421 & 35 & .0456 & 1.7914 & 1.8370 \\
\hline 18 & 2.9332 & .9270 & $3 . \$ 602$ & 36 & .0036 & 6.8567 & 6.86003 \\
\hline 19 & 1.4777 & 1.9422 & 3.4199 & \multirow{2}{*}{\multicolumn{4}{|c|}{ Mean value of $A^{2}=2.54 .59$}} \\
\hline 20 & .0294 & 1.5961 & 1.6255 & & & & \\
\hline
\end{tabular}


34 Economic Cycles: Their Law and Cause

Table III.-Anveal Rainfall in Illinois

\begin{tabular}{|c|c|c|c|}
\hline YEAR & Rainfali in INChes & YEAR & RAINFALL in INChEs \\
\hline 1870 & 29.65 & 1891 & 34.11 \\
\hline 1871 & 36.53 & 1892 & 44.17 \\
\hline 1872 & 33.98 & 1893 & 35.89 \\
\hline 1873 & 41.62 & 1894 & 28.99 \\
\hline 1874 & 32.91 & 1895 & 32.92 \\
\hline 1875 & 40.34 & 1896 & 38.27 \\
\hline 1876 & 45.50 & 1897 & 37.44 \\
\hline 1877 & 42.76 & 1898 & 49.09 \\
\hline 1878 & 37.61 & $1 \varsigma 99$ & 34.95 \\
\hline 1879 & 36.10 & 1900 & 36.19 \\
\hline 1880 & 42.31 & 1901 & 27.17 \\
\hline 1881 & 42.32 & 1902 & 42.65 \\
\hline 1882 & 49.04 & 1903 & 35.97 \\
\hline 1883 & 47.81 & 1904 & 39.33 \\
\hline 1884 & 45.83 & 1905 & 37.33 \\
\hline 188.5 & 40.80 & 1906 & 38.10 \\
\hline 1886 & 36.16 & 1907 & 40.61 \\
\hline $18 S 7$ & 33.40 & $190 \mathrm{~S}$ & 36.76 \\
\hline 1SSS & 39.41 & 1909 & 44.74 \\
\hline 1889 & 36.27 & 1910 & 34.34 \\
\hline 1890 & 40.34 & Mean & 38.53 \\
\hline
\end{tabular}




\section{CHAP'TER III}

\section{RAINFALL AND THE CROPS}

"It is mere weather . . . doing and undoing without end." - William James.

In the preceding chapter the course of annual rainfall in the great cereal-producing area of the United States has been shown to move in cycles: There is a groundswell of thirty-three years in length upon which cycles of eight years in duration are superposed. Our object in studying the rhythmic changes in the volume of rainfall was to bring these changes into relation with the variations in the yield per acre of the crops, and in the present chapter we shall be able to realize our purpose. The actual course of the varying yield per acre of the crops will be shown to have both a secular and a cyclical movement; these two movements will be separated for representative crops; and the cyclical movements will be shown to be dependent upon the cyclical movements in the weather represented by the cycles of rainfall.

\section{The Secular Trend in the Yield of the Crops}

'The' state of Illinois was chosen in the preceding chapter to illustrate the general conditions of rainfall in the Corn Belt of the Middle West, and we shall now examine the statistics of the yield of its most important crops. 
According to the Yearbook of the Department of Agriculture for 1912, we find the acreage and value of the leading Illinois crops as they are given in the subjoined Table:

Acreage and Value of Crops in Illunois, 1912

$\begin{array}{lrr}\text { Crop } & \text { Acreage } & \text { Value of Crop } \\ \text { (1) Corn } & 10,658,000 & \$ 174,791,000 \\ \text { (2) Oats } & 4,220,000 & 54,818,000 \\ \text { (3) Hay } & 2,512,000 & 41,152,000 \\ \text { (4) Wheat } & 1,183,000 & 8,641,000 \\ \text { (5) Potatoes } & 137,000 & 8,302,000 \\ \text { (6) Barley } & 57,000 & 952,000 \\ \text { (7) Rye } & 48,000 & 538,000 \\ \text { (8) Buckwheat } & 4,000 & 70,000 \\ \text { (9) Tobacco } & 900 & 62,000\end{array}$

It is clear, from this Table, that five crops-corn, oats, hay, wheat, and potatoes-make up the bulk of the crops of Illinois, and one could not go far wrong if he based his generalizations as to the conditions of agriculture in the state upon these five crops. But for the purposes we have in view, in this and other chapters, it is not possible to utilize the statistics of wheat production because both spring and winter wheat are grown in the state, and the statistics of their relative yield and price are not given in the published material for the long record covered in our investigation. Accordingly, the crops that have been actually used in our inquiry are corn, oats, hay, and potatoes. These crops total 93.13 per cent. of the crop acreage and 96.45 per cent. of the crop value as these quantities are given in the'above Table. 
As the yield per acre of the various crops may show a secular as well as a complex cyclical change, it will be necessary, before their cyclical elements can be brought into relation with the corresponding cyclical changes of rainfall, to eliminate from the recorded course of the yield per acre of the several crops the element of change that is secular in character.

The method that has been adopted here to effect the elimination of the secular change is simple, but to secure a first approximation, it is adequate. For a period of time covered by the statistics, a change is regarded as a secular change if, for the period of time taken as a whole, the yield per acre of the crop shows a tendency either to increase or to decrease. In order to determine whether there is a secular change in the yield per acre, for a certain period of time, the yield data are correlated with time, and the existence or non-existence of a secular change is inferred from the relative magnitudes of the coefficient of correlation and its probable error. If there be a secular change, the calculation of the coefficient of correlation of the yield with time is then a first-step toward the elimination of the secular element by means of a regression equation in which the coefficient of correlation is a factor.

The method may be illustrated by taking the history of the yield per acre of corn. In Figure 9 the actual yield per acre in Illinois is plotted for the period 18701910. The straight line showing the secular trend of the yield is the graph of the regression equation between the yield per acre and time. The correlation of the 


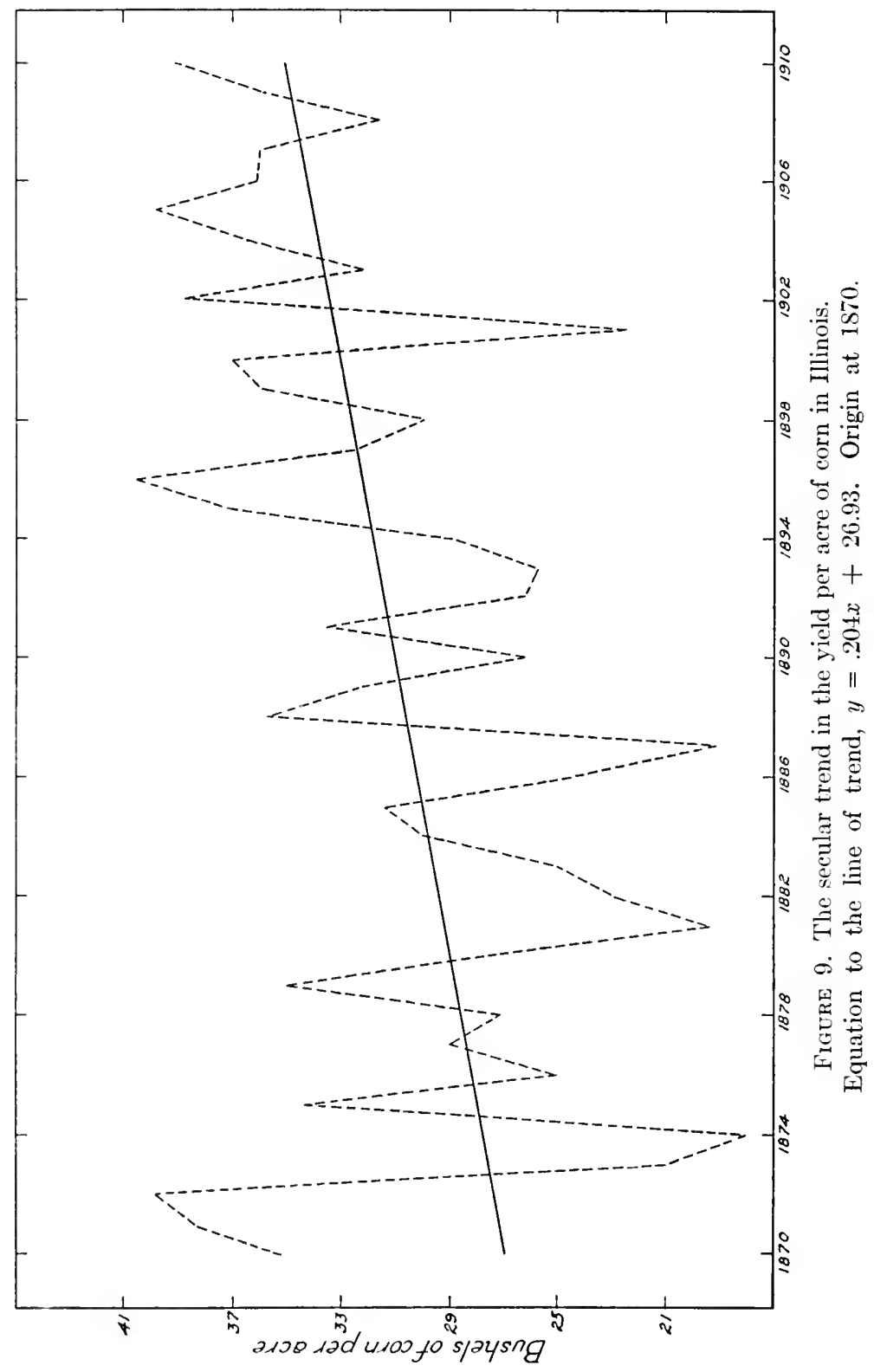


yield per acre and time is $r=.382 \pm .090$, and the regression equation is, $y=.204 x+26.93$, where $y=$ yield per acre, $x=$ time, and the origin is at 1870 . The secular trend is eliminated by means of the facts summarized in the regression equation: Beginning with the year 1870, as many times .204 are subtracted from the yield per acre for the several years, as the respective years differ from 1870. For example, the yield for the year 1872 was 39.8 bushels per acre; consequently the reduced yield for that year was $39.8-2(.204)=39.8-$ $.408=39.39$. Figure 10 traces the yield per acre of corn freed from the secular trend.

Of the four leading crops of Illinois that form the basis of our investigation, only two, corn and potatoes, show a significant ${ }^{1}$ tendency to secular change. The correlation between the yield per acre and time is, for hay, $r=.013 \pm .105$ and, for oats, $r=.043 \pm .105$; consequently the figures for the yield per acre of these two crops have not been reduced. In the case of potatoes, $r=.122 \pm .104$, and the regression equation is $y=.233 x+70.51$, where the origin is at 1870 . The figures for the actual yield per acre and the reduced yield per acre for corn and potatoes, as well as the figures for the yield of hay and of oats, are given ${ }^{2}$ in Table I of the Appendix to this chapter.

${ }^{1}$ The indicated secular trend in potatoes is not significant in the mathematical sense, beeause the probable error of the coefficient of correlation is nearly as large as the coefficient itself. I have nevertheless eliminated the indicated secular trend before using the data.

${ }^{2}$ The raw data were taken from Bulletins 56, 58, 62, 63 of the 
Economic Cycles: Their Law and Cause

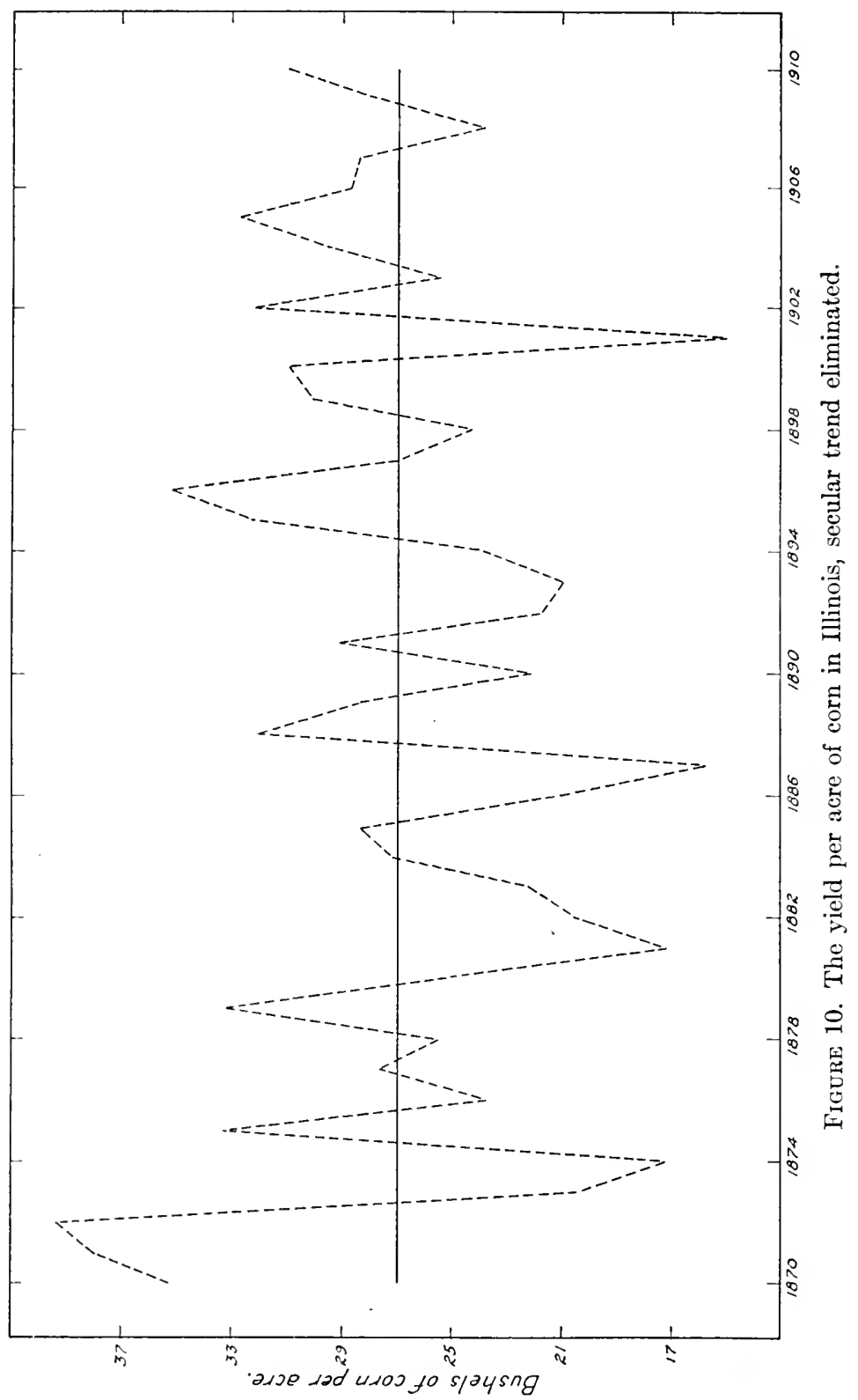




\section{Critical Periods of Growth}

If the rhythmical changes in rainfall are to give the clue to the changes in the yield of the crops, the variations in the rainfall must be closely related with the variations in the yield of the crops. But different crops have different times of planting and of harvesting, different periods of growth, and different requirements of moisture at the various stages of growth. The direct way to find whether the course of rainfall determines the course of the varying yield of the crops is first to ascertain the critical season for every crop; and then to compare the course of the yield of each crop with the course of the rainfall of its critical season.

The method of discorering the critical period of a crop may be illustrated in the treatment of corn. In Table II of the Appendix to this chapter, the mean ${ }^{1}$ monthly rainfall for Illinois is tabulated for seven months, March, April, May, Jume, July, August, and September. Table I of the Appendix records the data

Bureau of Statisties of the United States Department of Agrieulture and from recent Yearbooks of the United States Department of Agrieulture.

1 The raw data were taken from Bulletin IV of the Weather Bureau of the United States and from the Ammal Reports of the Chief of the Weather Bureau. The stations used in computing the mean monthly rainfall were, in Northem Illinois: Aurora, Cambridge, Chicago, Tiskilwa, Galva, Kishwaukee, Ottawa, Winnebago and I Ienry. In Centrul Illinois: Charleston, Carlinville, Coatsburg, Decatur, (iriggsville, Knoxville, Havana, LaHarpe, Pana, Peoria and Fipringfield. In Sonthern Illinois: Cairo, Colxlen, Carlyle, Golconda, Flora, Greenville, MeLeanshoro, Mascontah, Mt. Carmol and Palestine. 
referring to the yield per acre of the several crops after the secular trends have been eliminated. These two Tables furnish the statistical material for ascertaining the critical periods of the respective crops. The facts as to the times of planting and harvesting may be obtained from an article in the Yearbook of the United States Department of Agriculture, 1910, pp. 488-494, on "Seedtime and Harvest: Average Dates of Planting and Harvesting in the United States." The method of detecting the period of critical relation between yield and rainfall consists in ascertaining, for each crop, the month or combination of months, within the interval between planting and harvesting, ${ }^{1}$ whose rainfall gives the highest correlation with the ultimate yield per acre of the crop. The time for planting corn in Illinois, according to the official publication cited above, begins about April 30, it is general about May 13, and it ends about June 2. The average time for harvesting, according to the same publication, begins about September 26 , is general by October 29, and ends about December 10 . The correlation between the yield of corn per acre (secular trend eliminated), and the rainfall for June is, $r=.069$; for July, $r=.496$; for August, $r=.293$; for September, $r=.087$; for July and August combined, $r=.589$. The critical period of growth for corn has, therefore, been assumed to be the interval of two months-July and August. ${ }^{2}$

${ }^{1}$ For some purposes it would be desirable to test the correlation beyond these limits.

${ }^{2}$ Of course all possible combinations of months have not been 
The critical periods for the other crops are, for oatsMay, June, July, $r=.290$; for hay-March, April, May, June, $r=.620$; for potatoes-July and August, $r=.666$. The critical season for corn, as we found a while ago, is July and August, $r=.589$.

The high correlation between the yield of the crops and the rainfall of their respective critical seasons promises well for the theory as to the relation of the cycles of rainfall and cycles of crops. In the last chapter we found that by examining the periodogram of annual rainfall in the Ohio Valley, cycles of eight years and of thirty-three years were discovered; and that by taking periods of thirty-three years and eight years with their semiharmonics, a good fit to the annual rainfall curve was obtained. It was then shown that the annual rainfall in Illinois is correlated with the annual rainfall in the Ohio Valley, the correlation coefficient being $r=.600$. Upon the basis of this relatively high correlation, it was assumed that the annual rainfall in Illinois passed through similar cycles to the rainfall in the Ohio Valley, and we found that this assumption was justified by the facts inasmuch as the harmonic analysis applied in the same way to the Illinois data afforded as good a fit as when it was applied to the data of the Ohio Valley. Since in two of the four representative crops the correlation between the yield and the rainfall exhausted in the above case, nor have we made any attempt to place the eritical period for a smaller interval of time than a month. If for any other period a closer relation could be found than $r=.589$, the conelusions that we draw from our investigation would only be strengthened. 
of the critical season of growth is greater than the correlation between the annual rainfall in Illinois and the annual rainfall in the Ohio Valley, there would seem to be excellent ground for believing that the cycles of the yield of the crops would flow congruently with the cycles of rainfall during their respective critical periods.

Cycles in the Yield of the Representative Crops and the Corresponding Cycles of Rainfall

The method of bringing the cycles of rainfall for the critical period of growth of the several crops into relation with the cycles of the respective crops is similar to the method that was employed in passing from the cycles of annual rainfall in the Ohio Valley to the corresponding cycles in the state of Illinois. The laborious but direct way of treating the problem would be to compute the periodogram of rainfall for the critical period of growth of each crop, and then to compare the results with the corresponding periodograms of the respective erops. It may be that this laborious process may eventually have to be followed. The process that has been adopted in the present investigation makes several assumptions which it is highly desirable to have clear in mind. It is assumed

(1) That the course of the annual rainfall is the mean course of the rainfall of the parts of the year and that, consequently, by computing the periodogram of anmual rainfall, we obtain a general type of curve for describing not only 
the annual rainfall but also the rainfall of any considerable part of the year. Or, more concretely, that the annual rainfall and the rainfall of any considerable part of the year may be described by an equation of the form

$$
\begin{aligned}
y=A_{0} & +A_{1} \sin \left(\frac{2 \pi}{33} t+e_{1}\right)+A_{2} \sin \left(\frac{4 \pi}{33} t+e_{2}\right) \\
& +a_{1} \sin \left(\frac{2 \pi}{8} t+\eta_{1}\right)+a_{2} \sin \left(\frac{4 \pi}{8} t+\eta_{2}\right),
\end{aligned}
$$

where the constants in the series may be different for the several parts of the year.

(2) That where the correlation between the yield per acre of a particular crop and the rainfall of its critical season is high, the same general type of equation will fit both groups of data, the data of rainfall and the data of the yield per acre of the crops.

(3) That both of the preceding assumptions are greatly fortified if the compound curves deduced from the actual data of rainfall and yield satisfy a reasonable test of fit to the data.

The working out of the consequences of these assumptions is exhibited in Figures 11, 12, 13, and the equations descriptive of the several curves appear on the corresponding Figures.

To measure the degree of fit of the curves to their respective data, we shall employ a coefficient $K$, which may be described as the ratio of the arithmetical sum of the deviations of the observations from the curve 


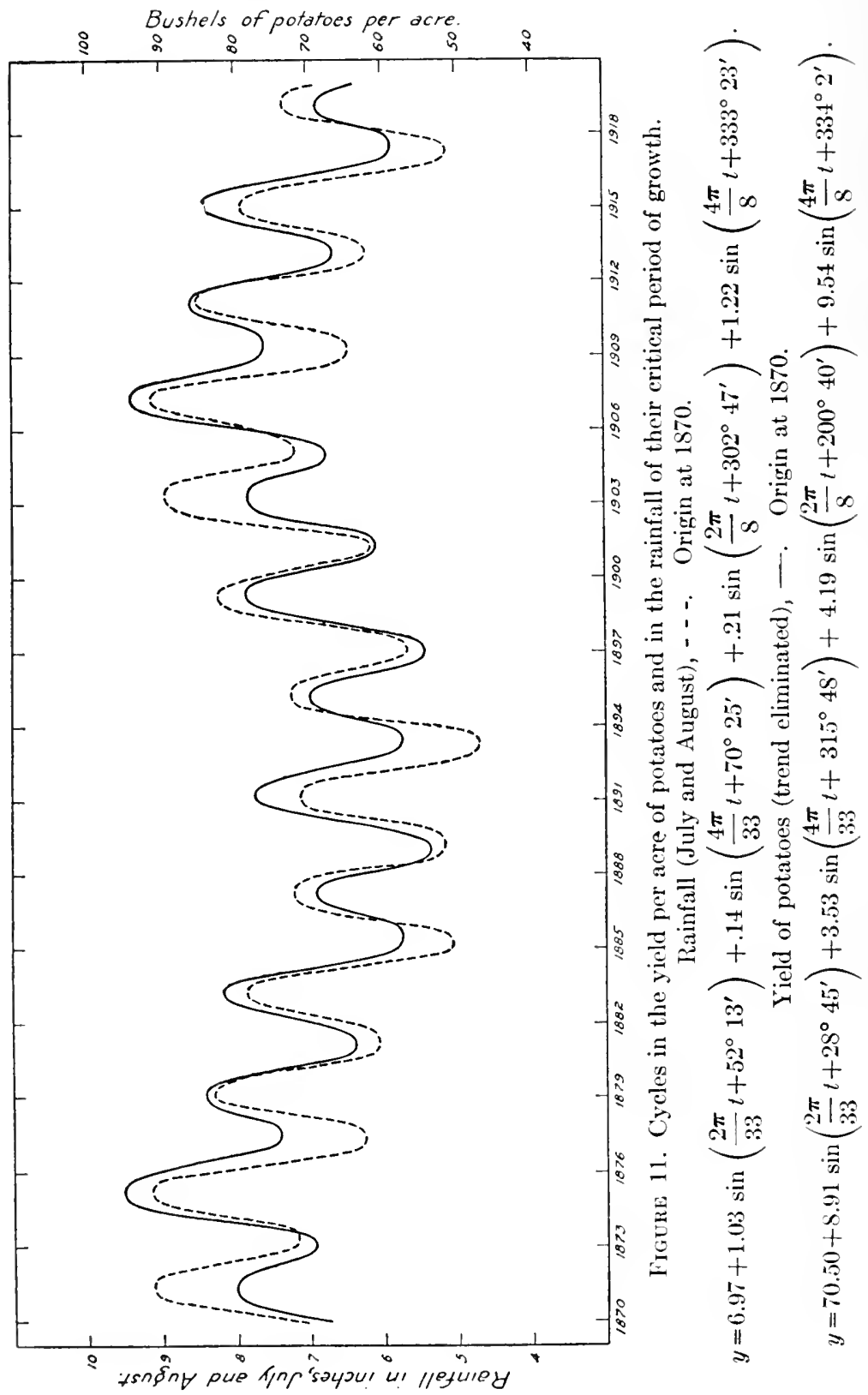




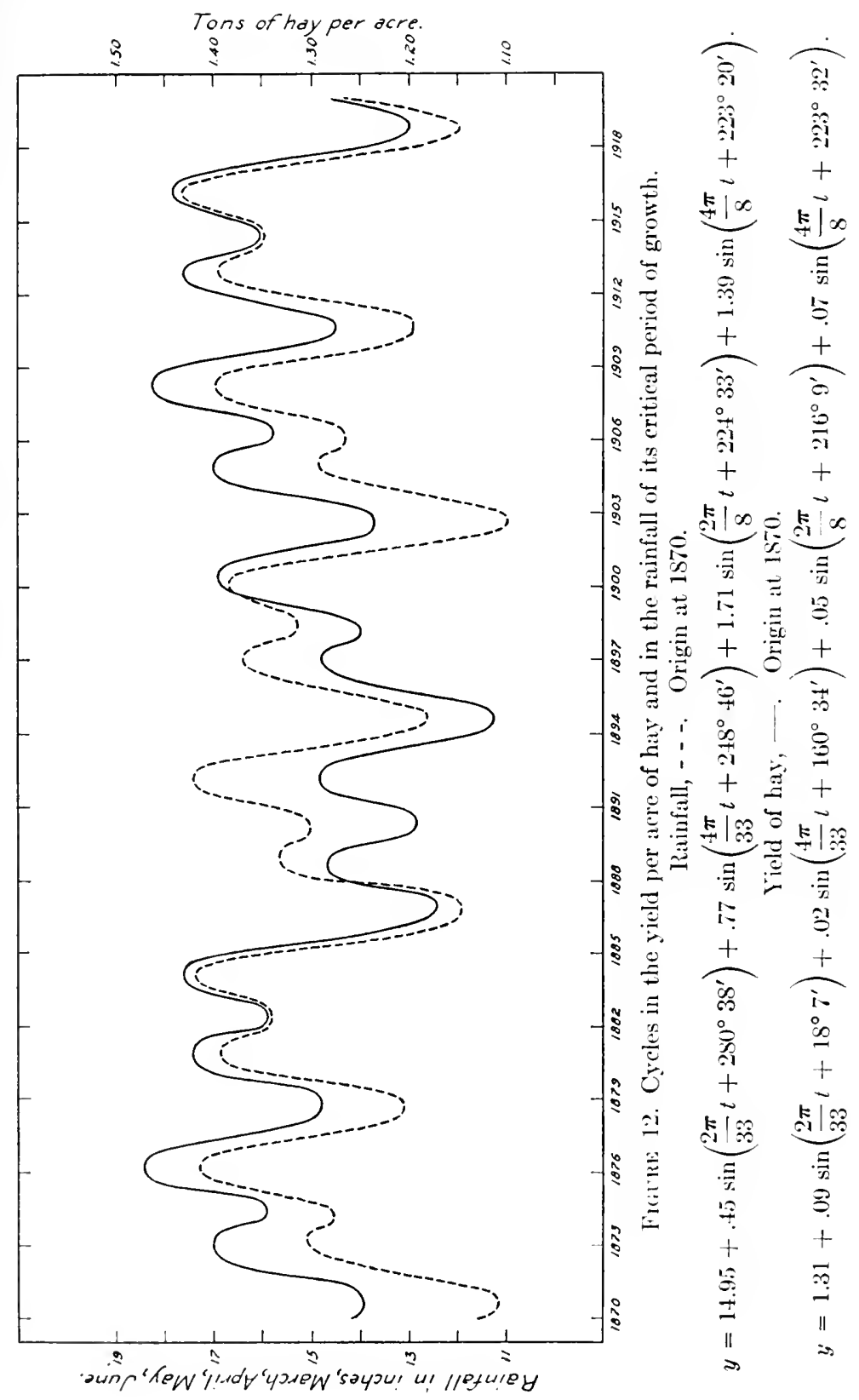




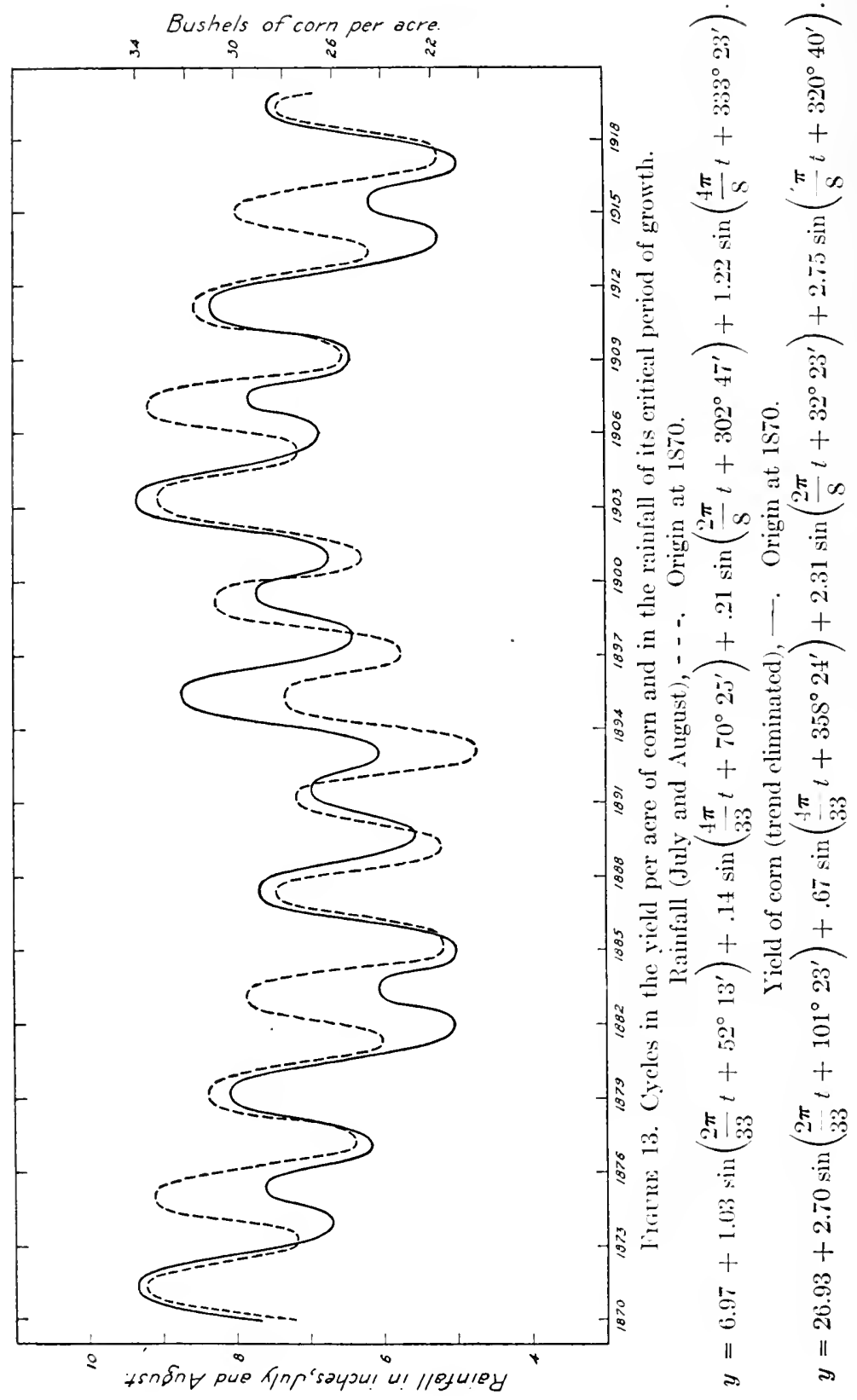


divided by the area included between the eurve and the straight line indicating the mean value of the observations. In the equation to the compound cycle describing the typical curve with which we shall have to deal, the first term gives the mean value of the observations, and the remaining four harmonic terms trace the area about the horizontal line drawn at a distance from the base line equal to the mean value of the observations. The reason for adopting this complex coefficient $K$ is that the eurves whose relative degrees of fit are in question apply to qualitatively different things. From the method of calculating $K$, it follows that the smaller the value of $K$, the better is the degree of fit of the curve to the observations.

Passing now to the calculations referring to the representative crops, we find,

For potatoes, the correlation of the yield per acre with the rainfall of its critical period-July and August-is $r=.666$. The measure of the fit of the compound cycle of thirty-three years and eight years with their semiharmonics is, in case of the yield per acre, $K=1.97$, and in case of the rainfall of the critical period of growth, $K=1.30$.

For hay, the correlation of the yield per acre with the rainfall of its critical period-March, April, May, June-is $r=.620$. The measure of the fit of the compound cycle to the data is, in case of the yield per acre, $K=1.57$, and in case of the rainfall of the critical season, $K=1.63$.

For corn, the correlation of the yicld per acre with 
the rainfall of the critical season-July and Augustis $r=.589$. The measure of the fit of the compound cycle to the data is, for the yield per acre, $K=1.52$, and, for the rainfall of the critical season, $K=1.30$.

For oats, the computation of the equation has not been carried out because no critical period of growth could be found in which the correlation between yield and rainfall was higher than $r=.3$. The correlations were, for March, $r=-.181$; for April, $r=-.147$; for May, $r=120$; for June, $r=.297$; for July, $r=.140$; for May, June, and July, $r=.290$.

Referring now to the Figures 11, 12, 13 and to the calculations that have just been reviewed, we observe that the compound cycles of yield per acre and of the rainfall of the critical seasons flow almost congruently, and that the compound cycle of thirty-three years and eight years with their semiharmonics fits the yield data nearly as well as it fits the rainfall data.

Cycles in the Index of Crop Fluctuations and in the Corresponding Index of Mean Effective Rainfall

Does the cyclical movement of rainfall give a rhythmic movement to the fluctuations in the yield of the crops taken all together? The preceding section has treated the relation of the yield of the separate crops to the rainfall of their respective critical seasons; we now inquire whether the yield of all of the crops taken together shows a tendency to conform to the cyclical movement of rainfall. In order to answer this question two preliminary steps must be taken: (1) A method 
must be devised for measuring the fluctuation in the yield of the crops when the crops are taken all together; and (2) a method must be devised for combining the rainfall of the critical periods of the growth of the several crops. These two steps we shall now consider.

In regard to the first of these desiderata, it is clear that the measure of the fluctuation of crops taken as a whole should be based upon the best measure of the fluctuation of the yield of the crops taken singly. Moreover, there is a general agreement that the standard deviation of a frequency scheme is a good measure of the scatter of the observations about their mean value. A natural step, therefore, would be to assume that if the observations form a series in time, a good relative measure of their fluctuations at different epochs is afforded by the ratio of the deviations of the observations from their mean divided by the standard deviation. For example, the mean yield of oats in Illinois, for the period 1870 to 1910 , was 31.4 bushels per acre, and the standard deviation of the yield for the same period of time was $\sigma=5.2$ bushels. The yield per acre for the year 1910 was 38.0 bushels. If $\Delta$ be taken to represent the deviation of the yield of any year from the mean yield of the whole period, then the $\Delta$ for 1910 was $38.0-31.4=6.6$, and the fluctuation for 1910 was $\frac{\Delta}{\sigma}=\frac{6.6}{5.2}=1.27$. Similarly, for the year 1908 , when the yield was 23.0 bushels, the fluctuation was, $\frac{\Delta}{\sigma}=-1.62$. It happens that in the case of oats, there is no secular trend to the yield, but when the secular trend exists, 
it must be eliminated before the fluctuation is computed.

In Table III of the Appendix to this chapter the fluctuation for each of the forty-one years 1870-1910 is given for corn, oats, hay, and potatoes. By taking the algebraic sum of the fluctuations for all the erops for any given year and dividing by four - the number of the crops-a measure of the fluctuation of the crops taken all together is obtained. This measure we shall refer to as the index of the fluctuation of crops. The index for each of the years 1870-1910 is recorded in the last columm of Table III.

The index of crop fluctuation computed in the manner that has just been described is regarded as a more accurate measure of the fluctuation of crops than would be obtained from an index formed by taking as the fluctuation for each year, in case of each crop, the ratio of the deviation from the mean divided by the mean. If the crops differ in their eoefficients of variation, that is to say, if the ratio $\frac{\sigma}{M}$, where $M$ is the mean yield and $\sigma$ is the standard deriation, is not the same for all erops, then the crop with the largest coeffieient of variation would receive the largest weight in the general index. The coefficients of variation for the crops in our Table are, for corn, $\frac{5.84}{26.93}=.217$; for oats, $\frac{5.17}{31.44}=$ .164 ; for hay, $\frac{.18}{1.31}=.137$; for potatoes, $\frac{23.25}{70.51}=.330$. If the usual method of forming index numbers were employed in this case to measure crop fluctuations, the 
several crops would, in consequence of their different variabilities, receive disproportionate weights. The method of calculating the index which we have employed obviates this difficulty.

Having now obtained an index of the fluctuation of crops, we next consider the method of combining the rainfall of the critical periods of growth for the several crops. The method will be clear if we bear in mind that the critical period of growth of a crop is the combination of months whose rainfall gives the highest correlation with the yield. The mean effective monthly rainfall for the critical period of a crop is the total rainfall of the critical period of growth divided by the number of months making up the critical period. In case of hay, for example, the critical period of growth is March, April, May, June. The mean effective rainfall for any given year would be the total rainfall for the four months, March, April, May, June, divided by the number of the months. If the mean effective monthly rainfall for the several crops is summed for each year and divided by the number of crops, a measure is obtained of the mean effective monthly rainfall for the crops taken all together. In Table IV of the Appendix to this chapter the mean effective rainfall of the several crops, and of the crops taken all together, is tabulated for each of the years 1870-1910.

We have now an index of the fluctuation of crops and an index of the mean effective rainfall of the critical periods of the crops. The correlation between the two series is $r=.584$. In Figure 14 are traced the graphs 


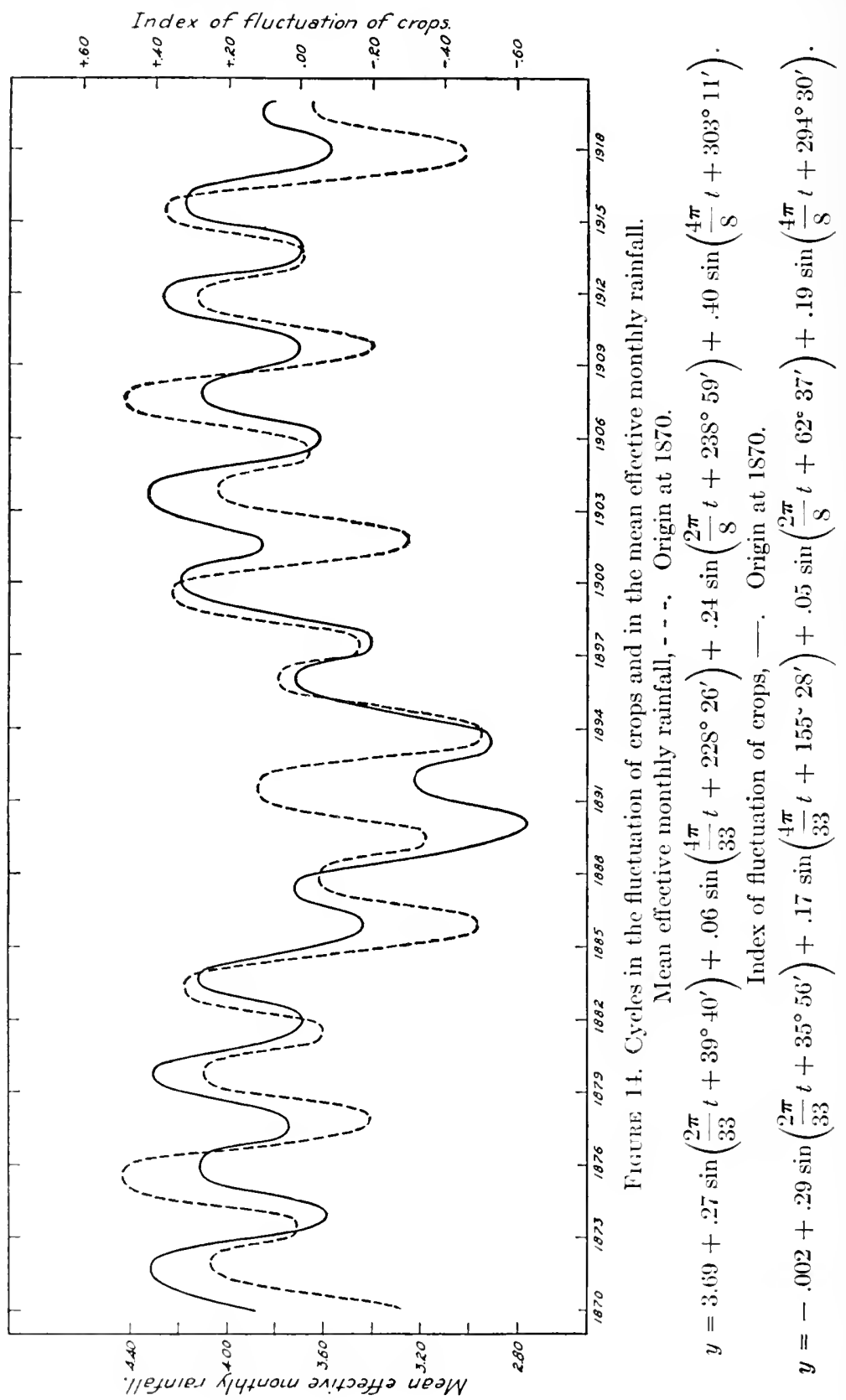


of the compound cycles that describe the two series, each graph consisting of two cycles and their semiharmonics, a thirty-three years cycle describing the ground-swell and the smaller cycle of eight years summarizing the minor cyclical movements. The measure of the degree of fit to the observations is, in case of the yield curve, $K=2.46$, and in case of the rainfall curve, $K=1.68$. The yield curve reproduces the general characteristic features of the rainfall curve.

Our findings with reference to the crops taken together are similar to what we discovered in case of the single crops: The yield per acre and the rainfall of the critical season are highly correlated; the rhythmical movements of the yield and of the effective rainfall may be accurately described by a compound cycle of thirty-three years and eight years with their semiharmonies; and the yield curve reproduces the general characteristics of the curve of effective rainfall.

Passing now to a summary of the contents of this chapter, we may collect our results in a series of propositions.

(1) The yield per acre of the four representative crops, corn, hay, oats, and potatoes is associated with the amount of the rainfall of their respective critical periods of growth. In three out of the four cases the degree of correlation lies between $r=.589$ and $r=.666$.

(2) The rhythmical changes in the yield per acre of the crops and in the rainfall of the respective 
critical seasons may both be accurately described by a compound cycle composed of a thirty-three years cycle with its semiharmonic, which summarizes the ground-swell of the movement, and a superposed cycle of eight years with its semiharmonic, describing the shorter rhythmical movements.

(3) In three of the four representative crops, the compound cycles summarizing the changes in the rainfall of the critical periods of growth and the changes in the yield per acre of the crops are so nearly congruent that, considering the high correlation of the yield with the rainfall, one may conclude, with a high degree of probability, that the rhythmical movement in the weather conditions represented by rainfall is the cause of the cycles of the crops.

(4) The index of the fluctuation of the crops taken together, and the index representative of the mean effective rainfall during the critical seasons are highly correlated, $r=.584$.

(5) The rhythmical changes in the index of the fluctuation of the crops and in the index of the mean effective rainfall are accurately described by a compound cycle which is made up of a thirty-three years cycle and an eight years cycle with their semiharmonics, and these two compound curves are, in their general characteristies, much alike.

(6) The investigation of the crops taken singly and 
taken together leads to the general conclusions:

(a) that there is a rhythmical movement in both the yield of the crops and in the rainfall of the critical periods which is summarized in a compound cycle, in which the constituent elements are a ground-swell of thirty-three years and its semiharmonic, and a shorter superposed cycle of eight years with its semiharmonic;

(b) that the cyclical movement in the weather conditions represented by rainfall is the fundamental, persistent cause of the cycles of the crops. 


\section{APPENDIX}

TABLE I.-The Crops of Illinols

\begin{tabular}{|c|c|c|c|c|c|c|}
\hline \multirow{2}{*}{ YEAR } & \multicolumn{2}{|c|}{$\begin{array}{l}\text { Yield Per Acre of } \\
\text { Corn, in Bushels }\end{array}$} & \multicolumn{2}{|c|}{$\begin{array}{l}\text { Yield Per ACre of } \\
\text { Potatoes, in Bushels }\end{array}$} & \multirow{2}{*}{$\begin{array}{c}\text { YIELD PER } \\
\text { ACCE OF } \\
\text { HAY, IN } \\
\text { ToNs } \\
\text { Ton }=2000 \\
\text { lbs. }\end{array}$} & \multirow{2}{*}{$\begin{array}{l}\text { YiELd PER } \\
\text { ACRE OF } \\
\text { OATS, IN } \\
\text { BUSHELS }\end{array}$} \\
\hline & $\underset{\text { Sctual }}{\text { IELd }}$ & $\begin{array}{l}\text { REDUCED } \\
\text { YIELD }\end{array}$ & $\begin{array}{l}\text { Actual } \\
\text { Yield }\end{array}$ & $\begin{array}{c}\text { REDUCED } \\
\text { YiEID }\end{array}$ & & \\
\hline 1870 & 35.2 & 35.2 & 81 & 81.0 & 1.15 & 26.0 \\
\hline 1871 & 38.3 & 38.1 & 61 & 60.8 & 1.31 & 33.1 \\
\hline 1872 & 39.8 & 39.4 & 75 & 74.5 & 1.35 & 36.6 \\
\hline 1873 & 21.0 & 20.4 & 40 & 39.3 & 1.25 & 30.0 \\
\hline 1874 & 18.0 & 17.2 & 55 & 54.1 & 1.20 & 17.5 \\
\hline 1875 & 34.3 & 33.3 & 128 & 126.8 & 1.37 & 33.0 \\
\hline 1876 & 25.0 & 23.8 & 75 & 73.6 & 1.40 & 20.0 \\
\hline 1877 & 29.0 & 27.6 & 93 & 91.4 & 1.60 & 37.0 \\
\hline 1878 & 27.1 & 25.5 & 67 & 65.1 & 1.49 & 35.9 \\
\hline 1879 & 35.0 & 33.2 & 88 & 85.9 & 1.21 & 32.0 \\
\hline 1880 & 27.2 & 25.2 & 75 & 72.7 & 1.45 & 31.8 \\
\hline 1881 & 19.4 & 17.2 & 48 & 45.4 & 1.30 & 33.4 \\
\hline 1882 & 23.0 & 20.6 & 85 & 81.8 & 1.25 & 40.7 \\
\hline 1883 & 25.0 & 22.4 & 92 & 89.0 & 1.45 & 36.1 \\
\hline 1884 & 30.0 & 27.1 & 79 & 75.7 & 1.40 & 32.8 \\
\hline 1885 & 31.4 & 28.3 & 87 & 83.5 & 1.30 & 32.8 \\
\hline 1886 & 24.5 & 21.2 & 67 & 63.3 & 1.34 & 31.8 \\
\hline 1887 & 19.2 & 15.7 & 33 & 29.0 & .80 & 29.5 \\
\hline 1888 & 35.7 & 32.0 & 80 & 75.8 & 1.40 & 35.8 \\
\hline 1889 & 32.3 & 28.4 & 99 & 94.6 & 1.39 & 37.5 \\
\hline 1890 & 26.2 & 22.1 & 30 & 25.3 & 1.30 & 21.0 \\
\hline 1891 & 33.5 & 29.2 & 92 & 87.1 & 1.25 & 34.0 \\
\hline 1892 & 26.2 & 21.7 & 52 & 46.9 & 1.25 & 26.3 \\
\hline 1893 & 25.7 & 21.0 & 53 & 47.6 & 1.21 & 27.2 \\
\hline 1894 & 28.8 & 23.9 & 50 & 44.4 & 1.14 & 36.1 \\
\hline 1895 & 37.4 & 32.3 & 77 & 71.2 & .66 & 24.4 \\
\hline 1896 & 40.5 & 35.2 & 97 & 90.9 & 1.38 & $2 S .0$ \\
\hline 1897 & 32.5 & 27.0 & 38 & 31.7 & 1.29 & 32.0 \\
\hline 1898 & 30.0 & 24.3 & 70 & 63.5 & 1.56 & 29.0 \\
\hline 1899 & 36.0 & 30.1 & 96 & 89.2 & 1.29 & 38.0 \\
\hline 1900 & 37.0 & 30.9 & 90 & 83.0 & 1.27 & 38.0 \\
\hline 1901 & 21.4 & 15.1 & 35 & 27.8 & 1.08 & $2 S .2$ \\
\hline 1902 & 38.7 & 32.2 & 118 & 110.5 & 1.50 & 37.7 \\
\hline 1903 & 32.2 & 25.5 & 72 & 64.3 & 1.54 & 26.6 \\
\hline 1904 & 36.5 & 29.6 & $10 \mathrm{~S}$ & 100.1 & 1.36 & 32.0 \\
\hline 1905 & 39.8 & 32.7 & 75 & 66.8 & 1.35 & 35.5 \\
\hline 1906 & 36.1 & $2 S .8$ & 97 & 88.6 & .98 & 29.5 \\
\hline 1907 & 36.0 & 28.4 & 87 & 78.4 & 1.40 & 24.5 \\
\hline 1908 & 31.6 & 23.8 & 71 & 62.2 & 1.53 & 23.0 \\
\hline 1909 & 35.9 & 27.9 & 91 & 81.9 & 1.45 & 36.6 \\
\hline 1910 & 39.1 & 30.9 & 75 & 65.7 & 1.33 & 38.0 \\
\hline
\end{tabular}


TABLE II.-Mean Monthly Rainfall in Illinois

\begin{tabular}{|c|c|c|c|c|c|c|c|}
\hline \multirow{2}{*}{ YEAR } & \multicolumn{7}{|c|}{ Mean Monthly Rainfall } \\
\hline & MARrH & APriL & MAY & JUNE & $J_{U L Y}$ & August & $\begin{array}{c}\text { SEPTEM- } \\
\text { BER }\end{array}$ \\
\hline 1870 & 3.92 & 1.43 & 1.64 & 1.93 & 2.85 & 3.95 & 3.69 \\
\hline 1871 & 3.31 & 2.47 & 3.06 & 4.00 & 3.11 & 3.50 & 1.22 \\
\hline 1872 & 2.59 & 3.39 & 3.60 & 5.68 & 5.00 & 3.65 & 4.29 \\
\hline 1873 & 1.75 & 4.98 & 4.87 & 2.18 & 3.99 & 1.77 & 3.19 \\
\hline 1874 & 2.39 & 3.50 & 2.25 & 3.45 & 2.06 & 4.28 & 3.95 \\
\hline 1875 & 2.83 & 2.60 & 4.57 & 5.36 & 9.37 & 1.96 & 4.60 \\
\hline 1876 & 5.13 & 3.38 & 4.68 & 5.53 & 4.91 & 3.83 & 4.33 \\
\hline 1877 & 4.02 & 3.53 & 3.13 & 7.39 & 3.27 & 2.78 & 2.29 \\
\hline 1878 & 3.04 & 4.66 & 5.04 & 2.72 & 3.83 & 4.10 & 1.61 \\
\hline 1879 & 2.59 & 2.42 & 2.10 & 4.33 & 3.44 & 4.89 & 1.48 \\
\hline 1880 & 3.31 & 4.29 & 5.93 & 3.53 & 3.10 & 3.65 & 3.59 \\
\hline 1881 & 3.16 & 2.18 & 2.26 & 5.93 & $2.5 \mathrm{~s}$ & 0.84 & 4.04 \\
\hline 1882 & 4.00 & 4.00 & 6.60 & 6.61 & 3.46 & 4.65 & 2.08 \\
\hline 1883 & 1.81 & 4.16 & 5.38 & 5.51 & 4.86 & 1.86 & 0.88 \\
\hline 1884 & 3.31 & 3.36 & 4.40 & 5.13 & 4.09 & 2.40 & 4.80 \\
\hline 1885 & 0.53 & 4.13 & 3.03 & 5.63 & 2.80 & 5.06 & 5.67 \\
\hline 1886 & 3.02 & 3.60 & 4.07 & 4.12 & 1.15 & 3.86 & 4.81 \\
\hline 1887 & 2.37 & 2.46 & 2.90 & 1.94 & 2.40 & 2.46 & 3.25 \\
\hline 1888 & 4.09 & 1.94 & 5.18 & 4.80 & 3.83 & 4.31 & 1.46 \\
\hline 1889 & 1.62 & 2.00 & 5.11 & 5.35 & 4.45 & 1.22 & 3.78 \\
\hline 1890 & 4.34 & 3.75 & 3.86 & 4.58 & 2.03 & 2.96 & 3.04 \\
\hline 1891 & 3.43 & 2.91 & 2.19 & 4.11 & $1.8 S$ & 4.71 & 1.02 \\
\hline 1892 & 2.17 & 6.43 & 8.06 & 5.77 & 3.71 & 3.03 & 2.01 \\
\hline 1893 & 3.31 & 7.64 & 4.24 & 3.51 & 2.20 & 0.96 & 3.09 \\
\hline 1894 & 2.98 & 2.73 & 3.29 & 2.31 & $1.5 \mathrm{~S}$ & 1.74 & 4.53 \\
\hline 1895 & 1.72 & 2.17 & 2.34 & 2.68 & 6.01 & 2.76 & 3.00 \\
\hline 1896 & 1.90 & $2 . \$ 4$ & 6.09 & 4.14 & 6.17 & 2.95 & 5.79 \\
\hline 1897 & 6.22 & 4.53 & 1.94 & $4.2 S$ & 3.59 & 1.19 & 0.99 \\
\hline 1898 & 7.70 & 3.47 & 6.26 & 4.71 & 2.84 & 4.70 & 5.07 \\
\hline 1899 & 3.19 & 1.64 & $6 .+1$ & 3.00 & 3.42 & 2.70 & 2.23 \\
\hline 1900 & 2.12 & 1.64 & 4.51 & 4.31 & 4.15 & 3.72 & 3.59 \\
\hline 1901 & 3.80 & 1.84 & 1.86 & 3.55 & $2 .(6 i)$ & 1.91 & 1.97 \\
\hline 1902 & 3.64 & 2.55 & 3.75 & 7.77 & 4.78 & 4.67 & 4.24 \\
\hline 1903 & 3.23 & 4.51 & 3.25 & 3.933 & 3.41 & 4.58 & 3.85 \\
\hline 1904 & 6.41 & 3.76 & 3.29 & $3.2 \mathrm{~S}$ & 5.23 & 4.25 & 5.43 \\
\hline 190.5 & 2.32 & 3.88 & 4.27 & 3.69 & 4.7s & 3.41 & 2.89 \\
\hline 1900 & 4.09 & 2.09 & 2.39 & 3.08 & $2.5 \%$ & 4.15 & 5.15 \\
\hline 1907 & 3.26 & 2.89 & 3.95 & 4.17 & 5.39 & 5.56 & 2.38 \\
\hline 1908 & 3.21 & 4.59 & 8.07 & 3.14 & 3.32 & 2.39 & 1.41 \\
\hline 1909 & 2.62 & 5.94 & 4.23 & 4.04 & $4.96 ;$ & 2.12 & 4.25 \\
\hline 1910 & 0.32 & $\because 66$ & 5.04 & 2.62 & 472 & 2.51 & 4.61 \\
\hline
\end{tabular}


TABle III.-Index of Fluctuation of Crops. $\Delta=$ Deviation from the Mean after the Secular Trend has been Elminated. $\sigma=$ Standard Deviation

\begin{tabular}{|c|c|c|c|c|c|c|c|c|}
\hline YeAr & $\begin{array}{c}\text { CoRN } \\
\frac{\Delta}{\sigma}\end{array}$ & $\frac{\stackrel{\Delta}{O^{\prime}}}{\sigma}$ & $\begin{array}{l}\mathrm{HAY}^{\Delta} \\
\frac{\Delta}{\sigma}\end{array}$ & $\begin{array}{l}\text { POTA- } \\
\text { TOES } \\
\frac{\Delta}{\sigma}\end{array}$ & $\begin{array}{l}\text { SUM OF } \\
\text { POSITIVE } \\
\text { F LuCTUA- } \\
\text { TIONS }\end{array}$ & $\begin{array}{c}\text { SUM OF } \\
\text { NEQATIV } \\
\text { FLUCTUA- } \\
\text { TIONS }\end{array}$ & $D_{1}$ & $\begin{array}{c}\text { INDEX } \\
\text { OF } \\
\text { FLUCT- } \\
\text { UATION } \\
\text { OF } \\
\text { CROPB }\end{array}$ \\
\hline 1870 & 1.43 & -1.04 & -.72 & .45 & $1 . S S$ & 1.76 & +.12 & +.03 \\
\hline 1 & 1.93 & .33 & .00 & -.42 & 2.26 & .42 & +1.81 & +.46 \\
\hline 1872 & 2.16 & 1.00 & .22 & .17 & 3.55 & .00 & +3.5 .5 & +.89 \\
\hline 1873 & -1.12 & -.27 & -.33 & -1.34 & .00 & 3.06 & -3.06 & -.76 \\
\hline 1874 & -1.67 & -2.67 & -.61 & -.70 & .00 & 5.65 & -5.65 & -1.41 \\
\hline 1875 & 1.10 & .31 & .33 & 2.42 & 4.16 & .00 & +4.16 & +1.04 \\
\hline 76 & -.67 & -2.19 & .50 & .13 & .63 & 2.86 & -2.23 & -.56 \\
\hline 57 & .12 & 1.08 & 1.61 & .90 & 3.71 & .00 & 71 & +.93 \\
\hline 1 & -.24 & .87 & 1.00 & .23 & 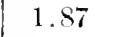 & .46 & & +.35 \\
\hline 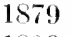 & 1.09 & .12 & -.56 & .66 & 1. &. & -1.31 & +.33 \\
\hline 1 & -.29 & .08 & .78 & .09 & .9 & 2 & +.66 & +.16 \\
\hline 1 & -1.69 & .38 & -.06 & -1.08 & .38 & 2.83 & -2.45 & -.61 \\
\hline 1 & -1.09 & 1.79 & -.33 & .48 & 2.27 & 22 & +.85 & +.21 \\
\hline 1 & -.78 & .90 & .78 & .79 & $?$ & .7 & +1.69 & +.42 \\
\hline & .03 & .27 & .50 & .22 & 1.1 & .0 & & +.25 \\
\hline 1 & .24 & .27 & -.06 & .56 & 1.0 & .06 & +1 & +.25 \\
\hline 1 & $-.9 \mathrm{~s}$ & $.0 \mathrm{~s}$ & .17 & - .31 & .2 & 1.29 & -1.04 & -.26 \\
\hline 1887 & -1.93 & -.37 & -2.83 & -1.78 & .00 & 1 & -6.91 & -1.73 \\
\hline 18 & .88 & .85 & .50 & .23 & . & & 46 & +.61 \\
\hline 1 & .26 & 1.17 & .44 & 1.03 & . & & + & +.72 \\
\hline 18 & -1.00 & -2.00 & -.06 & -1.94 & .0 & 0.0 & - & -1.25 \\
\hline 189 & .40 & .50 & -.33 & .71 & .6 & .3 & +1.28 & +.32 \\
\hline 1892 & -.90 & $-.9 S$ & -.33 & -1.01 & .0 & .2 & -3.22 & -.80 \\
\hline 03 & -1.02 & -.81 & -.56 & -.98 & .0 & 3.37 & 一 & - . .S4 \\
\hline 1 is & -.52 & .90 & $-\quad .94$ & -1.12 & .9 & 2 . & - & -.42 \\
\hline 1 & .93 & -1.35 & -3.61 & .03 & .9 & 4. & -4.00 & -1.00 \\
\hline 1 & 1.43 & -.65 & .39 & .88 & 2.70 & .6 & +2.05 & +.51 \\
\hline & .02 & .12 & -.11 & -1.67 & 11 & 1.78 & -1.64 & -.41 \\
\hline & -.45 & -.46 & 1.39 & -.30 & .39 & .21 & +.18 & +.0 .5 \\
\hline & .55 & 1.27 & --.11 & .80 & 2 & .11 & .51 & +.63 \\
\hline $1 !$ & .69 & 1.27 & -.22 & .54 & 2.50 & .22 & +2.28 & +.57 \\
\hline 1 & -2.03 & -.12 & $-1.2 \mathrm{~s}$ & -1.83 & .00 & 5.76 & -5.76 & -1.44 \\
\hline 19 & .91 & 1.21 & 1.06 & 1.72 & 4.90 & .00 & +4.90 & +1.22 \\
\hline 1 & -.21 & $-\quad .92$ & 1.28 & -.27 & 1.29 & 1.43 & -.15 & -.04 \\
\hline & .47 & .12 & .21 & 1.27 & 2.1 & .00 & +2.14 & +.54 \\
\hline & 1.00 & .79 & .22 & -.16 & 2.0 & $1 t$ & +1.85 & +.46 \\
\hline & .31 & -.87 & -1.83 & .78 & 1.09 & 2.20 & -1.11 & $-.2 s$ \\
\hline & .26 & -1.33 & .50 & .34 & 1.1 & 1.33 & -.23 & -.00 \\
\hline & -.53 & $-1 .(i 2$ & 1.22 & -.36 & 1. & 2.51 & $-1.29)$ & -.32 \\
\hline & .17 & 1.07 & $.7 s$ & .49 & 2 & .0 & & +.61 \\
\hline 1910 & .69 & 1.27 & .11 & .21 & 2.07 & .21 & .86 & +.46 \\
\hline
\end{tabular}


TABLE IV.-Medn Effective Monthly Ranfall ix Ildinols

\begin{tabular}{|c|c|c|c|c|c|c|}
\hline \multirow[b]{2}{*}{ YeAR } & \multicolumn{5}{|c|}{ MeaY Effertive MoNthly Rasifall } & \multirow{2}{*}{$\begin{array}{l}\text { MIEAN } \\
\text { EFFECTIE } \\
\text { MONTHLY } \\
\text { RAINFALL } \\
\text { FOR CROPS }\end{array}$} \\
\hline & $\begin{array}{l}\text { For } \\
\text { CORN }\end{array}$ & $\begin{array}{l}\text { For } \\
U_{A T S}\end{array}$ & $\begin{array}{l}\text { For } \\
\text { HAY }\end{array}$ & $\underset{\text { For }}{\text { POTATOLS }}$ & $\mid \begin{array}{c}\text { SCM of } \\
\text { PRECEDING } \\
\text { COLUMNS }\end{array}$ & \\
\hline $1 \leqslant 70$ & 3.40 & 2.11 & 2.23 & 3.40 & 11.17 & 2.79 \\
\hline $1>\ln$ & 3.30 & 3.39 & 3.21 & 3.30 & 13.20 & 3.30 \\
\hline 1472 & 1.33 & +.76 & 3.81 & $4.3: 3$ & 17.23 & 4.31 \\
\hline $1 \times 7: 3$ & $2 x$ & $3.6 s$ & 3.45 & $2 \mathrm{sin}$ & $12 \div 9$ & 3.22 \\
\hline $1 \backslash 7+$ & 317 & 2.59 & 290 & 3.17 & 11.83 & 2.96 \\
\hline 1 1 & $j .(i f$ & 6.13 & 3.84 & 5. 6 iti & 21.59 & 5.40 \\
\hline $1 \backsim i t$ & +37 & 5.04 & 4.65 & 4.37 & 15.46 & 4.61 \\
\hline $1 \gg 7$ & 3.02 & 4.60 & 4.52 & 3.02 & 1.5 .16 & 3.79 \\
\hline $1 ১ オ 心$ & 3.96 & 3.86 & 3.86 & $3.96 \mathrm{i}$ & 15.154 & 3.91 \\
\hline 1ลร! & +16 & 3.29 & $2 \times 6$ & $4.16 ;$ & 14.47 & $3 .(i 2$ \\
\hline $1 \triangleleft 0$ & 3.37 & t. 19 & t. 26 & 3.37 & 15.9 & 3.50 \\
\hline $1 S>1$ & 1.71 & $3.5 s$ & 3.35 & 171 & $10.3 i$ & $2.5 !)$ \\
\hline 1852 & 40.5 & $5 . i t i$ & 5.30 & $+(1.5$ & 15.6 & 4.74 \\
\hline 1883 & $3.33 i$ & 5.25 & 4.21 & 3.36 & 16.17 & 4.04 \\
\hline 1541 & 3.2 .5 & 4.54 & 4.05 & 3.25 & 15.09 & 3.77 \\
\hline 145 & 3.93 & 3.42 & 3.33 & 3.983 & 15.01 & 3.75 \\
\hline $1>8 ;$ & 2.51 & 3.21 & 3.5 & 2.51 & 12.01 & 3.09 \\
\hline 1SiT & 2.43 & 2.11 & 242 & 2.43 & 9.169 & $2+2$ \\
\hline 1565 & 4.07 & +60 & 1.00 & 4.07 & 16.74 & 4.18 \\
\hline 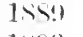 & 2.44 & 4.97 & 3.52 & 2.84 & 14.17 & 3.i.t \\
\hline $1 S 90$ & 2.50 & 3.49 & 4.13 & 2.50 & 12.62 & 3.15 \\
\hline $1 S ! 11$ & $3.2 !$ & 2.73 & 3.16 & 3.29 & 12.47 & 3.12 \\
\hline $1,9 ?$ & 3.37 & $i . \lambda$ & 5.61 & 3.37 & 15.20 & 4.55 \\
\hline $1 \wedge 93$ & 1.54 & 3.32 & 1.67 & 1.5. & 11.15 & 2.79 \\
\hline $1 \backslash 9 !$ & 1.66 & 2.39 & 2.83 & 1.60 & 5.54 & 2.14 \\
\hline $1,9,5$ & 4.35 & 3.tiv & 2.23 & 4.35 & 14.67 & 3.67 \\
\hline $1 \checkmark)(i$ & 4.56 & 5.47 & 3.74 & $4.51 ;$ & 14.33 & 4. \\
\hline $1 \wedge ! 7$ & 2.39 & 3.27 & 4.21 & 2.39) & 12.29 & 3.07 \\
\hline 1メরু & 3.77 & 4.60 & 5.53 & 3.7 & 17.67 & 4.42 \\
\hline $1 \backslash(t)\}$ & $3.0 \%$ & 1.21 & $3.5 t i$ & 3.06 & 13.96 & 3.49 \\
\hline 1900 & 393 & 4.32 & 3.15 & 3.93 & 15.33 & 3.33 \\
\hline 1901 & 2.27 & 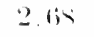 & 2.76 & 2.27 & $9.9 \mathrm{~s}$ & 2.50 \\
\hline 1.112 & 4.72 & $5+1$ & 1.13 & 4.72 & 19.31 & 4.28 \\
\hline $19(1)$ & $1(0)$ & $32: 3$ & 3.50 & 1.00 & 14.73 & 3 lis \\
\hline $1 ! 301$ & 1.71 & 3.93 & 4. is & 1.7 .1 & $17.5 !$ & 110 \\
\hline $190 . \overline{-}$ & $4 .(6)$ & 1.25 & 3.54 & 100 & 1.5 .97 & 3.949 \\
\hline $13(1) i$ & 3.36 & 2.63 & 291 & 3.36 & 12.31 & 3.05 \\
\hline 19017 & $5 .+7$ & 4.50 & 3.57 & 5.17 & 19.01 & 1.75 \\
\hline 19018 & 2.5 & I.S1 & 1.75 & 2. & $15.2 !)$ & $3 \times 2$ \\
\hline 19199 & 3.54 & 4.11 & $4: 2$ & 3 is & 15.71 & 3.93 \\
\hline 1910 & 3.11 & 4.13 & 2.91 & 3.61 & $11.26 ;$ & 3.36 \\
\hline
\end{tabular}




\section{CHAP'TER IV}

\section{THE LAW OF DEMAND}

Kann man nicht die Nachfragefunktion genauer feststellen, so genau, dass wir nieht bloss ein eindeutiges, sondern ein konkretes Resultat gewinnen? Ich glaube die Antwort zu hören: Welch' ein phantastisches Unterfangen-Unberechenbarkeit der wirtschaftlichen Vorgänge-steter Wechsel-u. s. w!

JoSEPH SCHUMPETER.

Questions affecting for the most part the supply of commodities have thus far been the object of our inrestigation, but the inquiry as to the cause and law of economic cycles must extend to a consideration of cycles of values and prices. Since the rhythmical variation in the supply of crops produces its effect upon crop prices in accordance with the laws of demand for the several crops, the obvious first and necessary step in bringing the results of the preceding chapters to bear upon the question of the cause and law of economic cycles is to solve the problem of the relation between the variations in the supply of the several crops and the resulting variations in their respective prices. It is required to derive from existing data the concrete laws of demand for the representative crops.

\section{The Theory of Demand}

The mathematical treatment of the theory of demand furnishes two doctrines that are of importance in our 
subsequent work: The doctrine of the uniformity of the demand function and the doctrine of the elasticity of demand. The exposition of these two doctrines will be facilitated by reference to Figure 15, in which, according to the usual practice, quantities of commodity are measured upon the axis of abscissas, and the corresponding prices per unit, upon the axis of ordinates.

The doctrine of the uniformity of the demand function, which is traceable to Cournot, ${ }^{1}$ but is especially stressed by

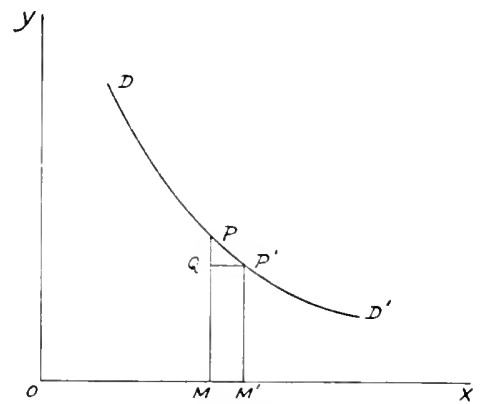

Figure 15. The law of demand.

Professor Marshall, has been put in these words: "There is then one general law of demand viz., that the greater the amount to be sold, the smaller will be the price at which it will find purchasers; or, in other words, that the amount demanded increases with a fall in price and diminishes with a rise in price." Re-

${ }^{1}$ Cournot: Recherches sur les prineipes mathématiques de la théorie des richesses, $\$ \$ 21,22$. Assuming that the relation between price and the amount demanded is represented by $F(p)$, he says, p. 54: "Si la fonction $F(p)$ est continue, elle jouira de la propriété conmune à toutes les fonctions de cette nature, et sur laquelle reposent tant d'applications importantes de l'analyse mathématique: les variations de la demande seront sensiblement proportionelles aux variations du prix, tant que celles-ci seront de petites fractions du prix originaire. D'ailleurs, ces variations seront de signes contraires, e'est-à-dire qu'à une augmentation de prix correspondra une diminution de la demande." 
ferring to Figure 15, this statement means that if at any point in the demand curve $D D^{\prime}$, say the point $P$, a straight line is drawn tangent to the curve, then the trigonometric tangent of the angle which the line makes with the positive direction of the axis of $x$, is negative. In Professor Marshall's words: "The one universal rule to which the demand curve conforms is that it is inclined negatively throughout the whole of its length." 1

As we proceed we shall find that the law of demand for some commodities cloes incleed conform to the type of curve which has just been described, but it will be a part of the work of the next chapter to show that the doctrine of the uniformity of the demand function is an idol of the static state of the method of catcris paribus-which has stood in the way of the successful treatment of concrete dynamic problems.

Assuming that the law of demand for a given commodity is represented by the descending curve $D D^{\prime}$ in Figure 15, the elasticity of demand for the commodity when $O M$ units are bought is measured by the ratio. $\frac{M I^{\prime}}{O . M} \div \frac{Q P}{P M}$. 'That is to say, in general terms, if the price of the commodity undergoes a small change, the amount of the commodity that is demanded likewise undergoes a small change, and the degree of the elasticity of demand for the commodity, in the given state of the market, is measured by the ratio of the relative change in

${ }^{1}$ Marshall: Principles of Economics, th edit., pp. 174, 174 note 2. In the subsequent reasoning we shall call tlis type of demand curve the negative type. 
the amount demanded to the small relative change in the price. Or, more definitely, if "a fall of 1 per cent. in price would cause an increase of 2 per cent. in the amount demanded, the elasticity of demand would be two;" if "a fall of 1 per cent. in price would cause an increase of $1 / 3$ per cent. in the amount demanded, the elasticity of demand would be one-third; and so on." 1

It will be observed that the theory of elasticity of demand in this classical form is presented from the point of view of infinitesimal changes in the two variables -, price and commodity demanded. It gives the degree of elasticity of demand for a point in time, for a given state of the market assuming all other things to remain the same; and for this reason it may be said to treat of elasticity of demand from a statical point of view. But this is not its most serious limitation. It postulates a knowledge of the demand curve, and while it gives an exposition of the method by which the degree of elasticity of demand might be determined provided the demand curve were known, there have been grave doubts as to whether the practical difficulty of deriving the demand curve would ever be overcome.

The problem before us is to derive the demand curve from statistics; to measure the degree in which it is an accurate description of the changes of actual industry; and to give the numerical coefficients of elasticity of demand for typical commodities.

${ }^{1}$ Marshall: Principles of Economics, 4th edit., pp. 177-178, note. 


\section{Statistical Laws of Demand}

Two fundamental defects in the current theoretical method of treating economic questions are exemplified in the case of the theory of demand: first, the assumption is made that all other things being equal (the old cateris paribus), an increase in the supply of the commodity will lead to a corresponding fall in the price; secondly, it is assumed that the concrete problem of the relation of price and supply of commodity will be simplified by attacking first the constituent elements of the question rather than by attacking directly the problem in its full concreteness. Neither assumption is satisfactory nor indeed admissible. The "other things" that are supposed to remain equal are seldom mentioned and are never completely enumerated; and consequently the assumption that, other unmentioned and unenumerated factors remaining constant, the law of demand will be of a certain type, is really tantamount to saying that under conditions which are unanalyzed and unknown, the law of demand will take the supposed definite form. The burden of proof is upon anyone using this method to show that the assumption does not at least involve a physical impossibility.

The second of the above two assumptions is not more satisfactory than the first. It reproduces the defects of the first assumption with others superadded. The movement of prices results from changes in many factors: According to the statical method, the method of cateris paribus, the proper course to follow in the 
explanation of the phenomenon is to investigate in turn, theoretically, the effect upon price of each factor, coteris paribus, and then finally to make a synthesis! But if in case of the relation of each factor to price the assumption cateris paribus involves large and at least questionable hypotheses, does one not completely lose himself in a maze of implicit hypotheses when he speaks of a final synthesis of the several effects? We shall not adopt this bewildering method, but shall follow the opposite course and attack the problem of the relation of prices and supply in its full concreteness.

The fruitfulness of the statistical theory of correlation stands in significant contrast to the vast barrenness of the method that has just been described, and the two methods follow opposed courses in dealing with a problem of multiple effects. Take, for example, the question of the effects of weather upon crops. What a useless bit of speculation it would be to try to solve, in a hypothetical way, the question as to the effect of rainfall upon the crops, other unenumerated elements of weather remaining constant? The question as to the effect of temperature, cateris paribus? How, finally, would a synthesis be made of the several individual effects? The statistical method of multiple correlation formulates no such vain questions. It inquires, directly, what is the relation between crop and rainfall, not cxteris paribus, but other things changing according to their natural order; what is the relation between erop and temperature, other things conforming to the observed changes in temperature; and, finally, what is 
the relation between crop and rainfall for constant values of temperature? The problem of the effects of the constituent factors is solved only after the more general problem has received its solution. This method offers promise of an answer to the question as to the relation between the effective demand price and the supply of the commodity.

The chief difficulties in the computation of statistical laws of demand are due to changes that occur in the market during the period to which the statistics of prices and of quantities of commodities refer. In order that the statistical laws of demand shall have sufficient validity to serve as prediction formula, the observations must be numerous; and in order to obtain the requisite number of observations, a considerable period must be covered. This usually means that, during the interval surveyed in the statistical series, important changes occur in the condition of the market. But in case of staple commodities, such as the agricultural products with which we shall have to deal, the effects of those changes in the condition of the market that obscure the relation between prices and amounts of commodity may be largely eliminated. As far as the law of demand is concerned, the principal dynamic effects that need to be considered are changes in the volume of the commodity that arise from the increasing population, and changes in the level of prices which are the combined result of causes specifically responsible for price cycles and of causes that produce a secular trend in prices. 
The effects of these two fundamental changes may be eliminated approximately by a single statistical device, namely, by deducing the law of demand from a generalized treatment of the elasticity of demand.

The degree of elasticity of demand, according to the classic formula, is measured by the ratio of the relative change in the amount of the commodity that is bought to the relative change in the price per unit of the commodity. Suppose, now, that instead of restricting this conception to infinitesimal changes in price and in amount of commodity, we extend it to the finite changes that actually occur in the market. Then, the relative change in the amount of commodity that is bought may be correlated with the relative change in the corresponding price, and the resulting appropriate regression equation will give the statistical law of demand for the commodity. By taking the relative change in the amount of the commodity that is demanded, instead of the absolute quantities, the effects of increasing population are approximately eliminated; and by taking the relative change in the corresponding prices instead of the corresponding absolute prices, the errors due to a fluctuating general price level are partially removed. If the observations should cover the period of a major cycle of prices, and the commodity under investigation should be a staple commodity such as the representative agricultural products with which we shall have to deal, the above method of deriving the demand curve will give an extremely accurate formula summarizing the relation between variations in price 
and rariations in the amount of the commodity that is demanded.

The method may be illustrated by deriving the law of demand for corn. In Table I of the Appendix to this chapter are recorded, for the period of 1866-1911, in the United States, the quantities of corn annually produced, the corresponding prices per bushel, the relative changes in the quantity produced and the relative changes in the price per bushel. If the correlation of the relative change in the amount of corn that is produced and the relative change in the corresponding price per bushel of corn is assumed to be linear, the coefficient of correlation is $r=-.789$, and the equation of regression is $y=-.8896 x+7.79$, the origin being at $(o, o)$. (See Figure 16.)

In Tables ${ }^{1}$ II, III, IV, of the Appendix to this chapter, similar data are given for hay, oats, and potatoes. The coefficients of correlation are, for hay, $r=-.715$; for oats, $r=-.722$; and for potatoes, $r=-.856$. The regression equations are,

$$
\begin{aligned}
\text { for hay, } y & =-.7643 x+3.61 ; \\
\text { for oats, } y & =-1.0455 x+6.93 ; \\
\text { for potatoes, } y & =-1.2194 x+15.75
\end{aligned}
$$

the origin in all cases being at $(o, o)$.

The high coefficients of correlation that have just been given were obtained on the assumption that the correlation between relative change in amount de-

1 The data of the Tables I, II, III, IV were taken from the Yearbook of the Department of Agriculture of the United States, for 1911. 
The Law of Demand

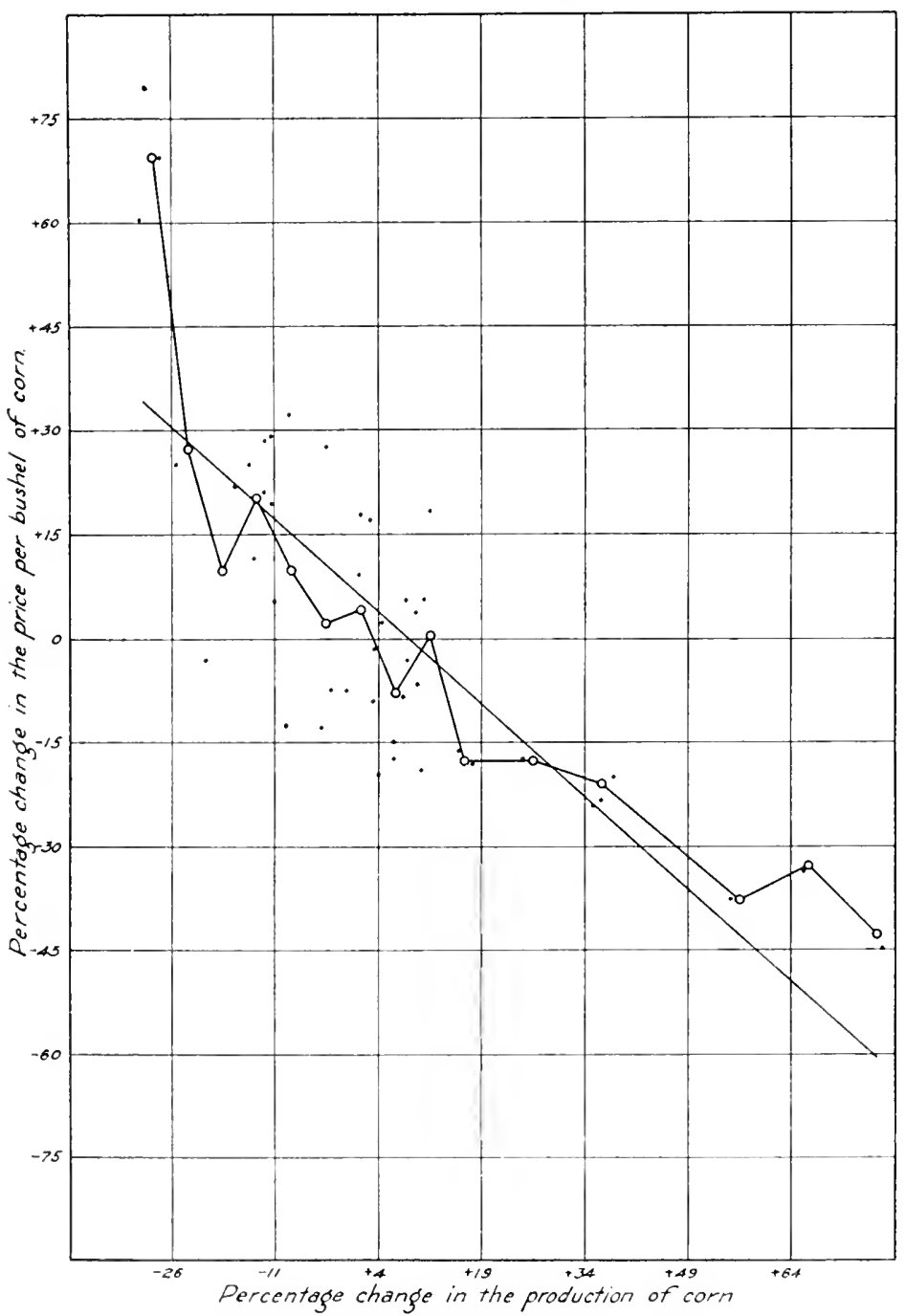

Figure 16. The law of demand for corn. $y=-.8896 x+7.79$, origin at $(O, O)$. 
manded and relative change in price is linear. We shall see later on that the two variables are even more intimately associated than would be suggested by the high coefficients of correlation. Just now we wish to know the form of the law of demand when the restriction involved in the assumption of linearity of regression is removed. What will be the statistical laws of demand for the representative commodities corn, hay, oats, and potatoes, if the regression of relative change in price upon relative change in quantity of commodity is assumed to be skew and of the type $y=a+b x+c x^{2}+d x^{3}$ ? The question is answered by fitting, according to the Method of Least Squares, the equation $y=a+b x+c x^{2}+$ $d x^{3}$ to the data of Tables I, II, III, IV of the Appendix to this chapter. The results of the computations are exhibited in Figures 17, 18, 19, 20 of the text.

The statistical laws of demand for the commodities corn, liay, oats, and potatoes present the fundamental characteristic which, in the classical treatment of demand, has been assumed to belong to all demand curves, namely, they are all negatively inclined; that is to say, speaking from the point of view of average results, "the greater the amount to be sold, the smaller will be the price at which it will find purchasers, or, in other words, . . . the amount demanded increases with a fall in price and diminishes witlı a rise in price." 1

1 Marshall: Principles of Economics, 4th edit., p. 174. In case of the law of demand for hay, there is a slight upward turn at the extremity of the curve. This is due to one extreme observation, and the variation is not a significant exception to the above general rule. 
The Law of Demand

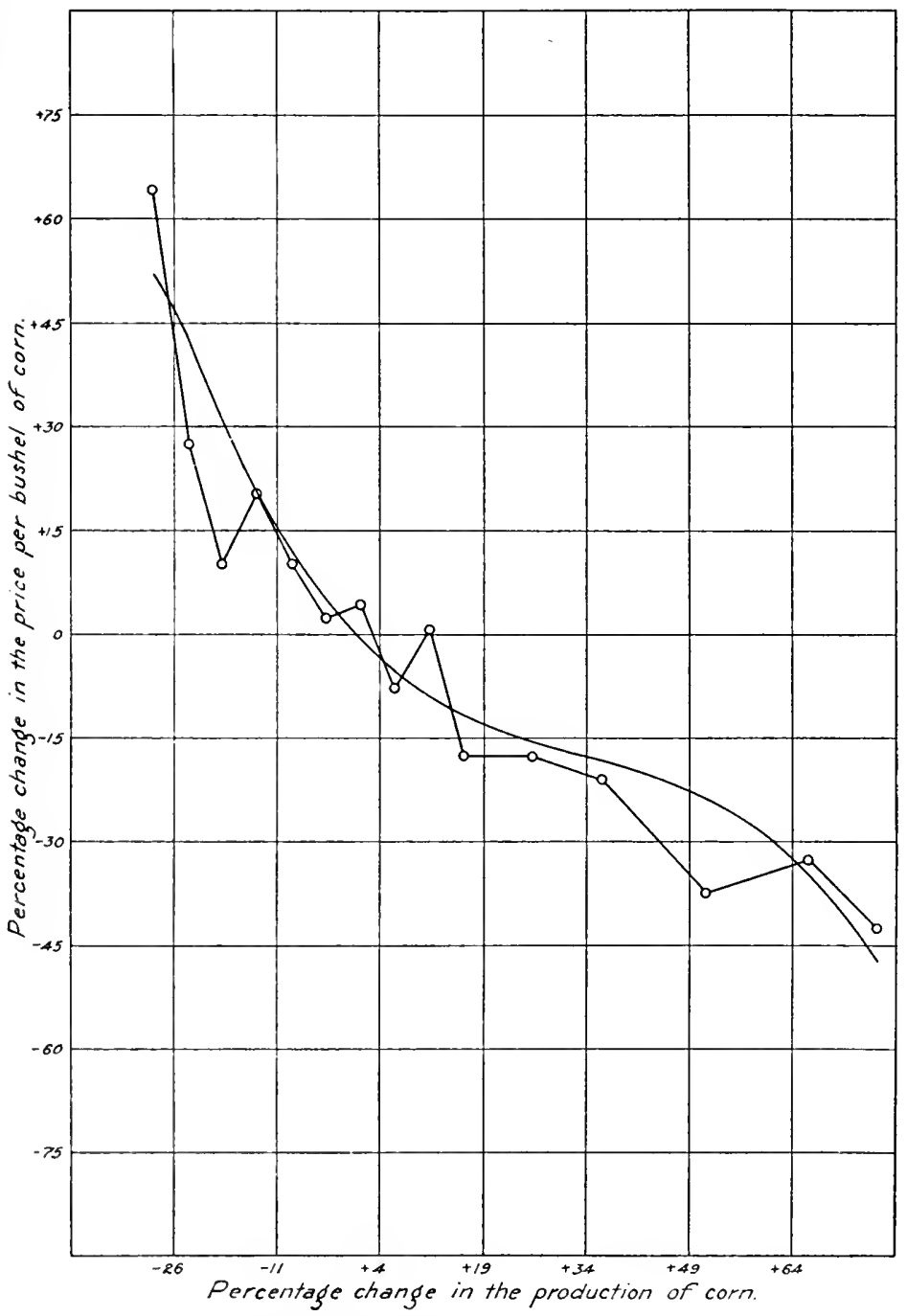

Figcre 17. The law of demand for corn.

$y=.94-1.0899 x+.02391 x^{2}-.000234 x^{3}$, origin at $(0, O)$. 
Economic Cycles: Their Law and Cause

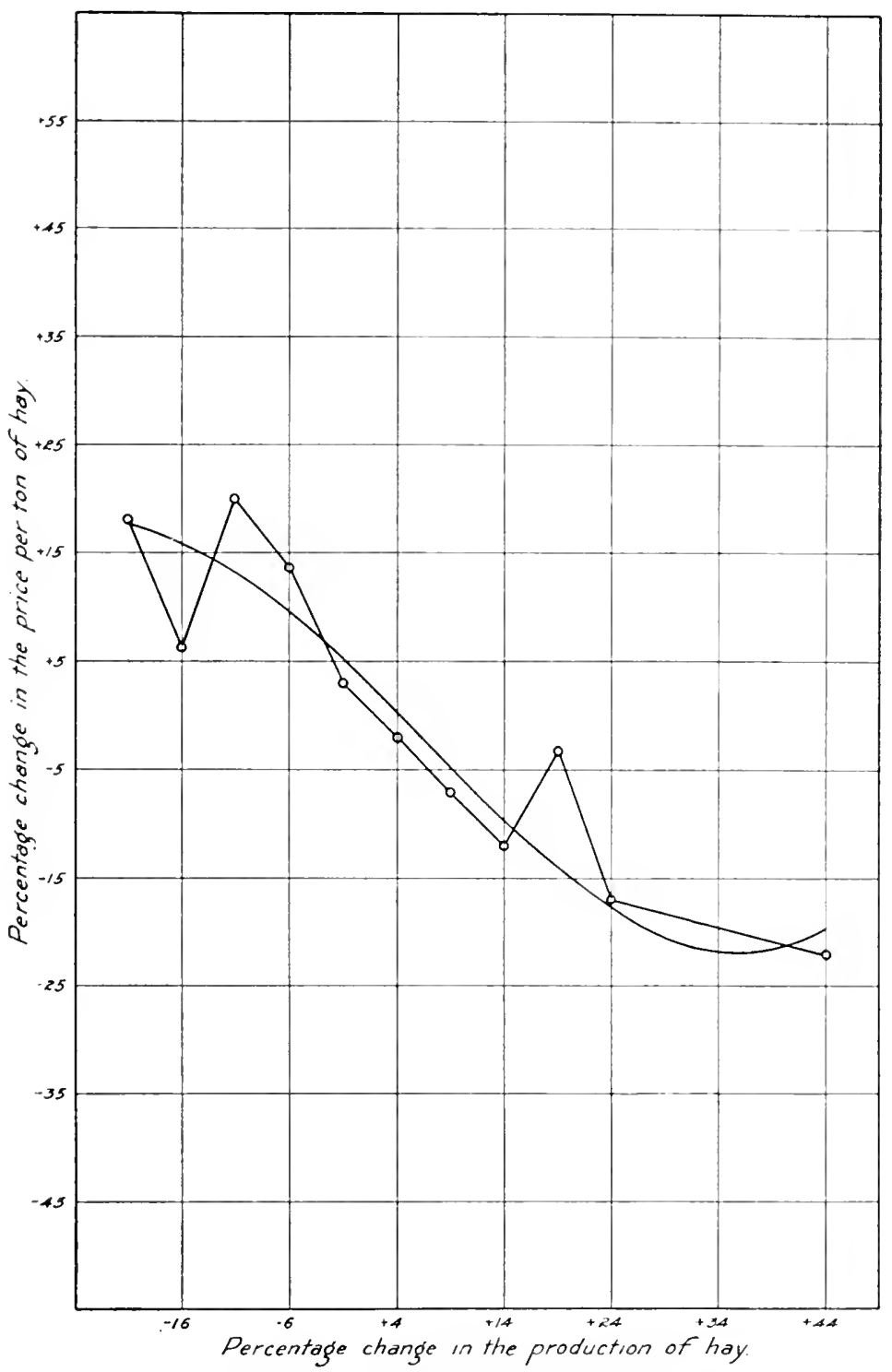

Figure 18. The law of demand for hay.

$y=4.17-.9460 x-.00770 x^{2}+.000385 x^{3}$, origin at $(0,0)$. 


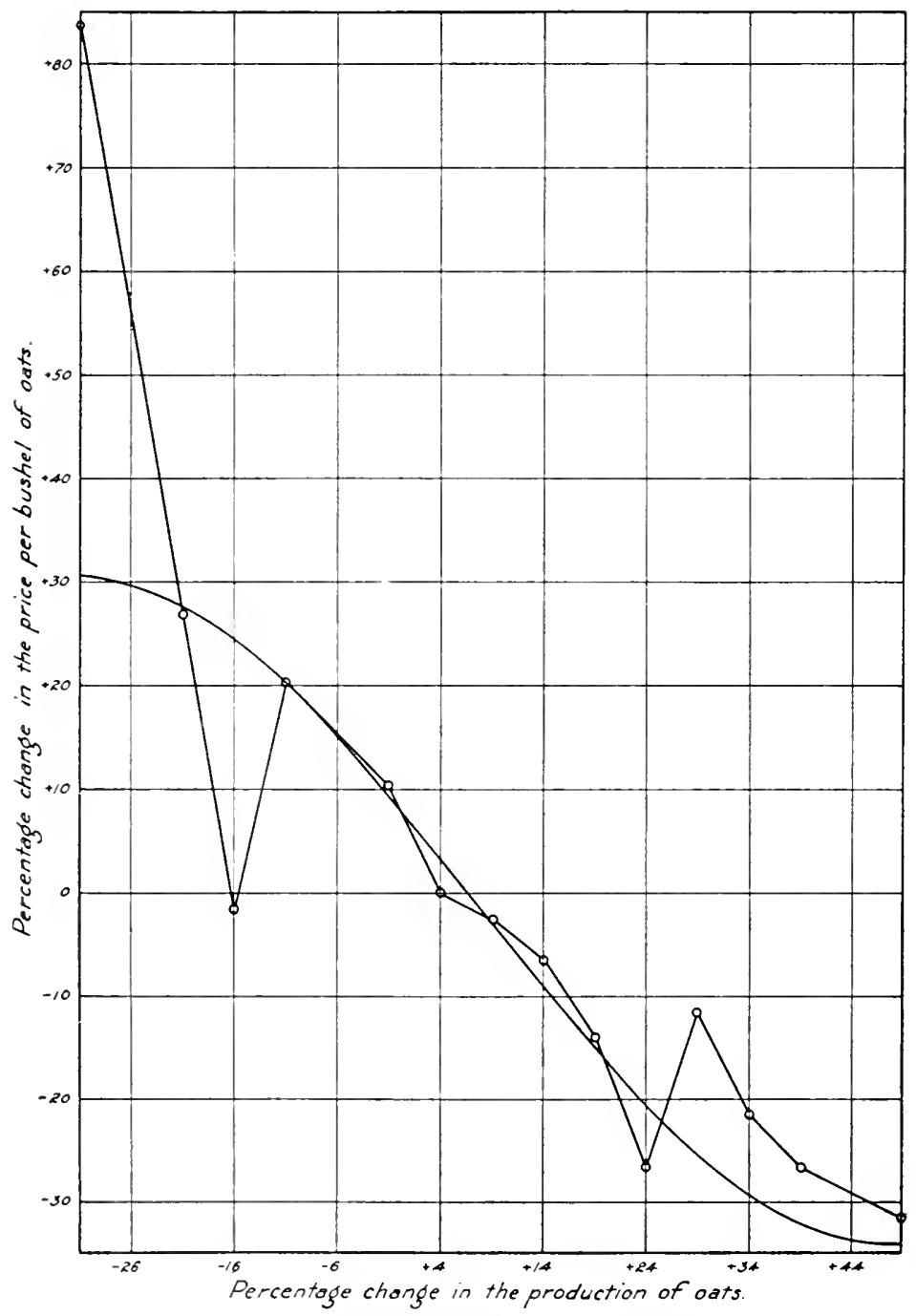

Figure 19. The law of demand for oats.

$y=8.22-1.1904 x-.00663 x^{2}+.000273 x^{3}$, origin at $(0,0)$. 


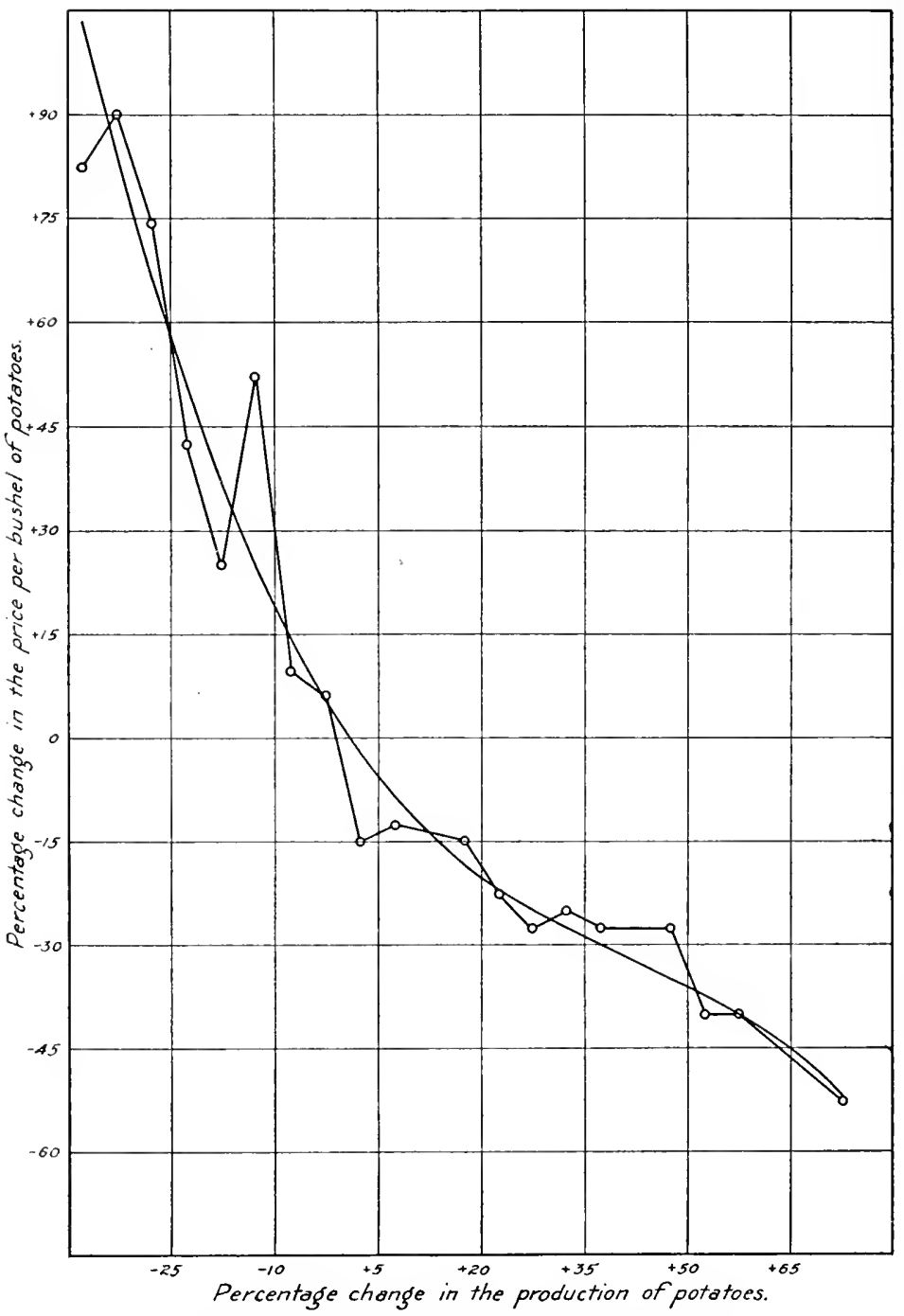

Figure 20. The law of demand for potatoes. $y=1.77-1.5062 x+.02489 x^{2}-.000197 x^{3}$, origin at $(0,0)$. 
But unlike the classical theory of demand which was limited to the simple enunciation of this one characteristic, ceteris paribus, the statistical laws that have just been derived apply to the average changes that society is actually undergoing. They summarize the changes in prices that are to be expected from changes in the supply of the commodity, thus enabling one to predict the probable variation in price that will follow upon an assigned variation in the amount of the commodity. They exhibit the connection of probable results not only in a qualitative but also in a quantitative form.

\section{The Prediction of Prices}

It has been said that the statistical laws of demand enable the economist to predict the probable variation in price that will follow upon an assigned variation in the quantity of commodity that is to be sold. How accurate are the results of prediction that are based upon the statistical law of demand?

The accuracy of the prediction in the case of any given commodity will vary according to the degree of fit of the type of curve that is assumed to represent the relation between the relative change in price and the relative change in the quantity of the commodity. If, for example, the commodity in question is corn in the United States, and the type of demand curve is assumed to be linear, then, according to the results in foregoing pages, the correlation between the two variables is $r=-.789$, and the regression equation is $y=-.8896 x$ +7.79 , the origin being at $(o, o)$. (Figure 16 will facili- 
tate the discussion of the case.) By means of this law of demand it is possible to predict the probable change in the price that will follow upon a given change in the quantity to be sold. In 1911, in the United States, the quantity of corn produced was 2,531,488,000 bushels, and the mean farm price on December 1, 1911 was 61.8 cents. In 1912 the quantity of corn produced was $3,124,746,000$ bushels; what, then, was the probable price of corn on December 1, 1912? The percentage change in the quantity produced was 23.44. Substitute this value for $x$ in the formula for the law of demand $y=-.8896 x+7.79$, and solve for the value of $y$. It is found that the probable change in price would be a fall of 13.06 per cent., which, since the price in 1911 was 61.8 cents, would give 52.7 cents as the probable price for December 1, 1912, whereas the actual price was 48.7 cents.

According to the theory of linear correlation, the accuracy of the regression equation as a prediction formula is measured by $S=\sigma_{y} \sqrt{1-r^{2}}$, where $r$ is the coefficient of correlation between the variables, $\sigma_{y}$ is the standard deviation of the variable $y$ about its mean value, and $S$ is the root-mean-square deviation of the actual observations about the regression line; or, in other words, $S^{2}$ is the mean value of the mean-square deviations about the regression line, of the observations in the several arrays of $y$ 's. From the Table of the Probability Integral it is known that in a symmetrical distribution of observations about their mean value, 68 per cent. of all the observa- 
tions fall within \pm the root-mean-square deviation of the observations from their mean value; 95 per cent., between \pm twice the root-mean-square deviation; and 99.7 per cent. between \pm three times the root-meansquare deviation. It is therefore possible, by means of the Probability Integral, to affix the degree of probability that a deviation shall fall within any given multiples or submultiples of the root-mean-square deviation. In case of the use of the linear law of demand for corn in the United States as a prediction formula, the root-mean-square deviation of the observations about the demand curve was $S=\sigma_{y} \sqrt{1-r^{2}}=$ 15.92 per cent. That is to say, if we assume the law of demand that was based upon observations from 1866 to 1911 to hold in 1912 , then it is 95 to 5 , or 19 to 1 , that the percentage variation in the actual price for 1912 from the percentage variation as calculated from the law of demand will be between \pm 2 (15.92), or 31.84 per cent. The calculated percentage change in the price for 1912 was a fall of 13.06 per cent.; the actual fall was 21.20 per cent., giving a difference of 7.14 per cent.

The precision with which the linear law of demand may be used for the prediction of the price of corn in the United States justifies the belief that for some purposes it is unnecessary to seek a greater degree of accuracy than is afforded by the simple linear laws. But it is well to be able to reach the maximum degree of precision, and for this reason we have fitted, to the data of the Tables in the Appendix, the more complex 
curves $y=a+b x+c x^{2}+d x^{3}$, the graphs of which, in case of the representative commodities corn, hay, oats, and potatoes, are given in Figures 17, 18, 19, 20. What is the gain in precision when the more complex curve is substituted for the simple straight line? The scatter of the observations about the straight line of regression was measured, a while ago, by taking the root-meansquare deviation of the observations about the line, that is, by using $S=\sigma_{y} \sqrt{1-r^{2}}$. In order to compare with this result the distribution of the observations about the more complex curve, $y=a+b x+c x^{2}+d x^{3}$, the distribution about the latter curve will likewise be measured by the root-mean-square deviation of the observations. In the little table given below, the measures of scatter of the observations for the two types of demand curves are presented in a form that will make comparison easy.

Scatter of Observations About the Law of Demand Root-Mean-Square Deviation of Observations

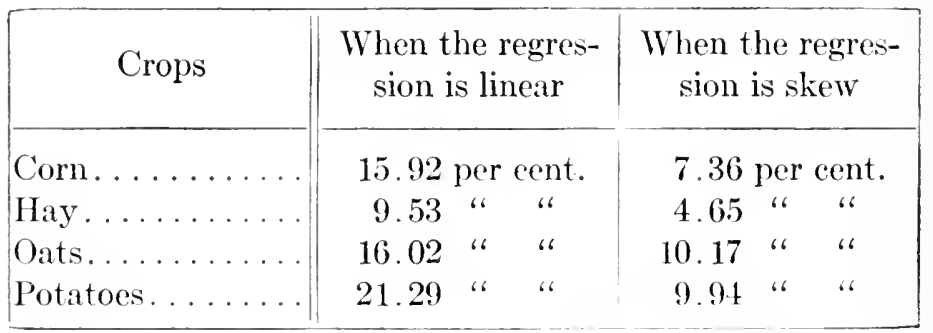

It is clear that in all cases a gain in precision is obtained by using the more complex curve.

Before leaving this topic a remark should be made 
that has a bearing upon the a priori theory of demand. In treatises on pure economics, particularly in those in which mathematical analysis is employed, the masters of the a priori method point out what they regard as the extreme difficulty of the actual problem of the relation of price to quantity of commodity - a difficulty growing out of the interrelation of the many factors in the problem. If, to limit the illustration to a simple case, one wishes to know how the price of corn is related to the quantity of corn that is produced, he is told that the problem is inextricably complex: If there is a deficiency in corn, then hay, or potatoes, or oats, or all three may be substituted in part for corn, and consequently the variation in the price of corn that follows upon a deficiency of corn cannot be traced without knowing in what degree, when the price of corn varies, hay, oats, and potatoes are used as substitutes. But this is not all. The degree in which hay, oats, and potatoes are substituted for corn is dependent not only upon the price of corn but also on their own several prices, and these latter prices are, in turn, dependent upon the supply and price of corn! This statement of the problem, complex as it appears, is unduly simplified; and it is presented not in order to ridicule the work of the masters who have elaborated the method of stating the problem in the form of simultaneous equations, but to show how hopelessly remote from reality is the very best theoretical treatment of the problem of the relation of price to the quantity of commodity, and to suggest, from the results of the preceding pages 
of this chapter, how imaginary, theoretical difficulties are dispelled by solving real problems.

Of course it is theoretically possible when there is a deficiency in the production of corn, that oats, hay, and potatoes may be substituted in part for corn, but instead of conjuring up these and other possibilities that are never tested, would it not be wise to ascertain first just how closely is the variation in the price of corn related to the variation in its own supply? When the statistical investigation is made and it is found that the correlation coefficient is $r=-.789$, and that when a skew relation is assumed instead of the usual linear relation, the connection between the variables is still closer, one sees very clearly, if our illustration is a typical case, that for most of the problems of actual life, it is unnecessary to face the complex possible interrelation of phenomena contemplated in the theoretical treatment. For the sake of economy of time and of talent, theoretical and statistical work should go hand in hand. Even the complex theoretical problem that has just been sketched may be tested as to its hypotheses and conclusion by the statistical method of multiple correlation.

\section{Elasticity of Demand}

The coefficient of the elasticity of demand for a commodity has been described as the ratio of the relative change in the quantity of the commodity demanded to the relative change in the price, when the relative changes are infinitesimal. Starting with this descrip- 
tion, we are able, by means of the laws of demand for the several commodities, to measure their respective degrees of elasticity of demand. It will be recalled that, in the form in which the laws of demand have been presented in preceding pages, the variable $x$ has been taken to represent the relative change in the quantity of the commodity, and the variable $y$, the corresponding relative change in the price. The coefficient of the elasticity of demand, therefore, is equal to $\frac{d x}{d y}$ when $x$ is zero. All that is needed to obtain the measure of the degree of elasticity of demand is to differentiate $y$ with respect to $x$ in the equation to the law of demand, place $x=$ zero, and then take the reciprocal of the result.

The method may be illustrated in case of the four representative commodities, corn, hay, oats, and potatoes. The law of demand for corn-see Figure 17-is

$$
y=.94-1.0899 x+.02391 x^{2}-.000234 x^{3}
$$

Therefore, $\frac{d y}{d x}=-1.0899+2(.02391) x-3(.000234) x^{2}$

When $x=0, \frac{d y}{d x}=-1.0899, \frac{d x}{d y}=-\frac{1}{1.0899}=-.92$

and consequently the coefficient of the elasticity of demand for corn is -.92 . Since the law of demand for hay is

$$
\begin{aligned}
y & =4.17-.946 x-.0077 x^{2}+.000385 x^{3} \\
\frac{d y}{d x} & =-.946 \text { when } x=\text { zero, }
\end{aligned}
$$

and the coefficient of elasticity of demand is -1.06 . For similar reasons the degrees of elasticity of demand 
for oats and for potatoes are respectively, -.84 and -.66 .

In obtaining these numerical values for the coefficient of elasticity, the laws of demand for the respective crops have been assumed to be parabolas of the third order. If the linear laws of demand had been taken for the purpose, the coefficients of elasticity would have been different. For example, the law of demand for corn-see Figure 16 -is $y=-. \$ \$ 96 x+7.79$ which would give $\frac{d y}{d x}=-.8896$, or $\frac{d x}{d y}=-1.12$, whereas the coefficient was -.92 in case of the more complex curve.

This discrepancy between the results when different types of curves are used for the demand curve shows the need of care in drawing conclusions that are based upon numerical values of the coefficient of elasticity. The discrepancy does not invalidate the method. When different measures of degrees of elasticity are afforded by different types of curves, there is a perfectly satisfactory criterion which makes it possible to decide between different coefficients of elasticity: The coefficient is to be preferred which is deduced from the demand curve that fits the data with the highest degree of probability. The demand curve that fits best the data affords the best measure of the degree of elasticity of demand.

The conclusions of this chapter may be briefly summarized. In the closing quarter of the last century great hopes were entertained by economists with regard to the capacity of economics to be made an 
"exact seience." Aceording to the view of the foremost theorists, the development of the doetrines of utility and value had laid the foundation of scientific economies in exact concepts, and it would soon be possible to erect upon the new foundation a firm structure of interrelated parts which, in definiteness and eogeney, would be suggestive of the severe beauty of the mathematico-physical seiences. But this expectation has not been realized. On the contrary, faith in the possibility of an adequate "exact" treatment of the science has progressively diminished, and interest in economic theory in general has decidedly lost ground. There must have been something fundamentally wrong with the traditional handling of the subject, for certainly it must be admitted that the parts of a seience most worthy of study are precisely those parts which are concerned with the general and the universal. Why, then, should there have been the gradual dissipation of interest in theoretical economics?

The explanation is found in the prejudiced point of view from which economists regarcled the possibilities of the seience and in the radically wrong method which they pursued. It was assumed gratuitously that econonics was to be modeled on the simpler mathematical, physical sciences, and this assumption created a prejudice at the outset both in selecting the data to be investigated and in conceiving of the types of laws that were to be the object of research. Economics was to be a "calculus of pleasure and pain," a "mechanies of utility," a "social mechanics," a "physique sociale." 
The biased point of view implied in these descriptions led to an undue stressing of those aspects of the science which seemed to bear out the pretentious metaphors. One would naturally suppose from this manner of conceiving the science that the economic theorists would at once have entered upon their task with the methods that had proved themselves useful in the physical sciences. But this they did not do. They seemed to identify the method of physical sciences with experimentation, and since, as they held, scientific experimentation is impossible in social life, a special method had to be devised. The invention was a disguised form of the classical cateris paribus, the method of the static state.

The point of view that has been exemplified in this chapter is that the facts in their full concreteness must never be lost from sight; that the laws which are sought are of necessity, at first, proximate laws, laws that obtain in full empirical reality, and are means of arriving at laws of larger generality; that the method to be followed is the method which makes progress from the data to generalization by a progressive synthesisthe method of statistics. ${ }^{1}$

${ }^{1}$ With regard to the methodology of the social sciences, the writings of Cournot are always helpful. The following quotation is taken from a treatise published thirteen years after his epoch making Recherches sur les principes mathématiques de la théorie des richesses.

Si nous restons dans l'ordre des eauses secondaires et des faits observables, le seul auquel la science puisse atteindre, la théorie mathématique du hasard . . nous apparait comme l'application la plus vaste de la science des nombres, et celle qui justifie le micux 
Starting with this point of view and pursuing the method that has just been described, we have attacked the old problem of the form of the law of demand. We have obtained the concrete laws of demand for representative commodities, have affixed the degree of precision with which the laws may be used as formulæ for predicting prices, and have measured the elasticity of demand for the respective commodities.

In all likelihood it will be said that what we have achieved is not exactly what the partisans of the method of cateris paribus proposed. To this criticism we reply that their immediate problem of the relation of price and quantity of commodity, cateris paribus, was vaguely conceived and actually abandoned by those who sought to give it definiteness, as being incapable of concrete

l'adage: Mundum regunt numeri. En effet, quoiqu'en aient pensé certains philosophes, rien ne nous autorise à croire qu'on puisse rendre raison de tous les phénomènes avec les notions d'étendue, de temps, de mouvement, en un mot, avee les seules notions des grandeurs continues sur lesquelles portent les mesures et les ealculs du géomètre. Les actes des êtres vivants, intelligents et moraux ne s'expliquent nullement, dans l'êtat de nos connaissanees, et il y a de bonnes raisons de croire qu'ils ne s'expliqueront jamais par la mécanique et la géométrie. Ils ne tombent done point, par le côté géométrirue ou mécanique dans le domaine des nombres, mais ils s'y retrouvent placés, en tant que les notions de eombinaison et de chance, de cause et de hasard, sont supérieures, dans l'ordre des abstractions, à la géométrie et à la mécanique, et s'appliquent aux phénomènes de la nature vivante comme à ceux que produisent les forces qui sollicitent la matière inorganique; aux actes réfléchis des êtres libres, comme aux déterminations fatales de l'appétit et de l'instinct.

Essai sur les fondements de nos comaissances et sur les caractìres de la critique philosophique, vol. 1, pp. 64-65. 
solution; that when the problem is clearly stated, it admits of solution by means of a method which we have indicated, the method of multiple correlation; and that what we have achieved is the solution of their ultimate problem of the relation of price and quantity of commodity in a dynamic society. 


\section{APPENDIX}

Table I.--The Production and the Price of Corn in the United States

\begin{tabular}{|c|c|c|c|c|}
\hline YEAR & $\begin{array}{c}\text { ProDCCTION OF } \\
\text { CORN IN THOE- } \\
\text { SANDS OF BUSHELS }\end{array}$ & $\begin{array}{c}\text { Average } \\
\text { Farm Price } \\
\text { Per Bushel } \\
\text { December 1, } \\
\text { 1. Cents }\end{array}$ & $\begin{array}{l}\text { Pencentage } \\
\text { Change in } \\
\text { Production }\end{array}$ & $\begin{array}{l}\text { Percentage } \\
\text { Change in } \\
\text { Price }\end{array}$ \\
\hline 1866 & 867,946 & 47.4 & & \\
\hline 1867 & 765,320 & 57.0 & -11.48 & +19.41 \\
\hline 1868 & 906,527 & 46.8 & +17.99 & -17.89 \\
\hline 1869 & 874,320 & 59.8 & -3.55 & +27.78 \\
\hline 1870 & $1,094,255$ & 49.4 & +25.15 & -17.39 \\
\hline 1871 & 991,898 & 43.4 & -9.35 & -12.15 \\
\hline 1872 & $1,092,719$ & 35.3 & +10.17 & -18.66 \\
\hline 1873 & 932,274 & 44.2 & -14.68 & +25.21 \\
\hline 1874 & 850,145 & 58.4 & -8.81 & +32.13 \\
\hline 1875 & $1,321,069$ & 36.7 & +55.39 & -37.16 \\
\hline 1876 & $1,283,828$ & 34.0 & -2.82 & -7.36 \\
\hline 1877 & $1,342,558$ & 34.8 & +4.57 & +2.35 \\
\hline 1878 & $1,385,219$ & 31.7 & +3.40 & -8.91 \\
\hline 1879 & $1,547,902$ & 37.5 & +11.50 & +18.30 \\
\hline 1880 & $1,717,435$ & 39.6 & +10.95 & +5.60 \\
\hline 1881 & $1,194,916$ & 63.6 & -30.42 & +60.61 \\
\hline 1882 & $1,617,025$ & 48.5 & +35.33 & -23.74 \\
\hline 1883 & $1,551,067$ & 42.4 & -4.08 & -12.59 \\
\hline 1884 & $1,795,528$ & 35.7 & +15.76 & -15.80 \\
\hline 1885 & $1,936,176$ & 32.8 & +7.83 & -8.12 \\
\hline $18 S 6$ & $1,665,441$ & 36.6 & -13.95 & +11.59 \\
\hline 1887 & $1,456,161$ & 44.4 & -12.57 & +21.31 \\
\hline 1888 & $1,987,790$ & 34.1 & +36.51 & -23.20 \\
\hline 1889 & $2,112,892$ & 28.3 & +6.29 & --17.01 \\
\hline 1890 & $1,489,970$ & 50.6 & -29.48 & +78.80 \\
\hline 1891 & $2,060,154$ & 40.6 & +38.27 & -19.76 \\
\hline 1892 & $1,628,464$ & 39.4 & -20.95 & -2.96 \\
\hline 1893 & $1,619,496$ & 36.5 & -.55 & -7.36 \\
\hline 1894 & $1,212,770$ & 45.7 & -25.11 & +25.21 \\
\hline 1895 & $2,151,139$ & 25.3 & +77.37 & -44.64 \\
\hline 1896 & $2,283,875$ & 21.5 & +6.17 & -15.02 \\
\hline 1897 & $1,902,968$ & 26.3 & -16.68 & +22.33 \\
\hline $1 S ! 8$ & $1,924,1 \$ 5$ & 28.7 & +1.11 & +9.13 \\
\hline 1899 & $2,078,144$ & 30.3 & +8.00 & +5.57 \\
\hline 1900 & $2,105,103$ & 35.7 & +1.30 & +17.82 \\
\hline 1901 & $1,522,520$ & 60.5 & -27.67 & +69.47 \\
\hline 1902 & $2,523,648$ & 40.3 & +65.75 & -33.39 \\
\hline 1903 & $2,244,177$ & 42.5 & -11.07 & +5.46 \\
\hline 1904 & $2,467,4,1$ & 44.1 & +9.95 & +3.76 \\
\hline 1905 & $2,707,994$ & 41.2 & +9.75 & -6.58 \\
\hline 1906 & $2,927,416$ & 39.9 & $+\$ .10$ & -3.16 \\
\hline 1907 & $2,592,320$ & 516 & -11.45 & +29.32 \\
\hline 1908 & $2,608,6,51$ & 60.6 & +2.91 & +17.44 \\
\hline 1909 & $2,772,376$ & 59.6 & +3.89 & -1.65 \\
\hline 1910 & $2,486,260$ & 45.0 & +4.11 & -19.46 \\
\hline 1911 & $2,531,1 \mathrm{~s}$ & 61.8 & -12.29 & +28.75 \\
\hline
\end{tabular}


TaBle II.-The Production and the Price of Hay in the United States

\begin{tabular}{|c|c|c|c|c|}
\hline YEAR & $\begin{array}{l}\text { Production OF } \\
\text { HAY IN THOU- } \\
\text { AAND OF ToN } \\
\text { (Ton = 2000 lbs.) }\end{array}$ & $\begin{array}{l}\text { AVERAGE FARM } \\
\text { P'RI'E PER TON } \\
\text { DECEMBER 1, } \\
\text { IN DOLLARS }\end{array}$ & $\begin{array}{l}\text { Percentage } \\
\text { Change iN } \\
\text { Production }\end{array}$ & $\begin{array}{l}\text { Percentage } \\
\text { ChaNGE IN } \\
\text { Price }\end{array}$ \\
\hline $1866^{\circ}$ & 21,779 & 10.14 & & \\
\hline 1867 & 26,277 & 10.21 & +20.65 & $+\quad .69$ \\
\hline 1868 & 26,142 & 10.08 & -2.42 & -1.27 \\
\hline 1869 & 26,420 & 10.18 & +1.06 & $+\quad .99$ \\
\hline 1870 & 24,525 & 12.47 & -7.17 & +22.50 \\
\hline 1871 & 22,239 & 14.30 & -9.32 & $+14.6 \mathrm{~s}$ \\
\hline 1872 & $23, \$ 13$ & 12.94 & +7.08 & -9.51 \\
\hline 1873 & 25,085 & 12.53 & +5.34 & -3.17 \\
\hline 1874 & 25,134 & 11.94 & +.20 & -4.71 \\
\hline 1875 & 27,574 & 10.78 & +10.90 & -9.72 \\
\hline 1876 & 30,867 & 8.97 & +10.74 & -16.79 \\
\hline 1877 & 31,629 & 8.37 & +2.47 & -6.69 \\
\hline 1878 & 39,608 & 7.20 & +25.23 & -13.98 \\
\hline 1879 & 35,493 & 9.32 & -10.39 & +29.44 \\
\hline 1880 & 31,925 & 11.65 & -10.05 & $\begin{array}{r}+25.00 \\
\end{array}$ \\
\hline 1881 & 35,135 & 11.82 & +10.05 & +1.46 \\
\hline 1882 & 38,138 & 9.73 & +8.55 & -17.68 \\
\hline 1853 & 46,864 & 8. 19 & +22.88 & -15.83 \\
\hline 1884 & 48,470 & 8.17 & +3.43 & -.24 \\
\hline 1585 & 44,732 & 8.71 & -7.71 & +6.61 \\
\hline 1886 & 41,796 & 8.46 & -6.56 & -2.87 \\
\hline 1887 & 41,454 & 9.97 & -.82 & +17.85 \\
\hline $18 \$ 8$ & 46,643 & 8.76 & +12.52 & -12.14 \\
\hline 1889 & 66,831 & 7.04 & +43.27 & -19.63 \\
\hline 1890 & 60,198 & 7.87 & -9.93 & +11.79 \\
\hline 1891 & 60,818 & 8.12 & +1.03 & +3.18 \\
\hline 1892 & 59,824 & 8.20 & -1.63 & $+\quad .99$ \\
\hline 1893 & 65,766 & 8.68 & $\begin{array}{r}+9.93 \\
\end{array}$ & +5.85 \\
\hline 1834 & 54,874 & 8.54 & -16.56 & -1.61 \\
\hline 1895 & 47,079 & 8.35 & -14.21 & -2.22 \\
\hline 1896 & 59,282 & 6.55 & +25.92 & -21.56 \\
\hline 1897 & 60,665 & 6.62 & +2.33 & +1.07 \\
\hline 1898 & 66,377 & 6.00 & +9.42 & -9.37 \\
\hline 1899 & 56,656 & 7.27 & -14.65 & +21.17 \\
\hline 1900 & 50,111 & 8.89 & -11.55 & +22.28 \\
\hline 1901 & 50,591 & 10.01 & $+\quad .96$ & +12.60 \\
\hline 1902 & $59, \$ 58$ & 9.06 & +18.32 & -9.50 \\
\hline 1903 & 61,306 & 9.07 & +2.42 & +.11 \\
\hline 1904 & 60,696 & 8.72 & -1.00 & -3.86 \\
\hline 1905 & 60,532 & 8.52 & $-\quad .27$ & -2.29 \\
\hline 1906 & 57,146 & 10.37 & -5.59 & +21.71 \\
\hline 1907 & 63,677 & $11.6 \mathrm{~s}$ & +11.43 & +12.63 \\
\hline 1908 & 70,798 & 8.98 & +11.18 & -23.12 \\
\hline 1909 & 64,938 & 10.62 & -8.28 & +18.26 \\
\hline 1910 & 60,978 & 12.26 & -6.10 & +15.44 \\
\hline 1911 & 47,444 & 14.64 & -22.19 & +19.41 \\
\hline
\end{tabular}


TaBle III.-The Production and the Price of Oats in the United States

\begin{tabular}{|c|c|c|c|c|}
\hline Year & $\begin{array}{l}\text { Prodection of } \\
\text { OATS IN THOU- } \\
\text { ANDS OF BUSHELS }\end{array}$ & $\begin{array}{c}\text { Average } \\
\text { Fary Price } \\
\text { Per Bushel } \\
\text { DeceMber 1. } \\
\text { IN Cents }\end{array}$ & $\begin{array}{l}\text { Percentage } \\
\text { Change in } \\
\text { Production }\end{array}$ & $\begin{array}{l}\text { Percentage } \\
\text { Change in } \\
\text { Price }\end{array}$ \\
\hline $1 S 66^{\circ}$ & 268,141 & 35.1 & & \\
\hline 1867 & 278,698 & 44.5 & +3.94 & +26.78 \\
\hline 1868 & 254,961 & 41.7 & -8.52 & -6.29 \\
\hline 1869 & 288,334 & 38.0 & +13.09 & -8.87 \\
\hline 1870 & 247,277 & 39.0 & -14.24 & +2.63 \\
\hline 18.1 & 25.743 & 36.2 & +3.42 & -9.66 \\
\hline 1872 & 271,747 & 29.9 & +6.26 & -17.40 \\
\hline 1873 & 270,340 & 34.6 & -.52 & +15.72 \\
\hline 1874 & 240,369 & 47.1 & -11.09 & +36.13 \\
\hline 1875 & 354,318 & 32.0 & +47.41 & -32.06 \\
\hline 1876 & 320,884 & 32.4 & -9.44 & +1.25 \\
\hline 1877 & 406,394 & 28.4 & +26.65 & -12.35 \\
\hline 1878 & 413,579 & 24.6 & $\begin{array}{r}+1.77 \\
\end{array}$ & -13.38 \\
\hline 1879 & 363,761 & 33.1 & -12.05 & +34.55 \\
\hline $18 s 0$ & 417,885 & 36.0 & +14.88 & +8.76 \\
\hline $18 S I$ & 416,481 & 46.4 & -.34 & +28.89 \\
\hline 1882 & 488,251 & 37.5 & +12.43 & -19.18 \\
\hline 1883 & 571,302 & 32.7 & +17.01 & -12.80 \\
\hline 1884 & 543,628 & 27.7 & $\begin{array}{r}+2.16 \\
\end{array}$ & -15.29 \\
\hline 1885 & 629,409 & 28.5 & +7.84 & +2.89 \\
\hline 1886 & 624,134 & 29.8 & -.84 & +4.56 \\
\hline 1857 & $(0.59,618$ & 30.4 & $+5.6 \mathrm{~s}$ & +2.01 \\
\hline 1858 & 701,735 & 27.8 & +6.39 & -8.55 \\
\hline 1859 & 751,515 & 22.9 & $\begin{array}{r}+7.09 \\
+\quad 5\end{array}$ & -17.63 \\
\hline 1830 & 523,621 & 42.4 & -30.32 & +85.15 \\
\hline 1891 & 735,394 & 31.5 & +41.02 & -25.71 \\
\hline 1892 & $6(61,035$ & 31.7 & -10.48 & +.63 \\
\hline 1893 & 635,855 & 29.4 & -3.30 & -7.26 \\
\hline 1894 & 662,037 & 32.4 & $\begin{array}{r}3.63 \\
+3\end{array}$ & +10.20 \\
\hline 1895 & $\$ 24,444$ & 19.9 & +24.53 & -38.58 \\
\hline 1896 & 707,346 & 18.7 & -14.20 & -6.03 \\
\hline 1897 & 698,765 & 21.2 & -1.21 & +13.37 \\
\hline 1895 & 730,907 & 25.5 & +4.00 & +20.28 \\
\hline 1599 & 796,178 & 24.9 & +8.93 & -2.35 \\
\hline $1: 000$ & 809,126 & $2 \pi .8$ & +1.03 & +3.61 \\
\hline 1901 & 736,609 & 39.9 & -894 & +54.65 \\
\hline 1902 & 987,843 & 30.7 & +34.07 & -23.06 \\
\hline 1903 & $7 \times 4,091$ & 34.1 & -20.52 & +11.07 \\
\hline 190,4 & 894,5966 & 31.3 & +14.09 & $-\$ .21$ \\
\hline 1905 & $9.3,216$ & 29.1 & +6.55 & -7.03 \\
\hline $190 ;$ & $96,4,90: 3$ & 31.7 & +1.23 & +8.93 \\
\hline 1907 & $7.54,143$ & 44.3 & -21.81 & +39.75 \\
\hline 1905 & solo7,15i & 47.2 & +6.99 & +6.55 \\
\hline 1909 & $1,007,353$ & 40.5 & +24.80 & -14.19 \\
\hline 1910 & $1,1 \times 6,3+11$ & 34.4 & +17.77 & -15.06 \\
\hline 1911 & 112.295 & 45.0 & -22.26 & +30.81 \\
\hline
\end{tabular}


Table IV.-The Production and the Price of Potatoes in the UNited States

\begin{tabular}{|c|c|c|c|c|}
\hline YEAR & $\begin{array}{c}\text { ProDUCTION OF } \\
\text { POTATOES IN } \\
\text { THGUANDS OF } \\
\text { BUAHELS }\end{array}$ & $\begin{array}{c}\text { Average } \\
\text { FARM PRice } \\
\text { Per Bushel } \\
\text { December 1, } \\
\text { IN Centy }\end{array}$ & $\begin{array}{l}\text { Percentage } \\
\text { Change in } \\
\text { Prodetion }\end{array}$ & $\begin{array}{c}\text { Percentage } \\
\text { Change in } \\
\text { Price }\end{array}$ \\
\hline 1866 & 107,201 & 47.3 & & \\
\hline $1 S 67$ & 97,783 & 65.9 & -8.79 & +39.32 \\
\hline 1868 & 106,090 & 59.3 & +8.50 & -10.02 \\
\hline 1869 & 133,886 & 42.9 & $\begin{array}{r}+26.20 \\
\end{array}$ & -27.66 \\
\hline 1570 & 114,775 & 65.0 & -14.27 & +51.52 \\
\hline 1571 & 120,462 & 53.9 & +4.95 & -17.08 \\
\hline 1872 & 113,516 & 53.5 & -5.77 & -.74 \\
\hline 1873 & 106,089 & 65.2 & -6.54 & +21.87 \\
\hline 1874 & 105,981 & 61.5 & $-\quad .10$ & -5.67 \\
\hline 1875 & 166,877 & 34.4 & +57.46 & -44.07 \\
\hline 1876 & 124,827 & 61.9 & -25.20 & +79.94 \\
\hline 1877 & 170,092 & 43.7 & +36.26 & -29.40 \\
\hline 1878 & 124,127 & 58.7 & -27.02 & +34.32 \\
\hline 1879 & 181,626 & 43.6 & +46.32 & -25.72 \\
\hline 1880 & 167,660 & 48.3 & -7.69 & +10.78 \\
\hline 1881 & 109,145 & 91.0 & -34.90 & +88.41 \\
\hline 1882 & 170,973 & 55.7 & +56.65 & -38.79 \\
\hline 1883 & 205,164 & 42.2 & $\begin{array}{r}+21.75 \\
\end{array}$ & -24.24 \\
\hline 1884 & 190,642 & 39.6 & -8.42 & -6.16 \\
\hline $18 S 5$ & 175,029 & 44.7 & -8.19 & +12.88 \\
\hline 1886 & 168,051 & 46.7 & -3.99 & $\begin{array}{r}4.47 \\
+\quad 4\end{array}$ \\
\hline 1887 & 134,103 & 68.2 & -20.20 & +46.04 \\
\hline $1 S 8 S$ & 202,365 & 40.2 & +50.90 & -41.06 \\
\hline 1859 & 204,881 & 35.4 & $\begin{array}{r}+1.24 \\
+\end{array}$ & -11.94 \\
\hline 1890 & 148,290 & 75.8 & -27.62 & +114.12 \\
\hline 1891 & 254,424 & 35.8 & +71.57 & -52.77 \\
\hline 1892 & 156,655 & 66.1 & -38.43 & +84.64 \\
\hline 1893 & 183,034 & 59.4 & +16.84 & -10.14 \\
\hline 1894 & 170,787 & 53.6 & -6.69 & -9.76 \\
\hline 1895 & 297,237 & 26.6 & +74.04 & -50.37 \\
\hline 1896 & 252,235 & 28.6 & -15.14 & +7.52 \\
\hline 1897 & 164,016 & 54.7 & -34.97 & $\begin{array}{r}+91.26 \\
\end{array}$ \\
\hline 1898 & 192,306 & 41.4 & +17.25 & -24.31 \\
\hline 1899 & 228,783 & 39.0 & +18.97 & -5.80 \\
\hline 1900 & 210,927 & 43.1 & -7.80 & +10.51 \\
\hline 1901 & 187,598 & 70.7 & -11.06 & +77.96 \\
\hline 1902 & 284,633 & 47.1 & +51.72 & -38.59 \\
\hline 1903 & 247,128 & 61.4 & -13.18 & +30.36 \\
\hline 1904 & 332,830 & 45.3 & +34.65 & -26.22 \\
\hline 1905 & 260,741 & 61.7 & -21.60 & +36.20 \\
\hline 1906 & 305,035 & 51.1 & +18.14 & $-17.1 \mathrm{~s}$ \\
\hline 1907 & 298,262 & 61.8 & -3.17 & +20.94 \\
\hline 1908 & 278,985 & 70.6 & -6.46 & +14.24 \\
\hline 1909 & $376,5: 37$ & 54.9 & +34.97 & -22.24 \\
\hline 1910 & 349,032 & 55.7 & -7.30 & +1.46 \\
\hline 1911 & $292,7: 37$ & 79.9 & -16.13 & +43.45 \\
\hline
\end{tabular}




\section{CHAPTER V}

\section{THE MECHANISM OF CYCLES}

"Agriculture is the Foundation of Manufacture and Commerce." - Motto of the United States Department of Agriculture.

Thus far in our investigation of the cause and law of economic cycles, we have shown that the annual rainfall in the principal grain-producing area of the United States passes through definite, well-defined cycles; and that the yield of typical, leading crops is so closely related to the rainfall of their respective critical seasons that the cyclical movement of the rainfall of the critical seasons is approximately reproduced in the yield per acre of the corresponding crops. These cycles of crops constitute the natural, material current which drags upon its surface the lagging, rhythmically changing values and prices with which the economist is more immediately concerned. In order to unclerstand the connection between the flow of the undercurrent of agricultural yield and the surface changes of values and prices, we have taken the necessary first step of connecting the prices of agricultural commodities with their supply. But the supply varies with the acreage as well as with the yield, and consequently to carry further our investigation we must know how closely the prices of crops are related to their yield. 
The Prices of Agricultural Commodities Correlated with the Yield of the Several Crops

The method employed in the preceding chapter to derive the law of demand of the several crops contained two stages: As a first stage, the correlation between the relative change in the total supply and the corresponding relative change in price was assumed to be linear, and upon the hypothesis of linearity of regression, the demand curve was computed and the degree of accuracy with which prices night be predicted from such linear demand curves we showed how to measure. The second stage in the theory of demand curves was to assume a skew relation between relative changes in price and supply, and we found that the degree of accuracy with which prices might be predicted from the skew demand curves was greater than when the law of demand was assumed to be linear. We shall follow these two stages in treating the relation between the yield per acre and the price of the crops.

If the correlation between the relative change in yield per acre and the relative change in price is assumed to be linear, we obtain for the coefficients of correlation in case of the four typical crops, the values placed in the first row of the accompanying Table, which, for purpose of comparison, also presents the corresponding coefficients in case of the linear demand curves. 
A Comparison of the Coffficients of Correlation in Case of Linear Yield-Price Curves and of Linfar Demand Curves

\begin{tabular}{|l|l|l|l|l|}
\hline & Corn & Hay & Oats & Potatoes \\
\hline $\begin{array}{c}\text { Relative change in } \\
\text { yield per acre and } \\
\text { relative change in } \\
\text { price }\end{array}$ & -.815 & -.656 & -.718 & -.873 \\
\hline $\begin{array}{l}\text { Relative change in } \\
\text { total supply and } \\
\text { relative change in } \\
\text { price }\end{array}$ & -.789 & -.715 & -.722 & -.856 \\
\hline
\end{tabular}

The data used in the above computation were, in case of the yield-price curve, the average yield per acre of the respective crops in the whole of the United States and the corresponding average prices for the United States, on the first of December of the years in which the crops were produced. The data for the demand curves, it will be recalled from the preceding chapter, were the total supply of the respective crops in the United States and the corresponding prices on December 1 . The period covered in both cases was from 1866 to 1911, inclusively. The data were obtained from recent Yearbooks of the United States Department of Agriculture.

It appears, from the cocfficients of correlation given in the above Table, that it is possible to predict the prices of the crops from the yield per acre with the same 
precision with which prices may be predicted from the demand curves. Or, to put the idea in another form, the productivity of the soil is as closely related to the prices of crops as the supply of the commodity is related to the same prices. In the chapter on the "Law of Demand," we found that, when the relative change in the supply is given, the mean shift in the corresponding change of price may be obtained from the regression equation, and that, furthermore, the root-mean-square deviation of the observations may be computed by the formula $S=\sigma_{y} \sqrt{1-r^{2}}$. This same formula may be used for a similar purpose in case of the yield-price curves.

We come now to the second stage in the derivation of the relation between price and the yield per acre of crops. We assume that the relation between the yield per acre and the price of a crop is skew, and that the relation between the two may be expressed by an equation of the form $y=a+b x+c x^{2}+d x^{3}$.

In Figure 21, the skew yield-price curves of our four representative commodities are drawn to a percentage scale. The equations to the curves, which were computed by the Method of Least Squares, are given upon the Figure. The root-mean-square deviation of the observations from their respective yield-price curves are given in the following Table which, for purposes of comparison, reproduces the coefficients that were found, in the preceding chapter, to measure the deviation of the observations about the skew laws of demand. 

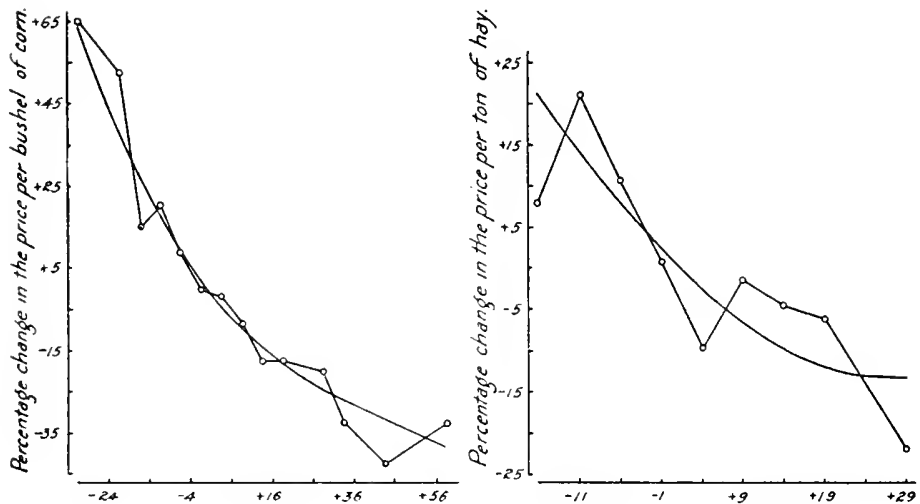

Percentage change in the yiela per acre of corn

Percentage change in the yield per acre of hoy.
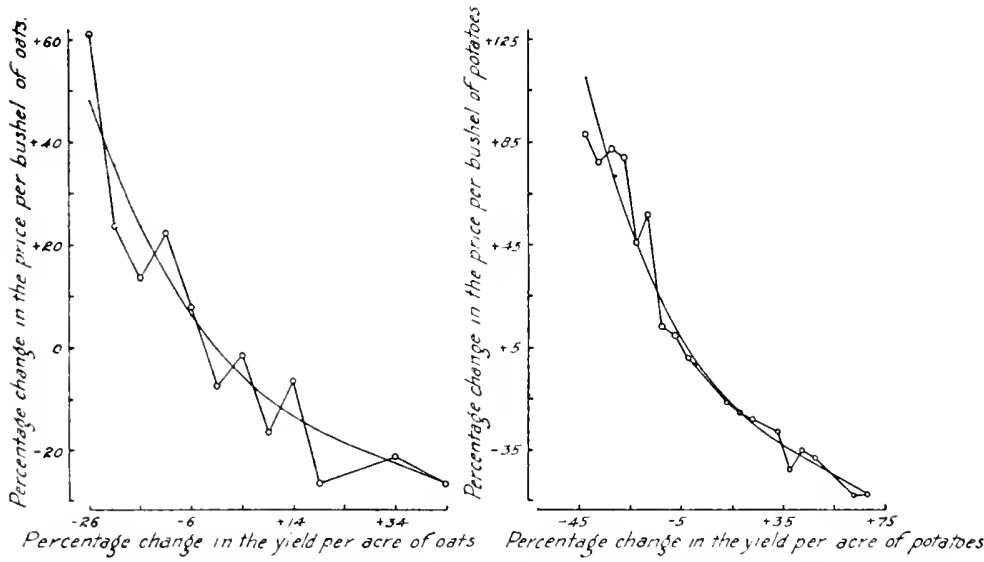

Figure 21. The relation between the price and the yield per acre of the several crops.

When the origin is at $(0, O)$, the equations are

For corn, $y=.17-1.2989 x+.01892 x^{2}-.000137 x^{3}$.

For hay, $y=1.17-1.0215 x+.01549 x^{2}+.00009 x^{3}$.

For oats, $y=-1.49-1.1346 x+.02324 x^{2}-.000238 x^{3}$.

For potatoes, $y=.49-1.4863 x+.01993 x^{2}-.0001+1 x^{3}$. 
a Comparison of the Root-Mean-Square Deviation in Case of Skew Yield-Price Curves and of Skew DeMand CuRves

\begin{tabular}{|c|c|c|c|c|}
\hline & Corn & Hay & Oats & Potatoes \\
\hline $\begin{array}{c}\text { Yield-Price } \\
\text { Curves }\end{array}$ & 5.48 & 5.72 & 7.05 & 9.39 \\
\hline $\begin{array}{c}\text { Demand } \\
\text { Curves }\end{array}$ & 7.36 & 4.65 & 10.17 & 9.94 \\
\hline
\end{tabular}

From the results given in the last two Tables, it is clear that the prices of the representative crops are as closely related to the yield per acre as to the total supply of the crops. This conclusion is of importance in the task of connecting the cycles in the productivity of the soil with the cycles in values and prices.

In obtaining the preceding close relations between the changes in prices and changes in yield, the figures for the whole of the United States were employed. The object of broadening the field of observation from the detailed investigation of the Middle West to the whole of the United States was two-fold: First, it seemed likely, a priori, that a more intimate relation between prices and yield would be obtained if the large market of the whole country were substituted for the local market of Illinois; secondly, because the object of this chapter is to bring the physical cycles of crops into relation with the industrial and commercial changes of the whole country, and to this end it seemed desirable that the crops of the 
whole country should be considered. We need, however, to assure ourselves that, in taking this more comprehensive view of the yield of crops, we have not lost the characteristic cyclical movement of the yield which we discovered in the more limited study. We desire to know how closely the yield per acre of the whole country is correlated with the yield per acre of our representative state of Illinois.

The correlations of the annual differences in the yield per acre in Illinois and the annual differences in the yield per acre in the United States were, in case of our four typical crops, for corn, $r=.855$; for hay, $r=.745$; for oats, $r=.800$; for potatoes, $r=.843$. The period covered in all cases was from 1866 to 1912 inclusively. The data were obtained from Bulletins, 56, 58, 62, 63 of the Bureau of Statistics of the United States Department of Agriculture and from the recent Yearbooks of the same Department. A reference to the Table given a moment ago will show that the yield per acre of crops in Illinois is at least as closely related to the yield per acre of the same crops in the United States, as the prices of the several crops are related either to the supply of the crops or to the yield per acre of the crops. Moreover, the very high values of the coefficients leave but little room for doubt that the cyclical movement of the yield per acre in the Middle West is representative of the movement of the crop yield in the whole of the United States. 
Rising and Falling Prices as Related to Yield-Price Curves

Thus far it is clear that the prediction of agricultural prices is dependent upon a knowledge (1) of the law of the variations of price with the yield per acre, and (2) of the law of the annual change in the yield per acre of the several crops. If the relation between prices and yield per acre were constant, the theory of agricultural cycles would be completely elucidated; for, once having discovered the law of the relation of price to yield per acre, nothing more would be necessary then to connect the yield with the meteorological conditions of its critical season, and the resulting prices for a long term of years could be predicted with great probability. But the relation between the price of the crops and the yield per acre varies with the level of general prices, and it is of the first importance to know the manner of variation.

If the course of prices in the United States for the period 1866 to 1911 is examined, it will be seen that, in general terms, we may with justness characterize the period 1866 to 1890 as a period of falling prices, and the period 1890 to 1911 as a period of rising prices. If therefore, in case of each of our representative commodities, we construct two yield-price curves, one for the period of falling prices and one for the period of rising prices, we shall, by comparing the two curves for the two periods, discover how the demand curves, or yield-price curves, vary in periods in which 
the movement of general prices is in opposite directions.

In Figure 22, the eight curves are drawn. Comparing the curves in the two periods for each of the four representative crops we infer that

(1) the demand schedule or yield-price curve is high when the general level of prices is high; and the demand schedule is low when the general level of prices is low;

(2) the general run of the curves remains nearly the same. That is to say, the principal difference between the period of falling prices and period of rising prices is that the yield-price schedules move down or up.

These are general statements in which quite obvious deviations are ignored and which, consequently, do not pretend to quantitative accuracy. The construction of the curves is dependent upon too few observations to admit of attaching significance to the apparent exceptions to the rule.

Since the prices of the representative crops are, as we know, dependent upon the yield per acre and the law of the relation between prices and the yield per acre, and since, as we have proved, the yield-price curves move with the general level of prices, our desideratum is to discover what determines the change in the level of general prices. 


\section{Economic Cycles: Their Law and Cause}
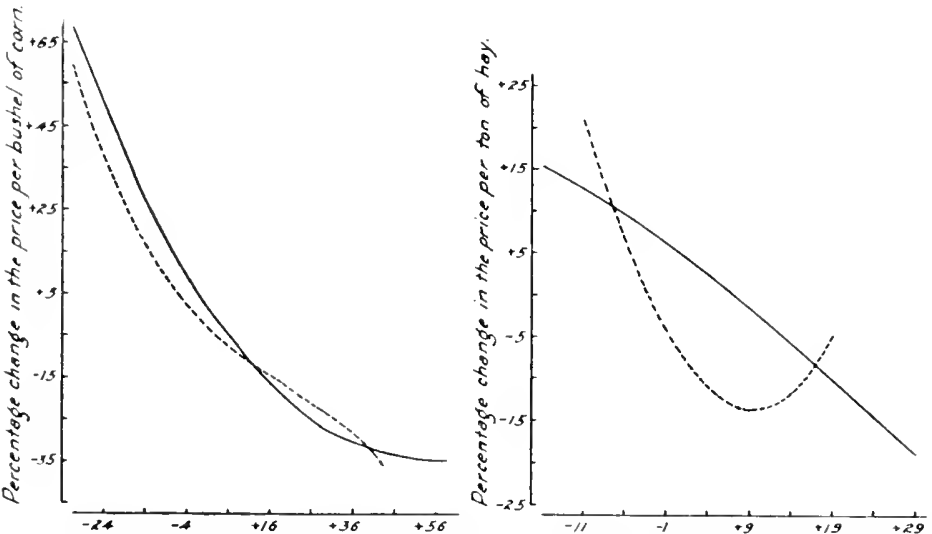

Percentage change in the yield per dere of corn

Percentage change in the yield per acre of hay.
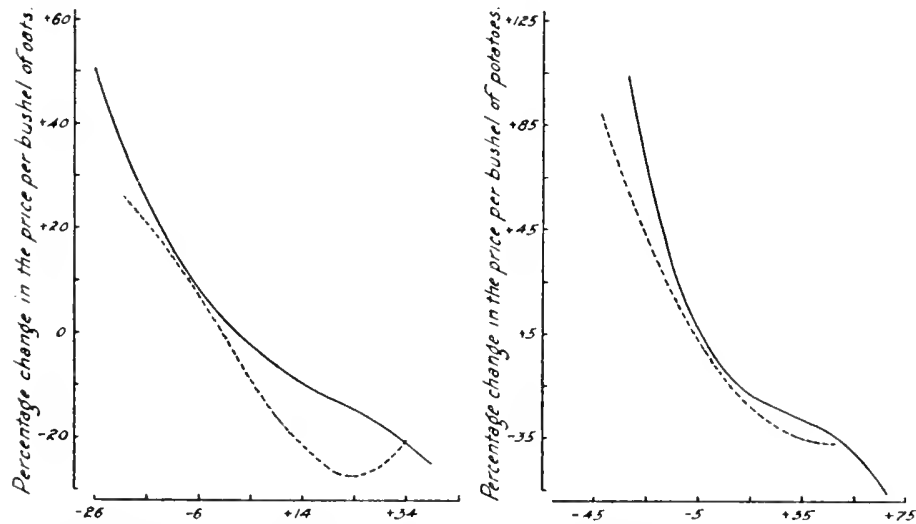

Percentage change in theyield per acre if ats

Dercentage change in theyield per acre of potatoes

Figure 22. The relation between the price and the yield per arre of the several crops.

When the origin is at $(0,0)$, the equations are

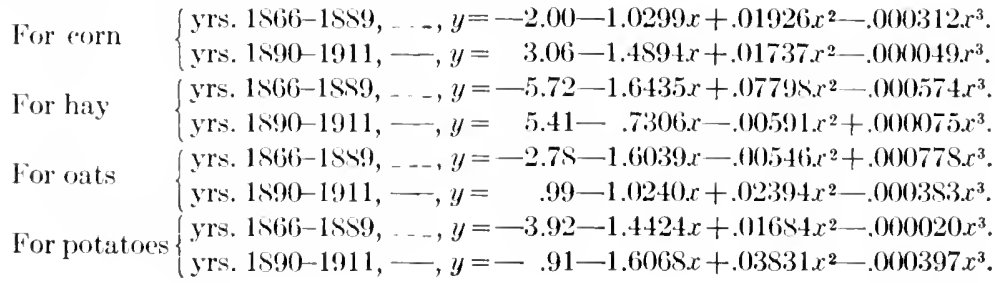




\section{The Volume of Crops and the Activity of Industry}

We shall approach the problem of the cause of the changing level of prices by considering two preliminary questions which will enter into the subsequent argument: (1) Is there any relation between the changing volume of the crops and the changing volume of those producers' goods whose fluctuations are generally regarded as indices of the activity of trade? (2) Is the law of demand for crops the type of law that is reproduced in the demand for all commodities, or is it not rather the case that the law of demand for pure producers' goods is of a different type from the law of demand for those commodities of which our four crops are samples?

The first of these two questions we shall consider in a form modified to bring its significance to bear upon the results that have already been established. The volume of crops varies with the extent of the acreage and with the average yield per acre. The question of interest to us at this point is whether the volume of producers' goods fluctuates with the yield per acre of the crops. We shall investigate this question, and, as a means of carrying forward our inquiry, we first construct an index number of the yield per acre of crops. The nine crops of the United States whose yield per acre throughout a long period is recorded in the Yearbooks of the Department of Agriculture are: corn, wheat, oats, barley, rye, buckwheat, potatoes, hay, cotton. ${ }^{1}$ If, in case

1 The figures for the yield per acre of cotton, 1s 50 -1910, were ob- 
of each of these erops, the mean yield per acre for the years 1890-1899 is taken as a base, and the yield per acre for each of the year's 1870-1911 is expressed as a ratio of the base, comparable indices for the crops during the period of forty-two years will be obtained. In order to combine the nine series of figures into a series that shall be representative of the whole of agriculture, the several series must be properly weighted. The method of weighting that was aclopted in this particular case was to assign to each crop an importance proportionate to its value as compared with the total value of the nine crops in 1911. The several weights were: for corn, 36 ; wheat, 12 ; oats, 9 ; barley, 3 ; rye, .7 ; buckwheat, . 3 ; potatoes, 6 ; hay, 16 ; cotton, 17 . The index numbers are given in Table I of the Appendix to this chapter.

Before comparing the index number for the yield per acre of the crops with the volume of producers' goods, we must make sure that we are keeping close to the results obtained from a detailed investigation of our four representative crops. If an index number of the four representative crops is constructed upon the same principle as the index for the nine crops, how closely would the indices be correlated? In computing the index of the yield per acre of the four representative crops, the weights assigned were: for corn, 50; hay, 2S; oats, 15 ; potatoes, 7 . The index is given in

tained from ('ircular 32, Bureau of Statistics, U. S. Department of Agriculture. The yied for 1911 was obtained from the Yearbook of the Department of Agriculture, 1911. 
Table I of the Appendix to this chapter. The coefficient of correlation between the index for the four representative crops and the index for the nine crops, is $r=.960$.

It is a common observation of writer's on economic crises that the production of pig-iron is an unusually good barometer of trade. The amount of pig-iron that is annually produced swells with the activity and volume of industry and trade, and it is among the first commodities to indicate the general shrinking in the ultimate demand which checks the activity of trade and causes its temporary decline. Is there any relation between the movement of this barometer of trade, the production of pig-iron, and the cycles of the crops? Can it be that the increase and decrease of the "ultimate demand" which lies back of the flow and ebb of trade has its source in the cyclical movements of the yield per acre of the crops?

The data for testing whether there is a relation between the yield per acre of the crops and the annual production of pig-iron are the statisties of the ammual production of pig-iron and the index numbers of the yield per acre of our nine crops.

The method of testing the relation presents difficulties, and as it will be used again to measure the relation between the cycles of crops and the eycles of general prices, we shall have a firmer grasp upon our problem if we stop now to gain a clear idea of the terms that continually occur in the argument. In any one of the 
series of figures that we shall use there are three distinct movements which need to be discriminated, and when any two of the series are compared, another important characteristic of the series requires to be taken into account. The three movements that are combined in each series are:

(a) The continuous fall or rise of the figures with the flow of time. This movement will be referred to as the secular trend of the figures;

(b) The rhythmical fluctuation of the figures about their secular trend. When this movement superposed upon the secular trend is the object of investigation, the combined movement will be referred to as the general cyclical movement of the figures. When the rhythmical movement unaffected by the complicating trend is being considered, it will be referred to simply as the cycles of the figures:

(c) The year to year temporary fluctuation about the general cyclical movement. These fluctuations will be referred to as the deviations of the figures.

When the cycles of any two series are compared, it will frequently happen, particularly if the one series is the cause of the other, that there is a considerable interval between the corresponding parts of the cycles in the two series. This interval will be referred to as the lag of the second series.

We shall be interested throughout the rest of this chapter primarily in the interrelations of eycles of 
crops, cycles in the activity of industry, and cycles in general prices. But we approach our general problem by considering first the temporary fluctuations which we have agreed to call deviations, and we inquire whether there is a relation between the deviations of the yield of the crops and the deviations in the production of pig-iron. The method that was adopted was first to obtain the general cyclical movements of the two series by averaging, in case of each series, the figures for each year with the figures that immediately preceded and followed the given year. For example, the index number of the yield per acre for the years $1870,1871,1872,1873$ were respectively 108, 105, 110, 99. The smoothed figure for the yield per acre in 1871 would therefore be $\frac{108+105+110}{3}=\frac{323}{3}=107.7$. Similarly, the smoothed index for 1872 would be 104.7. In Tables II and III of the Appendix to this chapter are presented the original and the smoothed figures for the production of pig-iron and for the index number of the yicld per acre of the nine crops. The statistics of the production of pig-iron were obtained from the Statistical Abstract of the United States for 1912, p. 774.

Aiter the general cyclical movements of the two series were determined, the deviations of the actual figures from the smoothed figures for each of the yours were calculated for both series of figures. These deviations are also given in Tables II and $11 \mathrm{I}$ of the Appendix to this chapter. The question upon which these differences are to throw light may be put in this form: Is 
the deviation of the yield per acre of the crops from its general cyclical movement associated with the deviation, in the following year, of the production of pigiron from the general cyclical movement of pig-iron? The answer is found by correlating the differences, always remembering that the difference for the yield per acre in any given year is to be taken with the difference of the production of pig-iron in the following year. The coefficient of correlation is $r=.254$.

We come now to the association between the cyclical movement of the yield per acre of the crops and the eyclical movement of the production of pig-iron. Each of these movements is superposed upon a rising secular trend, and before we can test the degree in which the cycles are related the secular trends must be eliminated. If, as a first approximation, the secular trend in each case is assumed to be linear, then by fitting a straight line ${ }^{1}$ to the data, it is possible to calculate the fluctuations of the cycles of crop yield and of production of pig-iron about their respective trends, and these fluctuations may be correlated. In Table IV of the Appendix to this chapter, the data for the calculation of the connection between the cycles are given. In columns 2 and 5 are tabulated the general cyclical movements of

1 The equations to the linear secular trends are, respectively, $y=.1844 x+98.57$, for the yield per acre of erops; and $y=582.71 x+$ 9525, for the production of pig-iron. The origin in the first case is at 1871 and in the latter case, at 1890 . The first equation was computed from the data for the years 1871-1906, and the sccond equation, from the data for 1871 to 1910 . 
the yield per acre of the crops and of the production of pig-iron; in columns 3 and 6 , the values of the linear secular trends are given; and in columns 4 and 7 , the deviations of the cyclical movement from the secular trend are recorded. These last deviations are the material for calculating the connection between the cycles of the yield per acre of the crops and the cycles of the production of pig-iron.

If the deviations of the cycles from their respective secular trends are correlated, the coefficient of correlation reaches the value, $r=.625$, but we must not be content to assume that even this relatively high coefficient represents the full degree of the relation between the cyclical movement of the crops and the cyclical movement of the activity of industry as that activity is typified in the production of pig-iron. It is quite likely that the good or bad crops may produce their maximum effect at a considerable interval after the period in which the crops are actually harvested. Time is required for the changing productivity of crops to work out its maximum effect, and this causes a lag in the adjustment of the cycles of the activity of industry to the eycles of the yield of the crops. We must therefore measure the amount of the lag.

If instead of correlating the cycles of the vield of the crops and of the production of pig-iron for corresponding years, we correlate them for lags of various intervals, we shall find it possible to determine the lag that will give the maxinum coefficient of correlation, and this particular value of the lag we may then regard as the 
interval of time required for the cycles in the crops to produce their maximum effect upon the cycles of the activity of industry. When the calculation of the coefficients of correlation is made according to this plan, it is found that for a lag

$$
\begin{aligned}
& \text { Of zero years, } r=.625 ; \\
& \text { Of one year, } r=.719 ; \\
& \text { Of two years, } r=.718 ; \\
& \text { Of three years, } r=.697 ; \\
& \text { Of four years, } r=.572
\end{aligned}
$$

It is clear, therefore, that the cycles in the yield per acre of the crops are intimately related to the cycles in the activity of industry, and that it takes between one and two years for good or bad crops to produce the maximum effect upon the activity of the pig-iron industry. Figure 23 illustrates the general congruence of the cycles of the crops and of the cycles in the production of pig-iron when a lag of two years is eliminated.

As to the general question concerning the relation between the harvests and the activity of industry, we may conclude from our statistical inquiry that there is a positive, intimate connection, and very probably a direct causal relation, between the bounty or niggardliness of nature and the flow or cbb of trade. ${ }^{1}$

\section{A New Type of Demand Curve}

A moment ago, we saw that two preliminary problems had to be treated before we could pass to the direct

${ }^{1}$ In a later' section of the chapter the method that has been used in treating this problem will be employed for another purpose and will then be illustrated in detail by means of graphs. 
Deviation of the general cyclical movement of the production of pigtron from its secular itind.

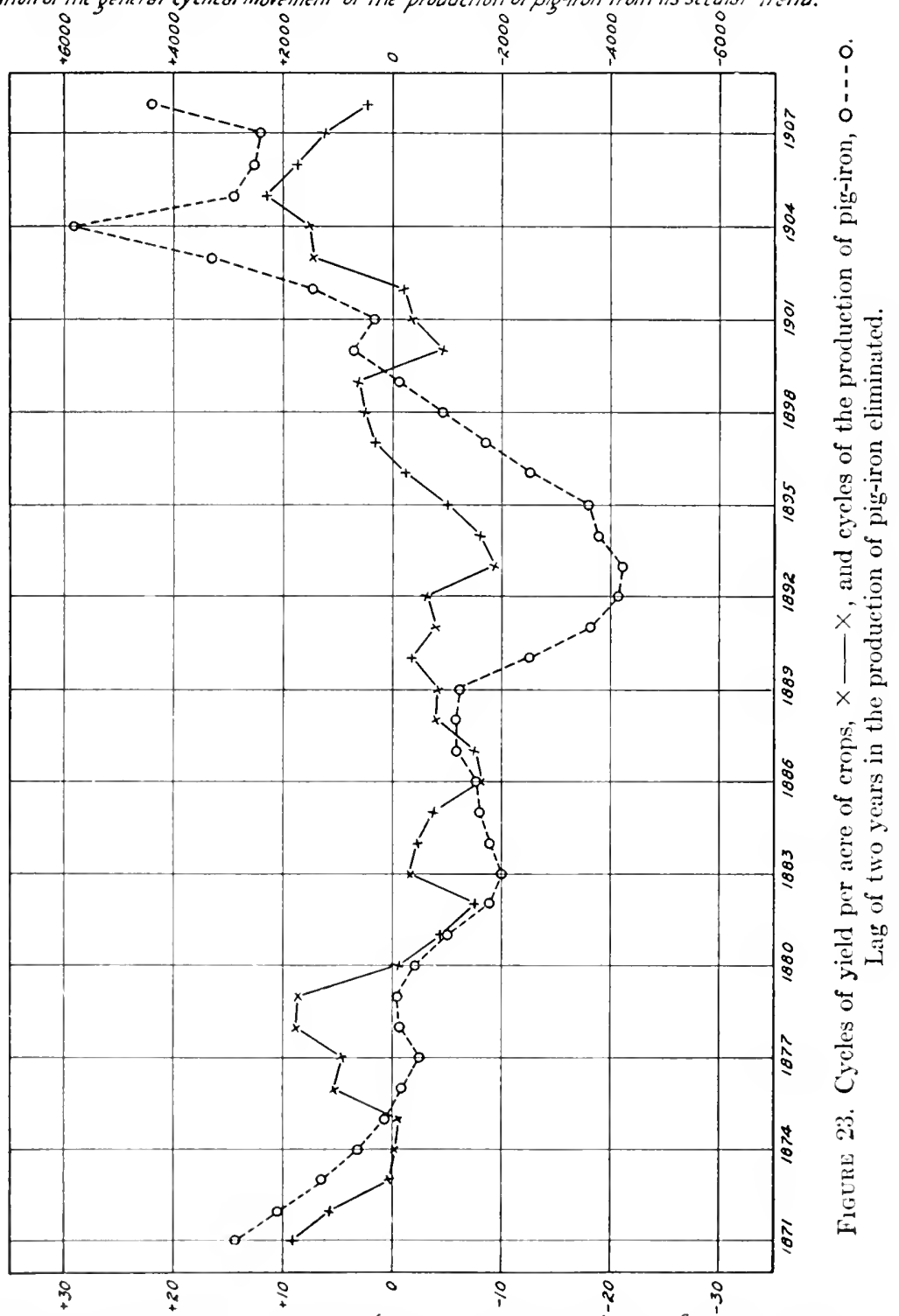


consideration of the cause and law of cycles of general prices. The first of these preliminary problems, namely, the influence of the bounty of nature upon the volume and activity of trade, we have just discussed, and we come now to the second preliminary problem, which we shall put in the form of a question: Are all demand curves in a dynamic society of the same type as the demand curves for the representative crops: corn, hay, oats, and potatoes?

This question must be answered as a preliminary to the more fundamental inquiry as to the cause of cycles of general prices, because if we assume that all demand curves are of the same negative type, we are confronted with an impossibility at the very beginning of our investigation. Upon the assumption that all demand curves are of the negative type, it would be impossible for general prices to fall while the yield per acre of crops is decreasing. In consequence of the decrease in the yield per acre, the price of crops would ascend, the volume of commodities represented by pig-iron would decrease, and upon the hypothesis of the universality of the descending type of demand curves, the prices of commodities like pig-iron would rise. In a period of declining yield of crops, therefore, there would be a rise of prices, and in a period of increasing yield of crops there would be a fall of prices. But the facts are exactly the contrary. During the long period of falling prices from 1870 to 1890 , there was a decrease in the yield·per acre of the crops, and during the long period of rising prices from 1890 to 1911 , there was an increas- 
ing yield of crops. It is obviously inadmissible to assume that in a dynamic society there is one law of demand for all commodities. The dogma of the uniformity of the law of demand is an idol of the static state.

If there are differences in types of demand curves, it is quite likely that as one type has been illustrated by the crops, another type will be exemplified by pure producers' goods. We shall accordingly investigate the demand curve of pig-iron, our representative producer's' good.

In Table $V$ of the Appendix to this chapter is contained the material for the computation of the law of demand for pig-iron. The anmual percentage changes in the production of pig-iron were computed from the figures of annual production, which were taken from the Statistical Abstract for 1912, p. 774. It was impossible to obtain directly the mean prices for which the annual production was sold, and consequently the percentage change in the mean price could not be computed directly. The device that was utilized to approximate these percentage changes is illustrated in Table $V$ of the Appendix. As the data needed for the solution of the problem were the anmual percentage changes in the mean price and not the actual mean annual prices themselves, it was regarded as sufficient for our purpose to substitute for the unobtainable annual percentage changes in the mean price, the mean amnual percentage changes in the prices of representative kinds of pig-iron. The annual prices for the lead- 
ing four kinds of pig-iron were obtained from the Statistical Abstract for 1912, p. 572, and the annual percentage changes in the prices of the four kinds, together with their mean annual percentage changes, are given in Table $\mathrm{V}$ of the Appendix. The second and last columns of Table $\mathrm{V}$ were used in computing the law of demand for pig-iron in the United States.

The graph of the law of demand for pig-iron is given in Figure 24. The correlation between the percentage change in the product and the percentage change in the price is $r=.537$. The equation to the law of demand is $y=.5211 x-4.58$, the origin being at $(o, o)$. Our representative crops and representative producer's' good exemplify types of demand curves of contrary character. In the one case, as the product increases or decreases the price falls or rises, while, in the other case, the price rises with an increase of the product and falls with its decrease.

The two preliminary difficulties are now cleared away. We know that as the yield per acre of the crops increases the physical volume of trade for producers' goods increases; and we know, furthermore, that the law of demand for a representative producers' good is such that as the product increases the price increases. If now a third fact, which has already been established, be added to these two, an hypothesis conformable to the three facts may be made which will give a working theory for examining whether the cycles in crops produce the cycles in general prices. The third fact to which reference is made is that the law of demand for 


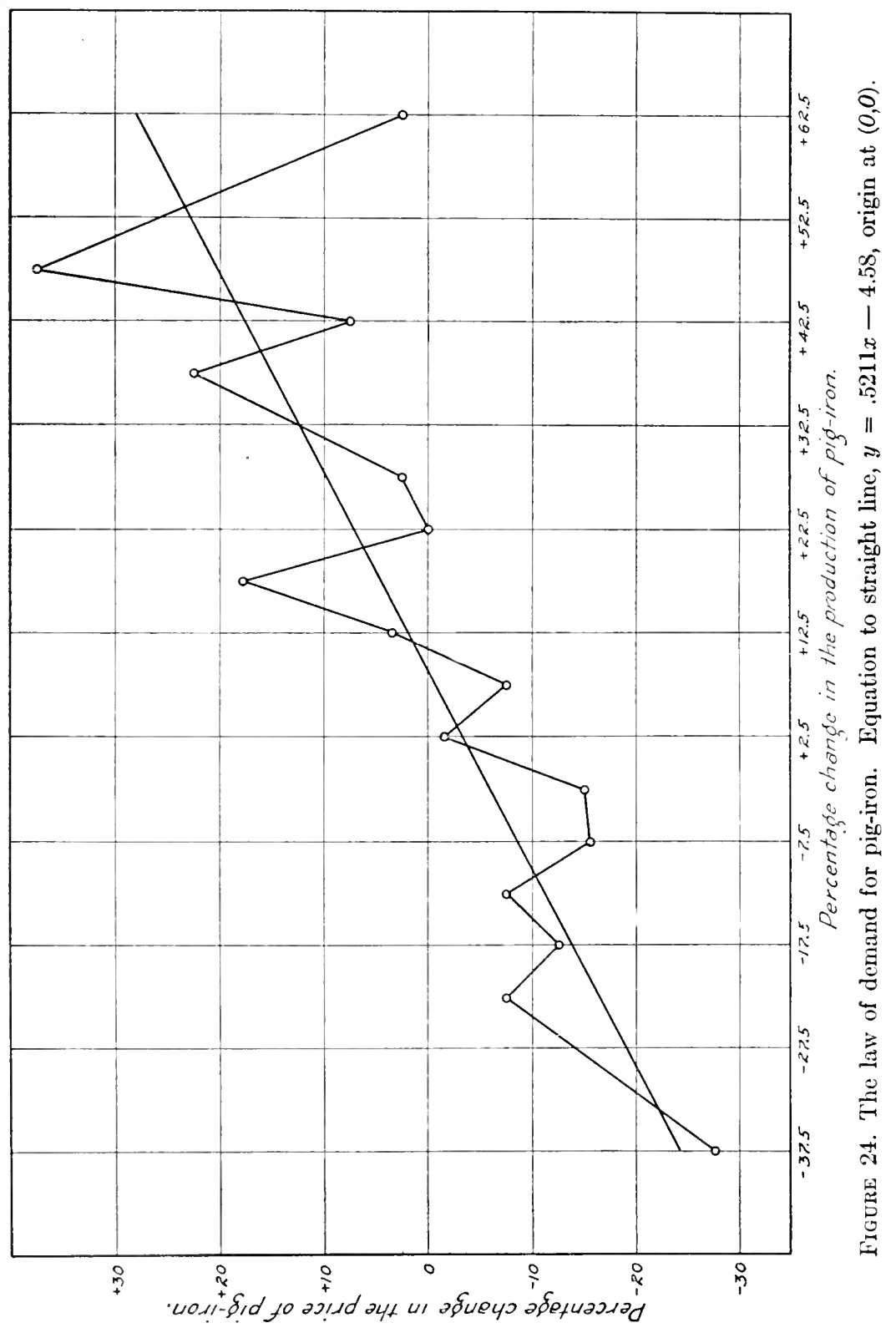


the crops falls during a period of falling general prices, and rises during a period of rising general prices. With these facts in mind it is not difficult to conceive how general prices may fall during a period of diminishing yield per acre of the crops and rise during the period that the yield is increasing. The falling yield in the crops would lead to a diminution of the volume of trade, a decline in the demand for producers' goods, a fall in the prices of producers' goods, a decrease in employment, a fall of the demand curves for crops, with the final result of a fall in general prices. Similarly, a rising yield in the crops would lead to an increase in the volume of trade, an increase in the demand for producers' goods, an increase of employment, a rise in the demand curves for crops, with the final result of a rise in general prices. Provided the interrelation of the economic factors are in accordance with this description, then it would follow that the cyclical movements in the yield of the crops should be reproduced in cyclical movements of general prices. If the actual facts bear out this deduction, there can be no doubt that the cause and law of economic cycles have been discovered.

The Fundamental, Pcrsistent Cause of Economic Cycles

To put the theory to the test of facts we require an index number of general prices throughout the period covered by most of the investigation in this Essaythe period from 1870 to 1911 . There is no one index number covering this period for the United States, but 
very fortunately there are two series that overlap in the middle of the period, so that it is possible to construct a series covering the whole term of years. The two series of index numbers in question are the Falkner index for "all articles" extending from 1870 to 1890 , and the index of the Bureau of Labor for "all commodities" extending from 1890 to 1911 . Since these two have the year 1890 in common it is possible, by applying the simple rule of proportion, to reduce the Falkner series to the base of the series published by the Bureau of Labor. The two original series and the continuous series are given in Table VI of the Appendix to this chapter.

The test of the theory that the cause and law of economic cycles are the cyclical movements of the yield per acre of the crops will be given in answer to two questions: First, are the deviations of the indices of general prices from their general cyclical movement correlated with the deviations of the indices of the yield per acre of the crops from their general cyclical movement? Secondly, are the cycles of prices and the cycles of crops correlated? The answers to these two questions are the substance of the following paragraphs.

In Tables III and VI of the Appendix to this chapter are given the indices of the yield per acre of the crops and the indices of general prices. The Tables likewise contain the smoothed indices and the deviations of the actual indices from the smoothed indices. The smoothed series were obtained in the manner that was described when the relation between the yield of the crops and the production of pig-iron was being treated. 
It will be recalled from that description that the smoothed index for any given year is the mean of three actual indices: the actual index for the given year, the actual index for the year preceding the given year, and the actual index for the year following the given year. The quantities whose correlation is in question are the deviations of the actual indices of general prices, and of yield per acre, from their respective smoothed series.

The results of the computation are as follows:

$$
\begin{aligned}
& \text { From } 1870-1911, r=.303, \\
& \text { From } 1870-1890, r=.370, \\
& \text { From } 1890-1911, r=.250 .
\end{aligned}
$$

In the first row the correlations were obtained from the continuous series in which the Falkner index was adjusted to the index of the Bureau of Labor. In the second row the correlations were derived from the Falkner index unaltered. In the third row the correlations were computed from the index of the Bureau of Labor. We infer that the deviations from their general cyclical movement of thejindices of general prices vary directly with the deviation from their general cyclical movement of the indices of the yield per acre of the crops.

The second of the two questions as to the cause and law of the cycles of general prices was stated in this form: Are the cycles of prices and the cycles of crops correlated? The preceding paragraphs have presented the results of the inquiry as to the relation between the deviations of actual prices and of yield from their 
respective general cyclical movements. The present question concerns the relation of the cyclical movements themselves, after their respective secular trends have been eliminated.

It will be recalled that the general cyclical movements were obtained by a process of smoothing the actual series of the indices of prices and of yield per acre, the process consisting in the formation of a progressive mean of the indices for three consecutive years. These smoothed series, which are given in Tables III and VI of the Appendix to this chapter, form the data of the present investigation.

The method of the investigation is presented in Figures $25,26,27$. In the first of these three Figures, the general cyclical movements of prices and of yield per acre are described according to the data of Tables III and VI. The graphs bring out clearly the rhythmical motions of both prices and yield and a comparison of the curres suggests that the price curve is a lagging reproduction of the yield curve. But before the amount of the lag and the degree of correlation between the cycles can be computed, the secular trends in the two series of values must be eliminated. From Figure 25 it is apparent that the price cycles move upon a falling secular trend while the yield cycles move upon a rising secular trend. If it is assumed as a first approximation that these secular trends are both linear, the equation to the trend for prices is $y=-.3702 x+122.01$, and to the trend for the yield per acre, $y=.1844 x+98.57$, the origin, in the former case, being at 1875 and, in the latter, 
120 Economic Cycles: Their Law and Cause

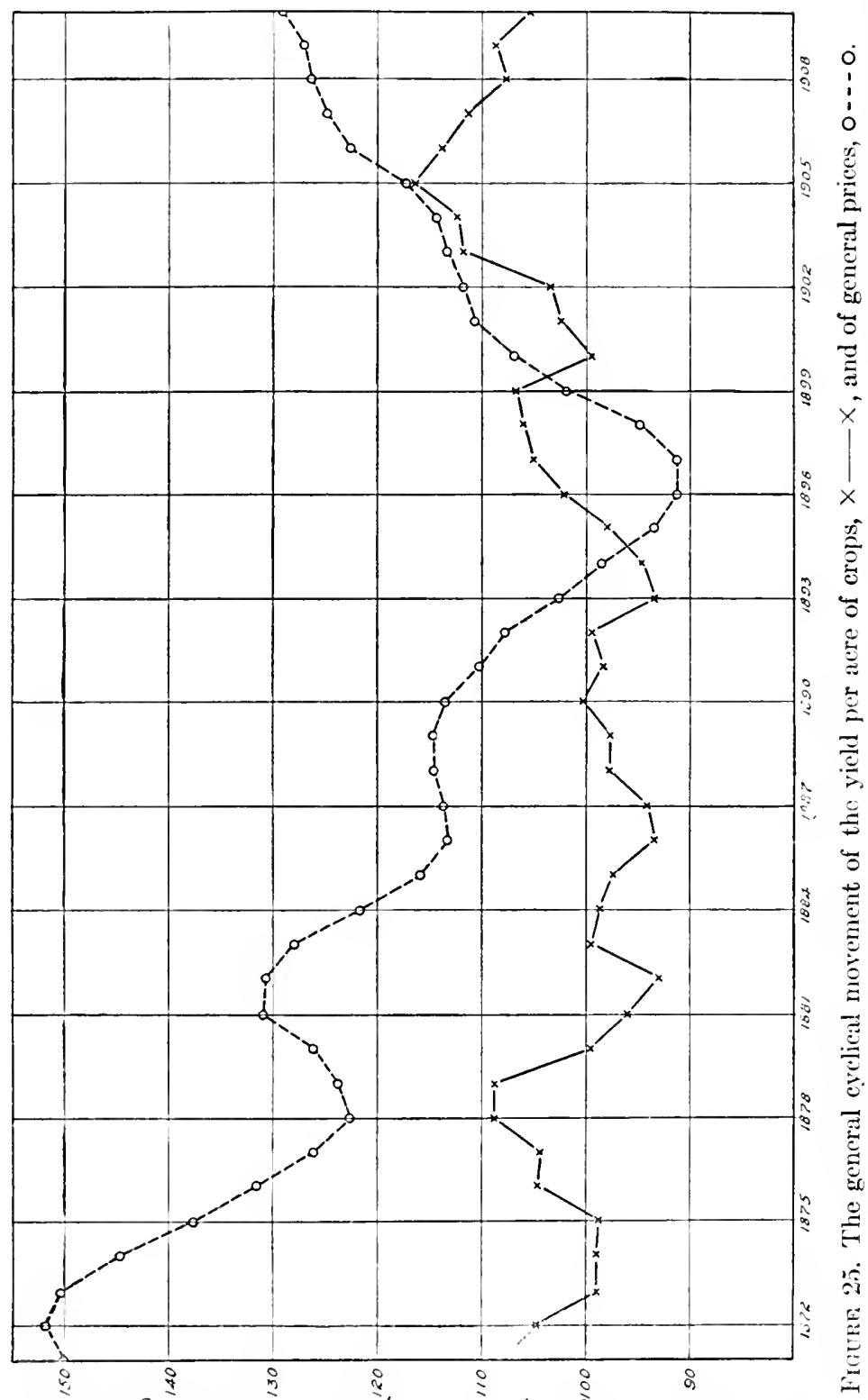

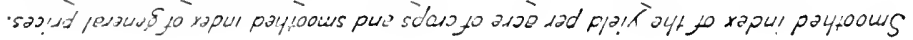




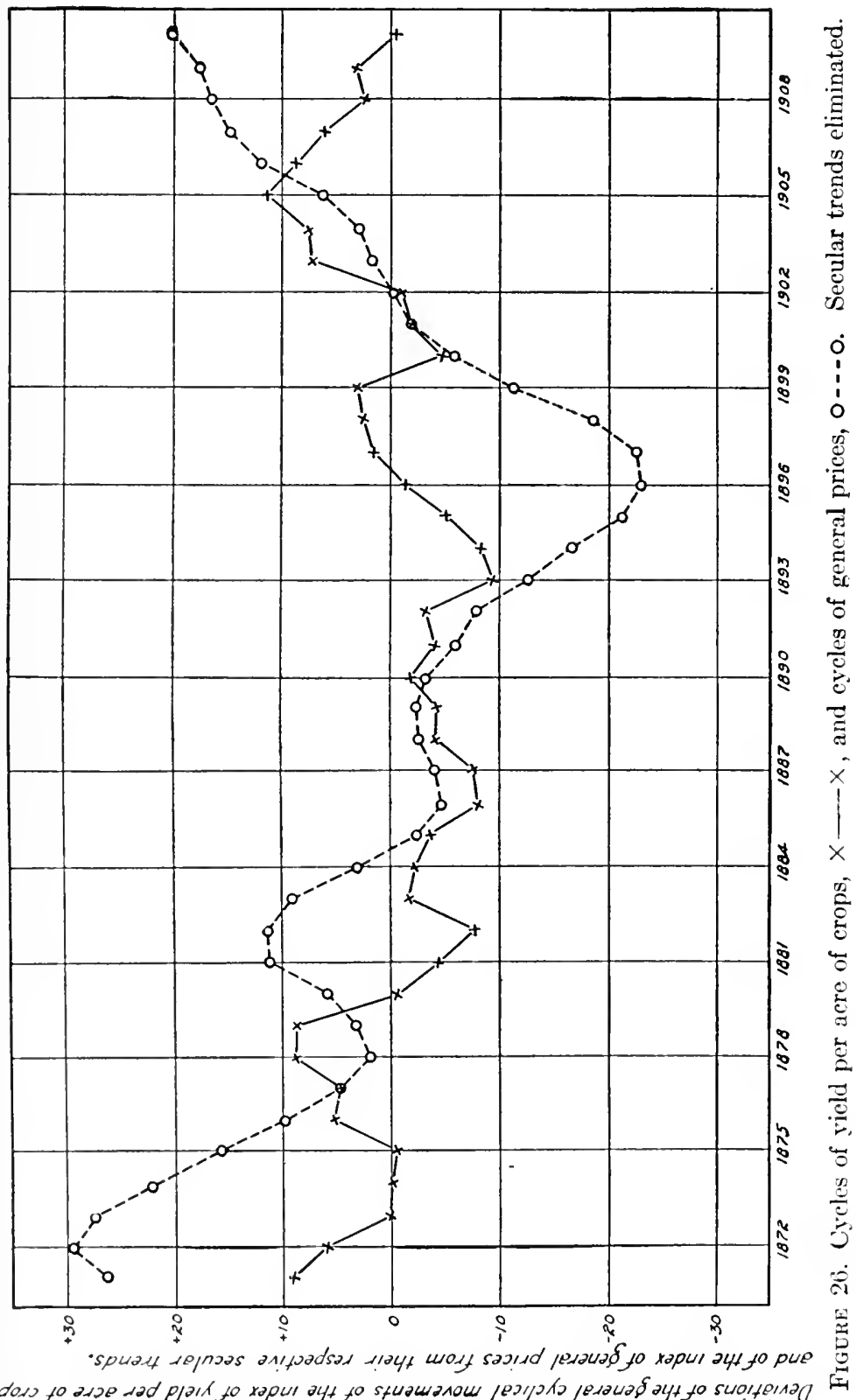


at $1871 .^{1}$ These two equations make it possible to eliminate the secular trends upon which move the cycles of prices and the cycles of yield. The results of the calculations are given in Table VII of the Appendix to this chapter.

Figure 26 presents the cycles of yield per acre and the cycles of general prices after the secular trends upon which they were respectively superposed have been eliminated. It is quite evident, now, from the appearance of the graphs, that the cycles of yield per acre and the cycles of general prices are closely related, and that the cycles of prices lag several years behind the cycles of crops. What is the amount of the lag and how closely are the cycles correlated? Both of these questions may be answered at once by following the method that was adopted to measure the lag in the cycles of pig-iron production. If the cycles of the yield per acre are correlated ${ }^{2}$ with the cycles of general prices we find, for a lag of three years in general prices, $r=.786$; for a lag of four years, $r=.800$; for a lag of five years, $r=.710$. The cycles in the yield per acre of the crops are, therefore, intimately connected with the cycles of general prices, and the lag in the cycles of general prices is approximately four year's.

Figure 27 presents the two series of cycles with the lag of four years in the cycles of prices eliminated. It is

1 The first equation was computed from the data for 1875-1910, and the second equation, from the clata for 1871-1906.

2 The data for the calculation are given in columns 4 and 7 of Table VII in the Appendix to this chapter. 


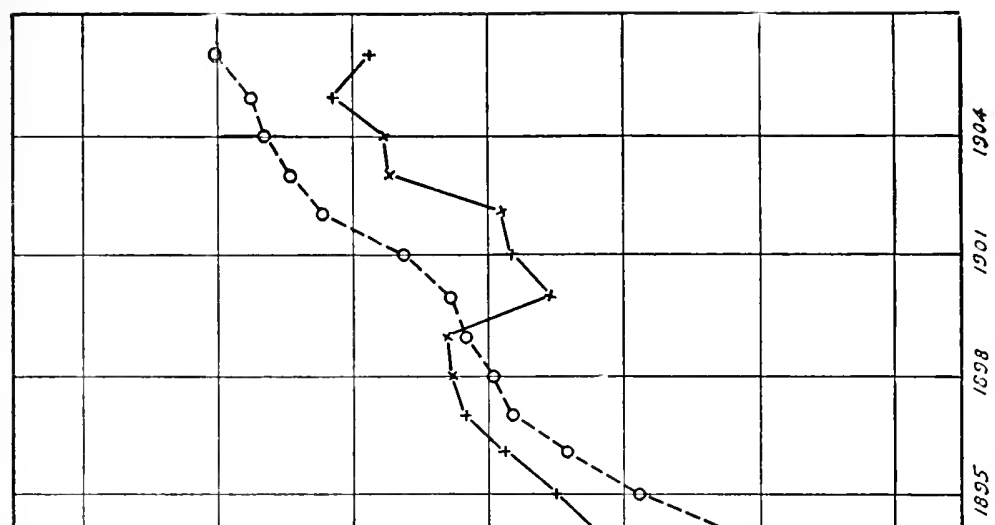

$\frac{7}{2}$

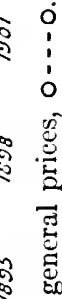

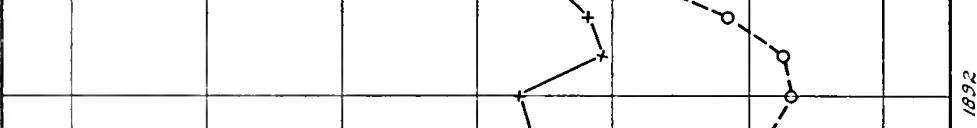

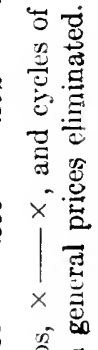

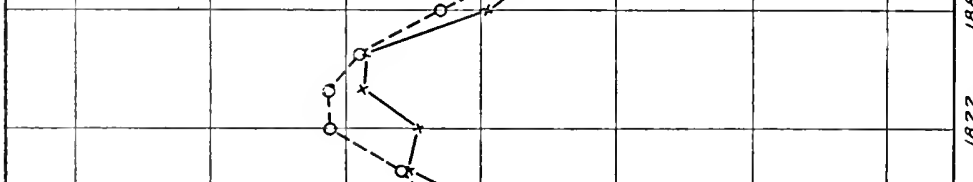

$\approx \quad 0$
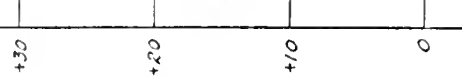

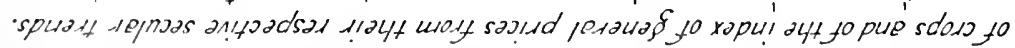

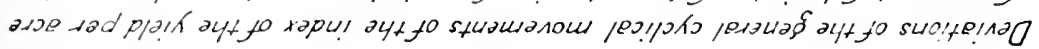


surely not an exaggeration to say that the congruence of the two rhythmical movements of crop yield and general prices is so close as to justify the inference that the one series is the cause of the other. Every important rhythmical feature of the yield curve is reproduced in the price curve: the long cycle which in both curves dips below the horizontal between 1880 and 1900, and the smaller superposed cycles that move upon the large ground-swell. The one apparent exception occurs in the price movement between 1887 and 1891 in which the price curve does not keep close to the yield curve. But this is not a real exception. For, in the first place, the price curve is convex between these limits, that is to say, it shows a tendency to conform to the yield curve; and, in the second place, since in the price curve a lag of four years has been eliminated, the date at which the disturbance occurs is really four years later than would appear from the dates on the chart. That would place the disturbance at about 1893, which was the year of the panic with extraordinary conditions in the state of the currency and the money market.

Considering the high correlation between the two series of cycles and the harmony of their congruence with the theory of economic cycles embodied in this Essay, we conclude that the cycles of the yield per acre of the crops cause the cycles of general prices and that the law of the cycles of crops is the law of the cycles of general prices. 
The chief results of this chapter may be summarized in a few propositions:

(1) The yield per acre, for the whole of the United States, of the four representative crops, corn, hay, oats, and potatoes is so closely correlated with the yield per acre of these crops in Illinois as to render it very probable that the cause of the cycles of the yield in the United States is the same as the cause of the cycles in Illinois. The meteorological cause of the rhythmical changes in the yield of Illinois has been discussed in an earlier chapter.

(2) The prices in the United States of the four representative crops are as closely related to the yield per acre of the crops as the prices are related to the total supply of the respective crops. For the purpose of prediction of prices, therefore, the yield-price curve is as useful as the demand curve.

(3) The curves representing the relation between the yield per acre and price, in case of the four representative crops, fall during a period of falling yield and falling general prices, and rise under the contrary circumstances.

(4) The falling or rising yield per acre of the crops leads to a falling or rising volume of trade in producers' goods. If the production of pigiron be taken as a representative producers' good, then

(a) The deviations of the annual production 
of pig-iron from the general cyclical movement in the production of pig-iron are directly correlated with the deviations, in the preceding year, of the yield per acre of the crops from their general cyclical movement;

(b) When the lag in the production of pigiron and the secular trend in both the production of pig-iron and in the yield per acre of the crops are eliminated, the cycles of production of pig-iron are very closely correlated with the cycles of the yield per acre of the crops. The coefficient of correlation is $r=.719$.

(5) Unlike the law of demand for the crops, the law of demand for a representative producers' good is such that as the supply increases the price rises, and as the supply decreases the price falls.

(6) With the falling of the yield per acre of the crops there is a falling volume of trade, a falling price of producer's' goods, an increase in unemployment, and a fall in the yield-price curves for the crops. The contrary conditions prevail under a rising yield per acre of the crops.

(7) The ultimate effect upon general prices of the process described in (6) is that

(a) The deviations of general prices from their general cyclical movement are 
directly correlated with the deviations of the yield per acre of the crops from their general cyclical movement;

(b) When the lag in general prices and the secular trend in both prices and yield per acre are eliminated, the cycles of general prices are very closely correlated with the cycles of the yield per acre of the crops. The coefficient of correlation is $r=.800$.

(8) The law of the cycles of crops is the law of the cycles in the activity of industry and the law of the cycles of general prices.

(9) The fundamental, persistent cause of the cycles in the activity of industry and of the cycles of general prices is the cyclical movement in the yield per acre of the crops. 
128 Economic C'ycles: Their Law and Cause

\section{APPENDIX}

TABLe I.-Index Number of the Yield Per Acre of Crops

\begin{tabular}{|c|c|c|c|c|c|}
\hline YeAr & $\mid \begin{array}{c}\text { INDEX FOR } \\
\text { NINE CROPS }\end{array}$ & $\begin{array}{l}\text { INDEX FOR } \\
\text { FOUR CROPS }\end{array}$ & $Y_{\text {EAR }}$ & \begin{tabular}{|l} 
INDEX FOR \\
NINE CROPG
\end{tabular} & $\begin{array}{l}\text { INDEX FOR } \\
\text { FOUR CROPS }\end{array}$ \\
\hline 1570 & 108 & 109 & 1891 & 108 & 107 \\
\hline 1871 & 105 & 113 & 1892 & 98 & 93 \\
\hline 1872 & 110 & 115 & 1893 & 92 & 95 \\
\hline 1873 & 99 & 98 & 1894 & 90 & 85 \\
\hline 1874 & \&s & 88 & 1895 & 102 & 104 \\
\hline 1475 & 110 & 114 & 1896 & 102 & 111 \\
\hline 1576 & 98 & 101 & 1897 & 102 & 102 \\
\hline 1877 & 106 & 110 & 1898 & 111 & 108 \\
\hline $1 S 78$ & 109 & 113 & 1899 & 105 & 108 \\
\hline 1879 & 111 & 114 & 1900 & 104 & $10 j$ \\
\hline $18 S 0$ & 106 & 107 & 1901 & 89 & 83 \\
\hline 1851 & 82 & 82 & 1902 & 114 & 117 \\
\hline 1852 & 100 & 99 & 1903 & 107 & 111 \\
\hline $1 \times 83$ & 97 & 100 & 1904 & 114 & 117 \\
\hline $1 S S 4$ & 101 & 105 & 1905 & 116 & 121 \\
\hline 18.55 & 98 & $10^{\circ}$ & 1906 & 119 & 120 \\
\hline $1 \times 86$ & 93 & 93 & 1907 & 106 & 107 \\
\hline $18 \$ 7$ & 89 & 85 & $190 \mathrm{~S}$ & 109 & 110 \\
\hline 1 SSS & 100 & 103 & 1909 & 108 & 111 \\
\hline 1889 & 104 & 106 & 1910 & 109 & 113 \\
\hline 1890 & 89 & 86 & 1911 & 99 & 95 \\
\hline
\end{tabular}


Table II.-The General Cyclical Movement and the Differences of the Production of Pig-Iron in the United STATES

\begin{tabular}{|c|c|c|c|c|c|c|c|}
\hline Year & $\begin{array}{l}\text { Produc- } \\
\text { TION OF } \\
\text { PIG-IRON } \\
\text { IN THOU- } \\
\text { SANDS OF } \\
\text { LONG } \\
\text { ToNs }\end{array}$ & $\begin{array}{l}\text { THE GEN- } \\
\text { ERAL CY- } \\
\text { CLICAL } \\
\text { MIOVE- } \\
\text { MENT } \\
\text { (PROGRES- } \\
\text { SIVE AY- } \\
\text { ERAGES OF } \\
\text { THREE } \\
\text { IEARS) }\end{array}$ & \begin{tabular}{|} 
DIFFER- \\
ENCE BE- \\
TWEEN \\
THE AC- \\
TUAL \\
PRODC- \\
TION AND \\
THE GEN- \\
ERAL CY- \\
CLICAL \\
MOVE- \\
MENT
\end{tabular} & Year & $\begin{array}{l}\text { ProdeC- } \\
\text { TION OA } \\
\text { PIO-IRON } \\
\text { IN THOU- } \\
\text { SANDS OF } \\
\text { LONG } \\
\text { ToNs }\end{array}$ & $\begin{array}{l}\text { THE GEN- } \\
\text { ERAL CY- } \\
\text { CLIGAL } \\
\text { MONE- } \\
\text { MENT } \\
\text { (PROGRE- } \\
\text { SIVE AV- } \\
\text { ERAGES OF } \\
\text { THREE } \\
\text { YEARS) }\end{array}$ & $\begin{array}{l}\text { DIFFER- } \\
\text { ENCE BE- } \\
\text { TWEEN THE } \\
\text { ACTUAL } \\
\text { PROLTC- } \\
\text { TION AND } \\
\text { THE GEN- } \\
\text { ERAL CY- } \\
\text { CLICAL } \\
\text { NIOVE- } \\
\text { MENT }\end{array}$ \\
\hline 1870 & $1,66.5$ & & & 1891 & $8,2 \times 0$ & 8,850 & -600 \\
\hline 1871 & 1,707 & 1,974 & & 1892 & 9,157 & 8,187 & +970 \\
\hline 1872 & 2,549 & 2,272 & +277 & 1893 & 7,125 & 7,647 & -522 \\
\hline 1873 & 2,561 & 2,504 & +57 & $1 s 94$ & $6,6.58$ & 7,743 & $-10,5$ \\
\hline 1874 & 2,401 & 2,329 & +72 & 1895 & 9,446 & 8,242 & +1234 \\
\hline 1875 & 2,024 & $2,09 \mathrm{~S}$ & -74 & $1 \$ 96$ & $8,62: 3$ & 9,241 & -619 \\
\hline 1876 & $1, \$ 69$ & 1,987 & -118 & $1 \backslash !)$ & $9,6.53$ & 10,017 & -361 \\
\hline 1877 & $2,06 i 7$ & 2,079 & -12 & 1.s!s & 11,774 & 11,683 & +91 \\
\hline 1878 & 2,301 & 2,370 & -69 & $1 \$ 99$ & 13,621 & 13,061 & +560 \\
\hline 1879 & 2,742 & 2,626 & +116 & 1900 & 13,789 & 14,429 & -640 \\
\hline 1880 & 3,835 & 3,574 & +261 & 1901 & $15,87 \mathrm{~s}$ & $15, \$ 29$ & $+\quad 49$ \\
\hline 1881 & 4,144 & 4,201 & -57 & 1902 & 17,821 & 17,236 & +5.55 \\
\hline 1582 & 4,623 & 4,454 & +169 & 1903 & 18,009 & 17,442 & +567 \\
\hline 1883 & 4,596 & 4,439 & +157 & 1904 & 16,497 & 19,166 & -2669 \\
\hline 1884 & $4,09 \mathrm{~s}$ & 4,246 & -145 & 190.5 & 22,992 & 21,599 & +1393 \\
\hline 188.5 & 4,045 & 4,609 & -564 & 1906 & $2.5,307$ & 21,693 & +614 \\
\hline 1856 & $5,6 \times 3$ & 5,382 & +301 & 1907 & 25,781 & 22,341 & +3440 \\
\hline 1887 & 6,117 & 6,197 & +220 & 1909 & 15,936 & 22,501 & -6.568 \\
\hline $18>S$ & $6,19)$ & $6, \$ 37$ & -347 & 1909 & $25,79.5$ & 23,012 & +2783 \\
\hline $1 S \varsigma 9$ & $\overline{7}, 60) \mathrm{t}$ & 7,766 & -162 & 1910 & $2 \pi, 301$ & $2,, 5 \times 3$ & +1721 \\
\hline $18 ! 0$ & $(1.2193$ & 8.362 & +841 & 1911 & $23,4,50$ & & \\
\hline
\end{tabular}


Table 1II.-The Geneiral Crclical Movement and the Differexces of the Index Number of the Yield Per Acre of Nine Crops

\begin{tabular}{|c|c|c|c|c|c|c|c|}
\hline YEAR & $\begin{array}{c}\text { INDEX OF } \\
\text { Y'IELD } \\
\text { PER } \\
\text { ACRE } \\
\text { (NINE } \\
\text { CROPS) }\end{array}$ & $\begin{array}{l}\text { THE GEN } \\
\text { ERAL CY- } \\
\text { ClICAL } \\
\text { MOVE- } \\
\text { MENT } \\
\text { (PROGRES- } \\
\text { SIVE AY- } \\
\text { ERAGES OF } \\
\text { THREE } \\
\text { YEARS) }\end{array}$ & \begin{tabular}{|} 
DIFFER- \\
ENCE BE- \\
TWEEN THE \\
ACTUAL \\
INDEX AND \\
THE GEN- \\
ERAL CY- \\
CLICAL \\
MOVE- \\
MENT
\end{tabular} & YEAR & $\begin{array}{c}\text { I NDEX OF } \\
\text { YIELD } \\
\text { PER } \\
\text { ACRE } \\
\text { (NINE } \\
\text { CROPS) }\end{array}$ & \begin{tabular}{|} 
THE GEN- \\
ERAL CY- \\
CIICAL \\
MONE- \\
MOENT \\
MROGRE- \\
SIVEAY- \\
ERAGES OF \\
THREE \\
I'EARS)
\end{tabular} & $\begin{array}{l}\text { DIFFER- } \\
\text { ENCE BE- } \\
\text { TWEENTHE } \\
\text { ACTLAL } \\
\text { INDEX AND } \\
\text { THEGEY- } \\
\text { ERAL CY- } \\
\text { CLICAL } \\
\text { MOVE- } \\
\text { MENT }\end{array}$ \\
\hline 1870 & 108 & & & 1891 & $10 \mathrm{~S}$ & 93.3 & +9.7 \\
\hline $1>71$ & 10.5 & 167.7 & -2.7 & 1892 & 9s & 99.3 & -1.3 \\
\hline $1 \times 72$ & 110 & $10 \div .7$ & +5.3 & 1893 & 92 & 93.3 & -1.3 \\
\hline 1873 & 99 & 99.0 & 0.0 & 1894 & 90 & 94.7 & -4.7 \\
\hline $187 t$ & 88 & 99.0 & -11.0 & 1895 & 102 & 98.0 & +4.0 \\
\hline 1875 & 110 & 95.7 & +11.3 & 1896 & 102 & 102.0 & 0.9 \\
\hline 1876 & 98 & 104.7 & -6.7 & 1897 & 102 & 105.0 & -3.7 \\
\hline 1877 & 100 & 104.3 & +1.7 & 1898 & 111 & 100.0 & +5.0 \\
\hline 1878 & 109 & 105.7 & +.3 & 1899 & 105 & 106.7 & -1.7 \\
\hline 1879 & 111 & 10.7 & +2.3 & 1900 & $10 \cdot$ & 99.3 & +4.7 \\
\hline 1880 & $100 ;$ & 99.7 & +6.3 & 1901 & 89 & 102.3 & -13.3 \\
\hline $18 \$ 1$ & 82 & 96.0 & -14.0 & 1902 & $11 t$ & 103.3 & +10.7 \\
\hline 1882 & 100 & 93.11 & +7.0 & 1903 & 107 & 111.7 & -4.7 \\
\hline 1883 & 97 & 99.3 & -2.3 & 1904 & $11 t$ & 112.3 & +1.7 \\
\hline 1884 & 101 & 95.7 & +2.3 & 1905 & 116 & 116.3 & -.3 \\
\hline $18 \$ 5$ & 98 & 97.3 & +.7 & 1906 & 119 & 113.7 & +5.3 \\
\hline 1886 & 93 & 93.3 & -.3 & 1907 & 106 & 111.3 & -5.3 \\
\hline $18 \$ 7$ & 89 & 94.0 & -5.0 & $190 \mathrm{~S}$ & 109 & 107.7 & +1.3 \\
\hline $18 S 8$ & 100 & 97.7 & +2.3 & 1909 & 108 & 108.7 & $-\quad .7$ \\
\hline $18 \$ 9$ & 104 & 97.7 & +6.3 & 1910 & 109 & 105.3 & +3.7 \\
\hline 1890 & 89 & 100.3 & -11.3 & 1911 & 99 & & \\
\hline
\end{tabular}


TABLE IV.-Cycles of Yield Per Acre of Crops and Cycles of Production of Pig-iRon

\begin{tabular}{|c|c|c|c|c|c|c|}
\hline$Y_{\mathrm{EAK}}^{r}$ & $\begin{array}{l}\text { GENERAI } \\
\text { CYCLICAL } \\
\text { MOVE- } \\
\text { MENT } \\
\text { OF YHELD } \\
\text { PER ACRE } \\
\text { OF CROPS }\end{array}$ & $\begin{array}{c}\text { ORDINATE } \\
\text { OF THE } \\
\text { SECULAR } \\
\text { TREND }\end{array}$ & $\begin{array}{l}\text { CYCLES } \\
\text { OF YIELD } \\
\text { PER ACRE } \\
\text { OF CROPS }\end{array}$ & $\mid \begin{array}{c}\text { GENERAL } \\
\text { CYCLCAL } \\
\text { AOVEMENT } \\
\text { OF PRODCC- } \\
\text { TION OF PIG- } \\
\text { IRON, IN } \\
\text { THOVSAND } \\
\text { OF TONS }\end{array}$ & $\begin{array}{c}\text { ORdiNate } \\
\text { OF THE } \\
\text { SECULAR } \\
\text { TrEND }\end{array}$ & $\begin{array}{l}\text { CYCles OF } \\
\text { ProDUCTION } \\
\text { OF PtG-iRON }\end{array}$ \\
\hline 1871 & $107 . \overline{7}$ & 94.6 & +9.1 & 1,974 & $-1,546$ & $+3,520$ \\
\hline 1872 & 104.7 & 9.5 & +5.9 & 2,272 & 964 & $+3,236$ \\
\hline 1873 & 99.0 & $9 \varsigma .9$ & +.1 & 2,504 & 381 & $+2,855$ \\
\hline 1874 & 99.0 & 99.1 & -.1 & 2,329 & 202 & $+2,127$ \\
\hline 1875 & 95.7 & 99.3 & - . .4 & 2,098 & $7 s t$ & $+1,314$ \\
\hline 1876 & 104.7 & 99.5 & +5.2 & $1,98 \mathrm{i}$ & 1,367 & +620 \\
\hline 1877 & 104.3 & 99.7 & +4.6 & 2,079 & 1,950 & +129 \\
\hline 1878 & 108.7 & 99.9 & +8.8 & 2,370 & 2,532 & -162 \\
\hline 1879 & 108.7 & 100.0 & +8.7 & 2,626 & 3,115 & -489 \\
\hline 1880 & 99.7 & 100.2 & -.5 & 3,574 & 3,698 & -124 \\
\hline 1881 & 96.0 & 100.4 & -4.4 & 4,201 & 4,281 & $-\quad s 0$ \\
\hline 1882 & 930 & 100.6 & -7.6 & 4,454 & 4,863 & -409 \\
\hline 1883 & 99.3 & 100.9 & -1.6 & 4,439 & 5,446 & $-1,007$ \\
\hline 1884 & 98.7 & 101.0 & -2.3 & 4,246 & $(6,029)$ & $-1,78: 3$ \\
\hline 185.5 & 97.3 & 101.2 & -3.9 & 4,609 & 6,611 & $-2,002$ \\
\hline 1886 & 93.3 & 101.3 & -8.0 & 5,382 & 7,194 & $-1,812$ \\
\hline 1887 & 94.0 & 101.5 & -7.5 & 6,197 & 7,777 & $-1,5)(0)$ \\
\hline 1888 & 97.7 & 101.7 & -4.0 & 6,837 & $8,3(i)$ & $-1,5: 3$ \\
\hline 1889 & 97.7 & 101.9 & -4.2 & 7,766 & 8,942 & $-1,176$ \\
\hline 1890 & 100.3 & 102.1 & -1.8 & 8,362 & 9,525 & $-1,163$ \\
\hline 1891 & 98.3 & 102.3 & -4.0 & S,SSO & $10,10 \mathrm{~s}$ & S', \\
\hline 1892 & 99.3 & 102.4 & -3.1 & $S, 1 s 7$ & 10,690 & $-2,503$ \\
\hline 1893 & 93.3 & 102.6 & -9.3 & 7,647 & 11,273 & $-3,626$ \\
\hline 1894 & 94.7 & 102.5 & -8.1 & $7,7+3$ & $11,5,56$ & $-4,112$ \\
\hline 1895 & 98.0 & 103.0 & -5.0 & $8,2+2$ & 12,439 & $-4,197$ \\
\hline 1896 & 102.0 & 103.2 & -1.2 & $9,2+1$ & 13,021 & $-3,780$ \\
\hline 1897 & 105.0 & 103.4 & +1.6 & 10,017 & 13,604 & $-3,587$ \\
\hline 1598 & 106.0 & 103.5 & +2.5 & 11,683 & $14,18 \mathrm{i}$ & $-2,504$ \\
\hline 1899 & 106.7 & 103.7 & +3.0 & 13,061 & 14,760 & $-1,70 \mathrm{~s}$ \\
\hline 1900 & 99.3 & 103.9 & -4.6 & 14,429 & 15,352 & -923 \\
\hline 1901 & 102.3 & 104.1 & -1.8 & 15,829 & 15,935 & -106 \\
\hline 1902 & 103.3 & 104.3 & -1.0 & 17,236 & $16,51 \mathrm{~s}$ & +718 \\
\hline 1903 & 111.7 & 104.5 & +7.2 & $17,+42$ & 17,100 & +342 \\
\hline 1904 & 112.3 & 101.7 & +7.10 & 19,166 & $17,6, \cdots, 3$ & $+1,4 \div 3$ \\
\hline $19(35$ & 116.3 & 104.8 & +11.5 & 21,599 & $14,20 t$ & $+0.3: 3.3$ \\
\hline $1 !)(1) 6$ & $11: 7$ & 10.5 .0 & +8.7 & 21,693 & 1২,২4く & +.5 .45 \\
\hline 1907 & 111.3 & 10.5 .2 & +6.1 & $22,3+11$ & $19,4: 31$ & $+2,910$ \\
\hline 1908 & 107.7 & 111.5 .4 & +2.3 & 22,501 & 20,011 & +2.4190 \\
\hline $19(7)$ & $11 x .7$ & $10 . \overline{5} . \overline{5}$ & +3.2 & 23,012 & 20,596 & $+2,4 \mathrm{ll}$ \\
\hline 19)10 & $10 \pi .3$ & $10) ; .7$ & - . .1 & $25,5<3$ & 21,179 & $+4,104$ \\
\hline
\end{tabular}


Table 1.-Percentage Change in the Production of Pigiron and Mean Percentage Change in the Price of Pig-iron

\begin{tabular}{|c|c|c|c|c|c|c|}
\hline \multirow[b]{2}{*}{ YEAR } & \multirow{2}{*}{$\begin{array}{c}\text { PERCENT- } \\
\text { TAGE } \\
\text { ChANGE IN } \\
\text { THE Pro- } \\
\text { DUCTION OF } \\
\text { PIO-IRON }\end{array}$} & \multicolumn{4}{|c|}{ Percentage Change in the Price of Pio-iron } & \multirow{2}{*}{$\begin{array}{c}\text { MEAN } \\
\text { PERCENT } \\
\text { AGE } \\
\text { CHANGE IN } \\
\text { PrICE OF } \\
\text { PIG-IRON }\end{array}$} \\
\hline & & $\begin{array}{c}\text { No. I } \\
\text { FOUNDRY } \\
\text { AT PHILA- } \\
\text { DELPHIA }\end{array}$ & $\begin{array}{c}\text { GRAY } \\
\text { FORGE AT } \\
\text { PHILADE- } \\
\text { PHIA }\end{array}$ & $\begin{array}{c}\text { GraY } \\
\text { ForGE } \\
\text { LAKE ORE } \\
\text { AT PITTS- } \\
\text { BURG }\end{array}$ & $\begin{array}{c}\text { BEssemer } \\
\text { AT } \\
\text { PITTSBUR }\end{array}$ & \\
\hline 1870 & & & & & & \\
\hline 1871 & +2.52 & +5.57 & & & & +5.57 \\
\hline 1872 & +49.33 & +39.51 & & & & +39.51 \\
\hline 1873 & +.47 & -12.57 & & & & -12.57 \\
\hline 1874 & -6.25 & -29.45 & & -24.13 & & -26.79 \\
\hline 1875 & -15.70 & -15.44 & & -12.85 & & -14.14 \\
\hline 1876 & -7.66 & $-13.0 \mathrm{~s}$ & & -8.15 & & -10.61 \\
\hline 1677 & +10.59 & -14.74 & & -5.24 & & -9.99 \\
\hline 1878 & +11.32 & -6.61 & & -12.18 & & -9.39 \\
\hline 1879 & +19.17 & +22.92 & & +22.44 & & +22.68 \\
\hline 1880 & +39.86 & +31.12 & & +26.32 & & +28.72 \\
\hline $1 S \$ 1$ & +8.06 & -11.62 & & -18.01 & & -14.82 \\
\hline 1882 & +11.56 & +2.38 & & +3.92 & & +3.15 \\
\hline 1893 & -.58 & -13.00 & -14.47 & -20.13 & & -15.87 \\
\hline 1884 & -10.84 & -11.64 & -8.38 & -9.82 & & -9.95 \\
\hline 1885 & -1.29 & -9.14 & -12.03 & -11.07 & & -10.75 \\
\hline 1886 & +41.61 & +4.00 & +5.26 & +8.58 & & +5.95 \\
\hline 1887 & +12.92 & +11.87 & +8.48 & +14.72 & +12.71 & +11.95 \\
\hline 1888 & +1.14 & -9.79 & -8.88 & -15.93 & -18.67 & -13.32 \\
\hline 1889 & +17.16 & -5.93 & -4.50 & -4.00 & +3.57 & -2.72 \\
\hline 1890 & +21.03 & +3.66 & +2.20 & +2.80 & $\begin{array}{r}+4.83 \\
\end{array}$ & +3.37 \\
\hline 1891 & -10.03 & -4.83 & -8.22 & -10.90 & -15.47 & -9.85 \\
\hline 1892 & +10.59 & -10.10 & -6.75 & -8.89 & -9.91 & -8.91 \\
\hline 1893 & -22.19 & -7.81 & -5.98 & -8.12 & -10.44 & -8.09 \\
\hline 1894 & -6.55 & -12.81 & -15.71 & -17.16 & -11.58 & -14.32 \\
\hline 1895 & +41.87 & $\begin{array}{r}+3.48 \\
\end{array}$ & +7.08 & +12.21 & +11.78 & +8.64 \\
\hline 1896 & -8.71 & -1.15 & -3.48 & -5.03 & -4.56 & -3.55 \\
\hline 1897 & +11.94 & -6.56 & -5.50 & -13.09 & -16.56 & -10.43 \\
\hline 1898 & +21.97 & -3.64 & -2.39 & +1.66 & +1.97 & -.60 \\
\hline 1899 & +15.70 & +66.04 & +62.27 & +82.14 & +84.22 & +73.67 \\
\hline 1900 & +1.23 & +3.20 & $\therefore \quad .66$ & +1.08 & +2.42 & +1.51 \\
\hline 1901 & +15.15 & -20.57 & -14.61 & -15.98 & -18.27 & -17.36 \\
\hline 1902 & +12.24 & +39.82 & +36.36 & +37.25 & +29.76 & +35.80 \\
\hline $19(03$ & +1.05 & -10.23 & -10.78 & -10.11 & -8.18 & -10.07 \\
\hline 1904 & -8.40 & -21.84 & -20.20 & -26.43 & -27.50 & -23.99 \\
\hline 190.5 & +39.37 & +14.84 & +13.97 & +21.18 & +18.90 & +17.22 \\
\hline 1906 & +10.07 & +17.34 & +14.18 & +16.45 & +19.44 & +16.85 \\
\hline 1907 & +1.87 & +13.87 & +18.38 & +18.31 & +16.89 & +16.86 \\
\hline $190 \mathrm{~S}$ & -38.19 & -2591 & -25.30 & -29.23 & -25.26 & $-26.44^{\prime}$ \\
\hline 1909 & +01.87 & $+\quad 62$ & +2.61 & +2.10 & +1.99 & +1.83 \\
\hline 1910 & +5.85 & -2.53 & -2.54 & -1.99 & -1.26 & -2.08 \\
\hline 1911 & -13.35 & -9.50 & -8.21 & -8.33 & -8.61 & -8.60 \\
\hline 1912 & +25.70 & +5.41 & +6.65 & +4.09 & +1.46 & +4.40 \\
\hline
\end{tabular}


TABLe VI.-The Index Number of General Prices. Its (ieneral Cyclical Monement and its Differences

\begin{tabular}{|c|c|c|c|c|c|c|}
\hline YeAr & $\begin{array}{l}\text { FALKNER'S } \\
\text { INDEX OF } \\
\text { PRICES OF } \\
\text { "AILAR- } \\
\text { TICLES" }\end{array}$ & $\begin{array}{l}\text { BUREAE OF } \\
\text { LABOR'S } \\
\text { INDEX OF } \\
\text { PRICES OF } \\
\text { "ALL COY } \\
\text { MODITIES" }\end{array}$ & \begin{tabular}{|} 
FALKNER'S \\
INDEX \\
ADJUTED \\
TO THE \\
BASE OF \\
THE BUR- \\
EAU OF \\
LABOR
\end{tabular} & $\begin{array}{l}\text { THE CON- } \\
\text { TINCOF' } \\
\text { I YDEX OF } \\
\text { PrRCE. }\end{array}$ & $\begin{array}{l}\text { GENERAL } \\
\text { CYCLITAL } \\
\text { MOVEVEYT } \\
\text { OF THE } \\
\text { CONTINe- } \\
\text { OCO INDEX } \\
\text { OF PIICES }\end{array}$ & $\begin{array}{l}\text { DIFFEREXCE } \\
\text { BETHEEX } \\
\text { THE ACTLAL } \\
\text { INDEX AND } \\
\text { THF CiEN } \\
\text { ERAL CY } \\
\text { CIICAL } \\
\text { MOVEMENT }\end{array}$ \\
\hline 1870 & 117.3 & & 143.5 & 143.5 & & \\
\hline 1871 & 122.9 & & 150.3 & 150.3 & $1+9.8$ & $+i$ \\
\hline 1872 & 127.2 & & 155.6 & 155.6 & 151.7 & +3.9 \\
\hline 1873 & 122.0 & & 149.2 & 149.2 & 150.3 & -1.1 \\
\hline 1874 & 119.4 & & 146.0 & 146.0 & 144.6 & +1.4 \\
\hline 1875 & 113.4 & & 138.7 & 138.7 & 137.6 & +1.1 \\
\hline 1876 & 104.8 & & 125.2 & 129.2 & 131.5 & -3.3 \\
\hline 1877 & 104.4 & & 127.7 & 127.7 & 120.0 & +1.7 \\
\hline 1878 & 99.9 & & 122.2 & 122.2 & 122.7 &.$- j$ \\
\hline 1879 & 96.6 & & 115.2 & 118.2 & $12: 3.7$ & ד. \\
\hline 1880 & 106.9 & & 130.8 & 130.8 & 126.1 & +4.7 \\
\hline 1881 & 105.7 & & 129.3 & 129.3 & 130.9 & $-1.1 ;$ \\
\hline 1882 & 108.5 & & 132.7 & 132.7 & 130.6 & +2.1 \\
\hline 1883 & 106.0 & & 129.7 & 129.7 & 120.0 & +1.7 \\
\hline 1884 & 99.4 & & 121.6 & 121.6 & 121.7 & -.1 \\
\hline 1885 & 93.0 & & 113.8 & 113.8 & 115.9 & —2.1 \\
\hline 1886 & 91.9 & & 112.4 & 112.4 & 113.2 & 一.s \\
\hline 1887 & 92.6 & & 113.3 & 113.3 & i13.6; & -.3 \\
\hline 1855 & 94.2 & & 115.2 & 115.2 & $11+6$ & +6 \\
\hline 1889 & 94.2 & & 115.2 & 115.2 & 114.1 & $+\ldots$ \\
\hline 1590 & 92.3 & 112.9 & & 112.9 & 113.3 & -.4 \\
\hline 1891 & & 111.7 & & 111.7 & 110.2 & +1.5 \\
\hline 1892 & & 106.1 & & 106.1 & $107 . s$ & -1.7 \\
\hline 1893 & & 105.6 & & 105.6 & 102.6 & +3.0 \\
\hline 1894 & & 96.1 & & 96.1 & 9 গ. 4 & -2.3 \\
\hline $189 \tilde{3}$ & & 93.6 & & 93.6 & 93.4 & +.2 \\
\hline $1 \diamond 96$ & & 90.4 & & 90.4 & 91.2 & - S \\
\hline 1897 & & 89.7 & & 89.7 & 91.2 & -1.5 \\
\hline 1898 & & 93.4 & & 93.4 & 94.9 & -1.5 \\
\hline 1899 & & 101.7 & & 101.7 & 101.9 & -2 \\
\hline 1900 & & 110.5 & & 110.5 & $10 . ; .9$ & +3.6 \\
\hline 1901 & & 105.5 & & 10.5 & 110.6 & -2.1 \\
\hline 1902 & & 112.9 & & 112.9 & 111.7 & +1.2 \\
\hline 1903 & & $113.6 \mathrm{j}$ & & 113.6 & 113.2 & +.4 \\
\hline 1904 & & 113.0 & & 113.0 & 114.2 & -1.2 \\
\hline 190,5 & & 115.9 & & 115.9 & 117.1 & -1.2 \\
\hline 1906 & & 122.5 & & 122.5 & 122.6 & -.1 \\
\hline 1907 & & $129 . \overline{5}$ & & ) & 124.9 & +46 \\
\hline $190 \mathrm{~S}$ & & 122.8 & & 122.8 & 129.3 & -3.5 \\
\hline $19(19)$ & & 126.5 & & 120.5 & $1: 7.0$ & -5 \\
\hline 1910 & & 131.6 & & 131.6 & 129.1 & +2.5 \\
\hline 1911 & & 129.3 & & 129.3 & & \\
\hline
\end{tabular}


134 Economic Cycles: Their Law and Cause

TABle VII.-Cycles of Yield Per Acre of Crops and Cycles of General Prices

\begin{tabular}{|c|c|c|c|c|c|c|}
\hline YEAR & $\begin{array}{c}\text { GeNeral } \\
\text { CrCLICAL } \\
\text { MONe- } \\
\text { MENT OF } \\
\text { YELD PER } \\
\text { ACRE OF } \\
\text { CROPS }\end{array}$ & $\begin{array}{c}\text { ORdinates } \\
\text { OF TIIE } \\
\text { SECULAR } \\
\text { TrEND }\end{array}$ & $\begin{array}{l}\text { CYCLES OF } \\
\text { THE YIELD } \\
\text { PER ACRE } \\
\text { OF CROPS }\end{array}$ & $\begin{array}{c}\text { General } \\
\text { CrClical } \\
\text { Move- } \\
\text { MENT of } \\
\text { Generai } \\
\text { Prices }\end{array}$ & $\begin{array}{c}\text { ORDINATES } \\
\text { OF THE } \\
\text { SECULAR } \\
\text { TREND }\end{array}$ & $\begin{array}{c}\text { Crcles of } \\
\text { General } \\
\text { Prices }\end{array}$ \\
\hline 1871 & 107.7 & 98.6 & +9.1 & 149.8 & 123.5 & +26.3 \\
\hline 1872 & 104.7 & 98.8 & +5.9 & 151.7 & 123.1 & $+2 S .6$ \\
\hline 1573 & 99.0 & 98.9 & $+\quad .1$ & 150.3 & 122.8 & +27.5 \\
\hline 1874 & 99.0 & 99.1 & 一 .1 & 144.6 & 122.4 & +22.2 \\
\hline 1875 & 98.7 & 99.3 & -.4 & 137.6 & 122.0 & +15.6 \\
\hline 1876 & 104.7 & 99.5 & +5.2 & 131.5 & 121.6 & +9.9 \\
\hline 1877 & 104.3 & 99.7 & +4.6 & 126.0 & 121.3 & +4.7 \\
\hline 1578 & 108.7 & 99.9 & +8.8 & 122.7 & 120.9 & +1.8 \\
\hline 1879 & 108.7 & 100.0 & +8.7 & 123.7 & 120.5 & +3.2 \\
\hline $18 s 0$ & 99.7 & 100.2 & -.5 & 126.1 & 120.2 & +5.9 \\
\hline $1 S \$ 1$ & 96.0 & 100.4 & -4.4 & 130.9 & 119.8 & +11.1 \\
\hline 1882 & 93.0 & 100.6 & -7.6 & 130.6 & 119.4 & +11.2 \\
\hline 1883 & 99.3 & 100.9 & -1.6 & 128.0 & 119.0 & +9.0 \\
\hline 1884 & 98.7 & 101.0 & -2.3 & 121.7 & 118.7 & +3.0 \\
\hline 1885 & 97.3 & 101.2 & -3.9 & 115.9 & 118.3 & -2.4 \\
\hline $18 \times 6$ & 93,3 & 101.3 & -8.0 & 113.2 & 117.9 & -4.7 \\
\hline $18 \times 7$ & 94.0 & 101.5 & -7.5 & 113.6 & 117.6 & -4.0 \\
\hline 1885 & 97.7 & 101.7 & -4.0 & 114.6 & 117.2 & -2.6 \\
\hline 1889 & 97.7 & 101.9 & -4.2 & 114.4 & 116.8 & -2.4 \\
\hline 1890 & 100.3 & 102.1 & -1.8 & 113.3 & 116.5 & -3.2 \\
\hline $1 \$ 91$ & $9 S .3$ & 102.3 & -4.0 & 110.2 & 116.1 & -5.9 \\
\hline 1892 & 99.3 & 102.4 & -3.1 & 107.8 & 115.7 & -7.9 \\
\hline 1893 & 93.3 & 102.6 & -9.3 & 102.6 & 115.3 & -12.7 \\
\hline 1594 & 94.7 & 102.8 & -8.1 & 98.4 & 115.0 & -16.6 \\
\hline 1895 & 95.0 & 103.0 & -5.0 & 93.4 & 114.6 & -21.2 \\
\hline $1 \$ 96$ & 102.0 & 103.2 & -1.2 & 91.2 & 114.2 & -23.0 \\
\hline 1897 & 105,0 & 103.4 & +1.6 & 91.2 & 113.9 & -22.7 \\
\hline $189 \mathrm{~s}$ & 106.0 & 103.5 & +2.5 & 94.9 & 113.5 & -18.6 \\
\hline 1899 & 106.7 & 103.7 & +3.0 & 101.9 & 113.1 & -11.2 \\
\hline 1900 & 99.3 & 103.9 & -4.6 & 106.9 & $112 . \mathrm{S}$ & -5.9 \\
\hline 1901 & 102.3 & 104.1 & -1.8 & 110.6 & 112.4 & -1.8 \\
\hline 1902 & $10: 3.3$ & 104.3 & -1.0 & 111.7 & 112.0 & $-\quad .3$ \\
\hline 1903 & 111.7 & 104.5 & +7.2 & 113.2 & 111.6 & +1.6 \\
\hline 1904 & 112.3 & 104.7 & +7.6 & 114.2 & 111.3 & +2.9 \\
\hline 1905 & 116.3 & 10.8 & +11.5 & 117.1 & 110.9 & +6.2 \\
\hline 1906 & 113.7 & 105.0 & +8.7 & 122.6 & 110.5 & +12.1 \\
\hline 1907 & 111.3 & 105.2 & +6.1 & 124.9 & 110.2 & +14.7 \\
\hline 1908 & 107.7 & 105.4 & +2.3 & 126.3 & 109.8 & +16.5 \\
\hline 1909 & 108.7 & $10 \pi .5$ & +3.2 & 127.0 & 109.4 & +17.6 \\
\hline 1910 & 105.3 & $10 \% .7$ & - .4 & 129.1 & 109.0 & +21.1 \\
\hline
\end{tabular}




\section{CHAPTER VI \\ SUMMARY AND CONCLUSIONS}

These cycles of crops constitute the natural, material current which drags upon its surface the lagging, rhythmically changing values and prices with which the economist is more immediately concerned.

The principal contribution of this Essay is the discovery of the law and cause of Economic Cycles. The rhythm in the activity of economic life, the alternation of buoyant, purposeful expansion with aimless depression, is caused by the rhythm in the yield per acre of the crops; while the rhythm in the production of the crops is, in turn, caused by the rhythm of changing weather which is represented by the cyclical changes in the amount of rainfall. The law of the cycles of rainfall is the law of the cycles of the crops and the law of Economic Cycles.

We shall recapitulate the main stages by which this conclusion was reached and shall take occasion, as the stages are reviewed, to suggest the care that must be observed in interpreting the statistical generalizations which form the structure of the argument.

When we begin to think seriously about the cause of Economic Cycles we are greatly impressed by the wide diffusion of these cyclical movements among the peoples of the world, and the inference appears to be inevitable that there must be some physical cause at work to 
account for so general a movement. As the most fundamental need of mankind is the need for food, it seems probable that the observed rhythmical economic changes may be produced by the physical cause through its effect upon the food supply. If this be so, then, as the fluctuations of the food supply are known to be subject to the supposed caprices of the weather, it seems not unlikely that the physical cause may be one or more of the elemental forces that are summarized under the term weather. The variation in the quantity of the rainfall is one of the weather changes known to have a marked effect upon the yield of the crops, and if this fact is taken into consideration with the preceding reasoning, we have a working theory as to the cause of Economic Cycles: The changes in the weather represented by the changes in the quantity of rainfall cause the changes in the yield per acre of the crops, and the variations in the yield of the crops cause the economic changes known as Economic Cycles. With this working theory in mind, we examined appropriate data with reference to three things: (1) The periodicity of rainfall; (2) the effect of rainfall on the crops; (3) the relation of the yield of the crops to Economic Cycles.

First, then, as to the periodicity of rainfall. The problem as to whether the quantity of rainfall passes through definite cycles involves two practical questions that affect the utility and the validity of the results that may be attained. These questions are, first, as to what rainfall data shall be used in the investigation of possible rainfall cycles; and, second, as to the method that shall 
be adopted to establish the existence of the cycles and to ascertain their characteristic lengths, amplitudes and phases. In our investigation, the choice of rainfall data was suggested by the scope of our general problem. Supposing that we could find definite periods in the varying amount of the rainfall, we should then desire to know the relation of rainfall to the yield of the crops, and the relation of the yield of the crops to Economic Cycles. It was necessary, therefore, that the data of rainfall should refer to an area in which important crops are produced, and it was desirable that the data of both rainfall and crops should refer to a highly dynamic society. For these reasons we collected the material for our investigation from the central part of the United States.

The method adopted in an investigation of the periodicity of rainfall must satisfy three conditions: (1) It must exhaust the data in the search for possible cycles; that is to say, the data must be made to yield all the truth they contain relating to the particular problem in hand. Frequently in the past, spurious periodicities have been presented as real periodicities, chiefly because the investigator started with a bias in favor of a particular period and did not pursue his researches sufficiently far to determine whether his result was not one among many spurious, chance periodicities contained in his material. In the search for real periodicities the data must be exhaustively analyzed. (2) The method must render possible the discrimination between a true periodicity, having its 
origin in a natural cause and persisting with a change in the samples of statistics, and a spurious periodicity which is purely formal, having its origin in accidental characteristics of the statistical sample and disappearing, or radically altering its character, when different samples of statistics are made the basis of the computation. (3) The method must not only make possible the isolation of real periodicities, but it must likewise enable one to determine their essential characteristics, their length, phases and amplitudes. The method we adopted in our researches, which is based upon the harmonic analysis, satisfies these three conditions.

The result of our investigation as to the periodicity of rainfall in the upper Mississippi Valley was the discovery that the annual rainfall passes through two cycles of approximately thirty-three years and eight years in length. The amplitude and phases of these two cycles were ascertained, and the equations to the separate cycles were calculated. The two cycles were then superposed, thus giving the general cyclical movement of rainfall; the equation of this compound cycle was computed and the graph was drawn. It was found that the curve of the rhythmical movement of rainfall computed from the equation to the superposed cycles fitted excellently well the actual observations of rainfall. These results constitute the solution of the first part of our general problem: Rainfall in the principal crop area of the United States passes through cycles of thirtythree years and of eight years.

The caution that should be observed in the use of our 
conclusions is suggested by the method that was employed and the subject that was investigated. The inquiry is a statistical study of an aspect of meteorology, and, therefore, the caution to be exercised in the use of the conclusions is the caution that should be applied to statistical work in general and to meteorology in particular. As far as the statistical work is concerned, it should be observed that the data were drawn from a limited area of the United States and covered, at most, seventy-two years. Consequently, while there seem to be very good reasons in favor of the belief that, for the purpose for which they were used, the data were representative of the whole country, it is highly desirable that similar studies should be made for other places and other times. Furthermore, the present investigation was limited to a study of the periodicity of rainfall, but a more adequate research would embrace the periodicity of temperature and of other weather elements, together with an investigation of the interrelation of the elements. Before passing on to consider the caution to be observed in the use of statistical studies of meteorology, a word should be said in justification of the limitation of the inquiry to the periodicity of annual rainfall. The object of taking annual rainfall was to ascertain the mean periodicity of the rainfall of the critical seasons of the several crops. It would have been more satisfactory to investigate the periodicity of the rainfall of the critical season in arse of each (rop, but, because of the extreme laboriousness of the calculations, a device had to be adopted to limit the amount of computation. 
In regard to the use of statistical generalizations in meteorology, we have the cautious opinion of Lord Kelvin: "I cannot say whether anything with reference to Terrestrial Meteorology is done once for all. I think probably the work will never be done." 'There is always need of checking up statistical conclusions in the light of new data, and this necessity applies to the generalization that in the Mississippi Valley the annual rainfall passes through a double cycle of thirty-three years and eight years. This conclusion is undoubtedly warranted by the data that lie at the basis of the investigation, but it would be a grave fault, indeed, to hold that the cycles do not alter with the flow of time. Whether they change or retain their characteristics can be determined only by accumulating more data than are at present available.

We come now to the second part of our general problem, namely, to the consideration of the relation between rainfall and the yield of the crops, and again the questions of data and method must be settled. In choosing the data, the prime consideration was to make sure that the crops selected should be representative of the conditions of crop-producing in the Middle West. The five principal crops in the Middle West are corn, hay, wheat, oats, and potatoes, and of these five all except wheat were taken to serve as representative crops. Wheat was omitted because of technical difficulties: First, it is impossible, except for recent years, to separate in the published statistics the yield per acre 
of spring wheat from the yield of winter wheat; and, secondly, since the growth seasons and critical periods of these two varieties of wheat are different, it seemed unwise to attempt to connect the rainfall of any season with the yield per acre of wheat in which the figures for the yield referred to spring and winter wheat taken together. For these reasons the representative crops were limited to corn, hay, oats, and potatoes; and the yield per acre of these several crops throughout a long period of time, together with the rainfall of their respective critical seasons, form the numerical data of the investigation.

The method of determining the critical seasons was to find, by the use of the statistical theory of correlation, the month or months, in the lifetime of the several crops, the rainfall of which gave the highest correlation with the ultimate yield. This preliminary inquiry afforded a partial answer to our general question as to the relation between rainfall and the crops. We found that in case of each of the crops the yield per acre is directly connected with the rainfall of some critical period, and in all of the crops except oats the connection is very close. It seemed probable, therefore, that since the rainfall passes through definite cycles, and since the yield per acre of the crops is intimately related with the rainfall of their respective critical seasons, the yield per acre of the crops should likewise pass through the double cycle described by the rainfall of the critical seasons.

The investigation of the relation of the cycles of the 
crops to the cycles of the rainfall of the critical seasons was carried out in two ways, first for the crops taken singly, and then for the crops taken all together. In the inquiry relating to the separate crops, the equations to the double cycle in the yield per acre and to the double cycle in the rainfall of the corresponding critical seasons were computed, and the graphs were drawn. When the graphs of the cycles of the crops were superposed upon the graphs of the cycles of rainfall of the respective critical seasons, the two curves were found to present a very remarkable congruence. In the inquiry relating to the crops taken all together, an index number of the yield per acre of the crops and an index number of the mean effective rainfall of the critical seasons were constructed. The equations to the double cycle in both indices were computed, their graphs were drawn and then superposed. It was found that the characteristic features of the rainfall curve were reproduced in the curve of the index number of the yield per acre of the crops.

These results, referring both to the crops taken singly and to the crops taken all together, are the answers to the second part of our general question: The yield per acre of the representative crops is closely connected statistically with the rainfall of the respective critical seasons, and the relation is so close that the cycles of the yield per acre of the crops reproduce in characteristic ways the cycles of the rainfall of the critical seasons. The fundamental, persistent cause of the cycles of crops is, therefore, the rhythmical movement 
in the conditions of the weather represented by the cycles in the amount of rainfall.

In the cautious use of the preceding generalizations, one will bear in mind that only four crops have been investigated, and that, in ascertaining the critical seasons, the monthly rainfall has been used. The critical seaons could undoubtedly be determined more accurately if the figures for the weekly rainfall were employed. Furthermore, the inquiry has been limited to the relation of the yield of the crops to rainfall, whereas a more adequate study would include at least the effects of temperature.

Thus far the investigation has established the law and cause of the cycles of the crops: The cause of the cycles in the physical productivity of the crops is the cyclical variation of the weather represented by the cycles of rainfall, and the law of the cycles of rainfall is the law of the cycles of the crops. In order to bring these physical results into relation with the rhythmical movements of prices and values, we had first to show how the prices of the several crops vary with their respective supplies. In technical terms, we had to discover the laws of demand for the individual crops.

The equations to the law of demand for corn, hay, oats, and potatoes were computed, and the graphs were drawn. The degree of precision with which these demand curves might be used as formulæ for predicting prices was ascertained, and the coefficients of the elasticity of demand for the representative commodities 
were calculated. The equations to the law of demand for all four crops conformed to a single type, indicating that as the supply of the commodity increases, the price falls. For reasons that were explained in the discussion, we named this type of demand curve the negative type.

It will be recalled that the three divisions of our general problem were (1) the periodicity of rainfall; (2) the effect of rainfall upon the crops; and (3) the relation of the yield of the crops to Economic Cycles. The elaboration of a method for calculating the demand curves placed us in position to examine the third and final part of the problem. The law of demand for the crops connects the price of the several crops with their respective supplies, but the supply is dependent upon both the yield per acre and the extent of the acreage. In order to bring our findings with regard to the periodicity in the yield per acre into relation with prices and values, it is clear that we must know the relation between the variation in the price of the commodity and the yield per acre of the commodity. This question we examined at length, and found the tie between price and yield per acre to be as close as the tie between price and supply. To differentiate between demand curves and curves showing the relation between yield per acre and price, we called the latter curves, yieldprice curves. We deduced the equations to the yieldprice curves for the four representative commodities and measured the degree of precision with which their equations might be used as formulæ for predicting 
prices. In all of these relations, the yield-price curves were found to be as accurate and as satisfactory as the demand curves themselves.

With the possession of the yield-price curves, showing the relation between the prices of the crops and their varying yield per acre, it might seem that the problem of agricultural cycles at least was completely elucidated. As we know how the periodicity in the yield of the crops follows upon the periodicity in the rainfall, and how the prices vary with the yield, one might conclude that the course of prices could be predicted for a long time. The inference would be entirely true but for the fact that the demand curves and the yield-price curves move alternately up and down with the flow of time. This complication made it necessary to investigate the rhythmical movement of the yield-price curves, and we found that the demand curves, or yield-price curves, rise or fall with the level of general prices and with the level of the index of the yield per acre of the crops.

The preceding facts seemed to involve a contradiction with an a priori doctrine of theoretical economics. According to the economic dogma of the uniformity of the demand function, all demand curves are of the negative type: As the amount of the commodity increases, the price falls. But if this be true, how is it possible for a fall of general prices to accompany a fall in the index of the yield per acre of the crops? If the yield per acre of the crops decreases, then, according to the yield-price curves and the demand curves, the price of the crops will rise. Moreover, as the profits of trade 
and commerce are largely dependent upon the volume of the crops, it seems likely that the demand for general commodities would decrease with a deficiency in the harvests, and, according to the dogma of the uniformity of the demand function, the prices of general commodities should rise. The ultimate result of bad harvests, therefore, would be a rise in general prices. The facts, however, bear out the contrary view. General prices fall with a decrease in the yield per acre of the crops.

A consideration of this difficulty led to the discovery that there is a positive type of demand curve as well as a negative type. For a representative producer's good, for example pig-iron, the law of demand is such that as the amount of commodity increases the price of the commodity rises, and as the amount of the commodity decreases the price of the commodity falls. The existence of both positive and negative types of demand in a highly dynamic society suggested a working theory which seemed to account for the interrelation of all the known relevant facts, and which may be stated in compact form. The rhythmically varying yield per acre of the crops is the cause of Economic Cycles: When the yield increases, the volume of trade, the activity of industry and the amount of employment increase; the demand for producers' goods increases and the prices of producers' goods rise; the demand curves for agricultural commodities rise; with the ultimate result of a rise of general prices. The contrary changes would follow upon a fall in the yield per acre of the crops. 
Beyond what we had already established, this theory of the interrelation of economic changes required for its complete demonstration the proof of the existence of two fundamental relations, to wit, that the cycles in the yield per acre of the crops are reproduced

(1) in the activity of general industry;

(2) in the movement of general prices.

In order to test whether these relations actually exist, an index number of the yield per acre of the crops was constructed for the nine crops, corn, wheat, oats, barley, rye, buckwheat, hay, cotton, and potatoes. To make sure of keeping close to the results already established for the representative commodities corn, hay, oats, and potatoes, the correlation of the index of the nine crops with the inclex of the four representative crops was computed and found to be $r=.960$.

As the production of pig-iron is generally regarded as a good "barometer" of the activity of industry, we sought an answer to the above first question by investigating whether the cycles in the yield per acre of the nine crops were reproduced in the cycles in the production of pig-iron. The inquiry involved the problems of the separation of the cyclical and the secular movements in the production of pig-iron, and the ascertainment of the amount of the lag in the cycles of pig-iron behind the cyeles in the yield per acre of the crops. We found that it takes between one and two years for the stimulation of increasing harvests to work out its maximum effect in promoting the activity of industry as that activity is represented in the "barom- 
eter" of industry, the production of pig-iron; and that, when an allowance is made for a lag of two years in the adjustment of the pig-iron industry, the cycles of the yield per acre of the crops are generally reproduced in the cycles of the production of pig-iron, the relation being so close that the coefficient of correlation is $r=.718$.

To find the relation of the cycles in the yield per acre of the crops to the cycles in the movement of general prices, we made use of an index number of general prices extending from 1870 to 1910 , and of our index number of the yield per acre of nine crops covering the same interval of time. The problem of separating the cyclical movements in these two series from their secular movements was solved, and the lag of the cycles of general prices behind the cycles in the yield of crops was found to be about four years. The coefficient of correlation between the cycles in the yield of the crops and the cycles in the general prices lagging four years behind the crop cycles reached the very high value $r=.800$. When the lagging cycles of general prices were plotted and their graph superposed upon the graph of the cycles in the yield per acre of the crops, the two curves were found to present a degree of congruence so close as to justify our working theory that the fundamental, persistent cause of the cycles of prices is the rhythmical movement in the yield per acre of the crops. The cycles in the yield per acre of the crops are followed at an interval of about two years by the cycles in the 
activity of industry and of the volume of trade, and at an interval of about four years in the cycles of prices. These conclusions brought to a close the last part of our general problem of the cause and law of Economic Cycles.

The links in the sequence of causation were completely established: The fundamental, persistent cause of the cycles in the yield of the crops is the cyclical movement in the weather conditions represented by the rhythmically changing amount of rainfall; the cyclical movement in the yield of the crops is the fundamental, persistent cause of Economic Cycles.

In the Introduction to this Essay it was observed that economic dynamics stands in need of a law that shall be to a changing society what the law of diminishing returns is to a society in a relatively static state. We may now formulate the law: The weather conditions represented by the rainfall in the central part of the United States, and probably in other continental areas, pass through cycles of approximately thirty-three years and eight years in duration, causing like cycles in the yield per acre of the crops; these cycles of crops constitute the natural, material current which drags upon its surface the lagging, rhythmically changing values and prices with which the economist is more immediately concerned. 

r THE following pages contain advertisements of Maremillan books by the same author. 



\section{LAWS OF WAGES}

\section{AN ESSAY IN STATISTICAL ECONOMICS}

By Henry Ludwell Moore

Professor of Political Economy in

Columbia University

Cloth, $\$ 1.60$, net.

Extract from the Introduction: "In the following chapters I have endeavored to use the newer statistical methods and the more recent economic theory to extract, from data relating to wages, either new truth or else truth in such new form as will admit of its being brought into fruitful relations with the generalizations of economic science."

\section{CONTENTS}

Introduction $\ldots \ldots \ldots \ldots \ldots \ldots \ldots \ldots \ldots \ldots \ldots \ldots \ldots$

\section{Chapter I}

Statistical Laws

A Scatter Diagram............................ 11

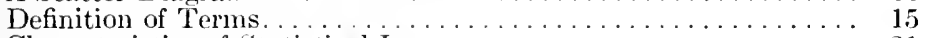

Characteristics of Statistical Laws...................... 21

\section{Chapter II}

Wages, Means of Subsistence, and the Standard of Life

Description of Data............................ 26

Wages and the Means of Subsistence.................. 29

Wages and the Standard of Life .................... 33

Wages of Skilled and of Unskilled Laborers ............... 39

\section{Chapter III}

Wages and the Productivity of Labor

Description of Data............................ 45

Fluctuations in the Rate of Wages and in the Value of the Product 46

(over) 


\section{LAWS OF WAGES by Henry Ludwell Moore-Continued}

\section{CONTENTS-Continued}

Fluctuations in the Laborer's Relative Share of the Product and in the Ratio of Capital to Labor ................... 55

The General Trend of Wages..................... 61

\section{Chapter IV}

Wages and Ability

An Hypothesis as to the Distribution of Ability . . . . . . . 74

Grounds for the Hypothesis. . . . . . . . . . . . . . . . . . 76

The Expression of the Gaussian Law in a Form that will facilitate

the Testing of the Differential Theory of Wages........... 78

The Standard Population.......................... 82

The Application of the Theory of the Standard Population........ 85

Remark upon the Preceding Demonstration ................ 93

\section{Chapter V}

Wages and Strikes

Outcome of Strikes as affected by the Strength of Trades-Unions 105

Outcome of Strikes as limited by Economic Law . . . . . . . . . . . 121

Summary ................................. 134

\section{Chapter VI}

Wages and the Concentration of Industry

Wages as affected by the Concentration of Industry . . . . . . . . 140

Amount of Employment. . . . . . . . . . . . . . . . . . . . . 153

Continuity of Employment . . . . . . . . . . . . . . . . . . . 156

Length of Working Day. . . . . . . . . . . . . . . . . . 161

\section{Chapter VII}

\section{Conclusions}

Statistical Economies and Industrial Legislation . . . . . . . . . . . 169

Practical Aspects of the Results of Preecoling Chapters. . . . . . . 174

Statistical Economies and Synthetie Economies. . . . . . . . . . . 196

\section{COMMENTS OF SPECIALISTS}

"Professor Moore brings to his task a wide acquaintance with the most difficult parts of the literature of eeonomics and statisties, a full appreciation of its large problens, a judicial spirit and a dignified style." F. W. TAussig, in the Quarterly Journal of Economics.

"Statisties of the ordinary official kind have often served to support the arguments of political economists. But this is the first time, we believer, that the higher statisties, which are founder on the Caleulus of 


\section{LAWS OF WAGES by Henry Ludwell Moore-Continued}

Probabilities, have been used on a large scale as a buttress of economic theory." F. Y. Edgeworth, in the Economic Journal.

"Professor Moore has broken new ground in a most interesting field, and while we may differ from him in the weight to be attached to this or that result or the interpretation to be placed on some observed coefficient, we may offer cordial congratulations on the work as a whole. G. U. Yule, in the Journal of the Royal Statistical Soeiety.

"Die Fruchtbarkeit der" verwendeten Methode scheint mir durch diese Untersuchungen zweifellos erwiesen, ebenso wic die Erreichbarkeit des Ziels, die Theorie ganz dicht an die Zahlenausdrücke der wirtschaftlichen Tatsachen heranzubringen. Und das ist eine Tat, zu der der Autor nur zu beglückwünschen ist. . . . Hat das Buch auch auf der Hand liegende Fehler-in der Zukunft wird man sich seiner als der ersten klaren, einfachen und zielbewussten Darlegung und Exemplifizierung der Anwendung der 'höheren Statistik' auf ökonomische Probleme dankbar erinnern." Joseph Schumpeter, in the Archiv für Sozialwissenschaft und Sozialpolitik.

"Non seulement il nous enseigne l'emploi d'une méthode qui dans de certaines limites peut être très féconde. Mais encore son habileté personnelle dans le maniement de cette méthode est très réelle. Il sait scruter les statistiques d'une façon fort pénétrante et exposer les résultats de ses recherches avec beaucoup d'élégance. Le lecteur français en particulier, appréciera l'ingéniosité avec laquelle il tire des statistiques françaises des inductions souvent nouvelles et justes." Albert AftaLion, in the Revue d'histoire des doctrines éeonomiqucs.

"Alcuni dei risultati ottenuti dall'autore, sono nuovi e suggestivi e da essi molte conclusioni si possono trarre (cui l'autore accenna nel capitolo finale della sua opera) sia rispetto alle teorie del salario che rispetto alla politiea sociale. Il libro è insomma, ripetiamo, un contributo molto importante all'investigazione scientifica dei fenomeni economici e vorremmo che esso stimolasse parechi altri studiosi a fare per altre industrie o per altri paesi, recerche analoghe. Constantino Bresclanl Turroni, in the Giomale degli Economisti.

\section{THE MACMILLAN COMPANY}

\section{Publishers 64-66 Fifth Avenue New York}






DATE DUE

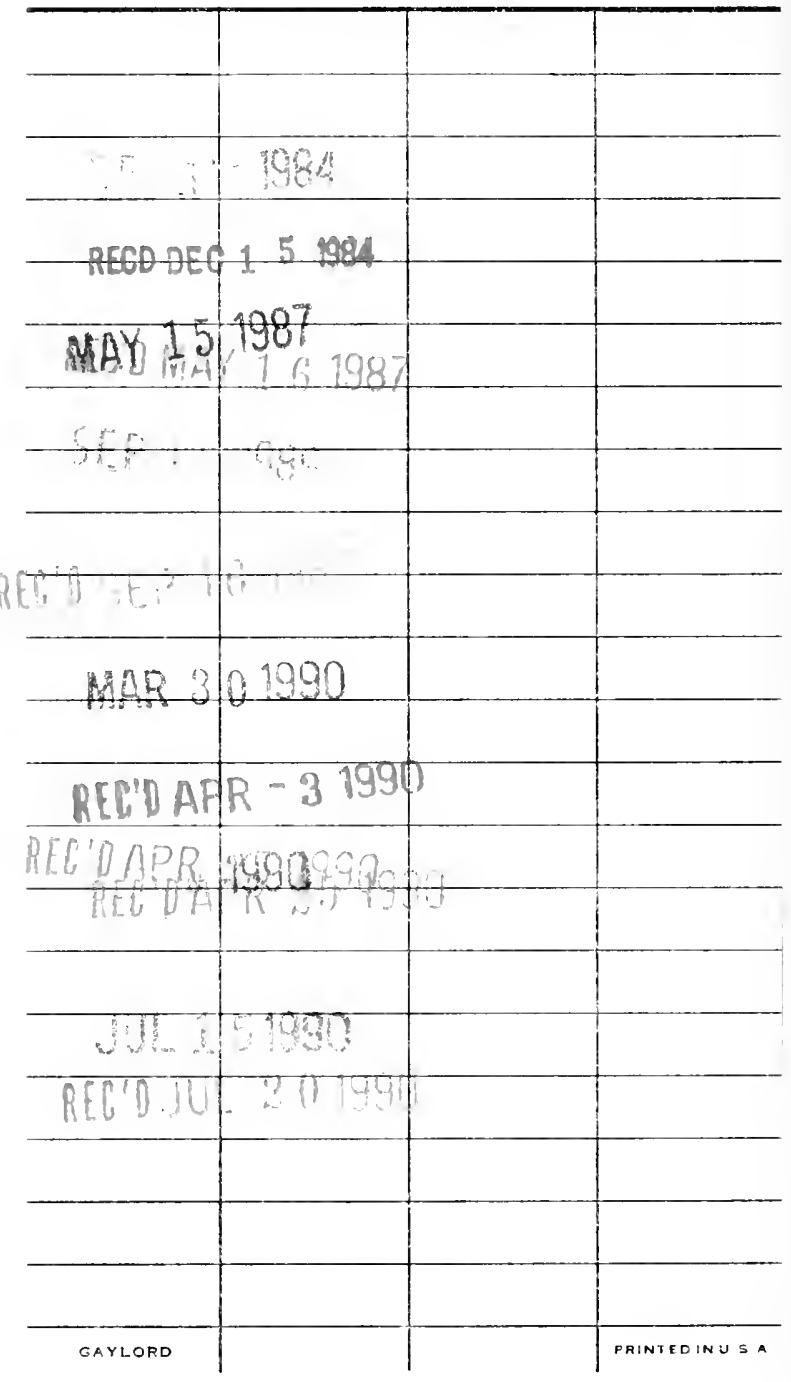




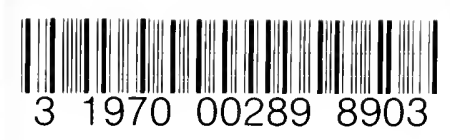

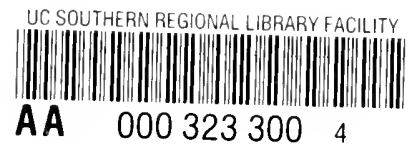


